Portland State University

PDXScholar

Winter 3-4-2016

\title{
An Investigation of School-Based Specific Learning Disability Identification
}

Bonnie Heather Bartos

Portland State University

Follow this and additional works at: https://pdxscholar.library.pdx.edu/open_access_etds

Part of the Educational Methods Commons, Special Education and Teaching Commons, and the Student Counseling and Personnel Services Commons

Let us know how access to this document benefits you.

\section{Recommended Citation}

Bartos, Bonnie Heather, "An Investigation of School-Based Specific Learning Disability Identification" (2016). Dissertations and Theses. Paper 2714.

https://doi.org/10.15760/etd.2710

This Dissertation is brought to you for free and open access. It has been accepted for inclusion in Dissertations and Theses by an authorized administrator of PDXScholar. Please contact us if we can make this document more accessible: pdxscholar@pdx.edu. 
An Investigation of School-Based Specific Learning Disability Identification

by

Bonnie Heather Bartos

A dissertation submitted in partial fulfillment of the requirements for the degree of

Doctor of Education

in

Educational Leadership: Special and Counselor Education

Dissertation Committee:

Stephen Isaacson, Chair

Christina Gildersleeve-Neumann

Samuel Henry

Amy Petti

Portland State University

2016 
(C) 2015 Bonnie Heather Bartos 


\begin{abstract}
Researchers have described the special education identification process for students with specific learning disabilities (SLD) as "muddled and confused" (Bocian, Beebe, MacMillan, \& Gresham, 1999) and "haphazard" and "capricious" (Shinn, 2007, p. 603). Bocian et al. proposed the theory of competing paradigms as a way to explain why researchers and school-based eligibility teams identify different groups of students as SLD. This qualitative study had two research questions: (a) To what extent do interviews of secondary resource teachers reveal the concepts of relativity, acceptability, and profitability as they reflect on the SLD process? and (b) What other themes regarding SLD eligibility determination emerge from interviews with secondary resource teachers? Utilizing the modified constant comparative method (Lincoln \& Guba, 1985), the author revealed that there was moderate support for the paradigms of relativity and acceptability, but less for the paradigm of profitability. In addition, the author identified other themes, such as difficulties with evaluating English language learners and the benefit of case management, that can be used to expand Bocian et al.'s theory. The author also argued that the paradigms overlap with one another during the special education identification process, rather than proceeding in a sequential order. Finally, the author discussed the implications of her findings in terms of improving school-based and policy practices.
\end{abstract}




\section{Dedication}

This dissertation paper is dedicated to three very important people in my life - my father, my husband, and my daughter. Dad, I think of you every day . . you used to make up "Dr. Heather” stories when I was a kid, but I don’t think you knew what kind of a doctor I would aspire to become! Thank you for giving me your love of language, your love of schooling, and your unconditional love for the first 26 years of my life. Jim, if my dad provided the inspiration, you provided the perspiration. You are "the practical one," and without you and your observation that I was good with people with special needs, I don't know that I ever could have discovered my calling. You have been my stable foundation, providing help with all of the practical things I'm not always so good at (or that don't even occur to me). You are "a man for others" in the best sense of the phrase. And for my daughter, Jasmyne Caroline, the reason I kept going to school to finish what I started, to show you not to give up even when it gets difficult. At 6 years old, you already know that the most important thing is "how big your love is." You are meant for great things and it is an honor to be your mom. 


\section{Acknowledgments}

If it is even possible to complete a dissertation entirely under the power of one individual, this is not that dissertation! Many people helped and encouraged me along the way. My wonderful husband, Jim, told me he knew when we got married that I would always be in school (and for the most part, he has been correct.) My 6-year-old daughter, Jasmyne Caroline, "helped" edit parts of my manuscript with me when she woke up early and disrupted my 5 a.m. study sessions and sat beside me to do her own "research" about dinosaurs and The Magic School Bus. My mom, Vicki Holob, told me I was a good writer and encouraged me throughout my childhood to write and do research, and my good friends, Marylin and Tony Villa, told me to keep going when it would have been easier to quit. I would like to thank Dr. Steve Isaacson, professor emeritus at Portland State University, for being a good mentor, teacher, and friend for more than 10 years, and Kim Ilosvay, Jerry Young, and Donna Barrow, for providing doctoral companionship, empathy, and inspiration along the way. I would like to thank the participants in my study for sharing their stories and insights about the ways schools identify students with specific learning disabilities. You are entrusted with the hopes of countless students and parents that we can identify an invisible disability and improve educational experiences, and in some small way, I hope this study calls attention to your daily efforts to get it right. And, finally, I would like to thank the hundreds of students and families I have been privileged to work with as a resource teacher-all of your stories, struggles and triumphs have enlightened and enriched my life. 
Table of Contents

Page

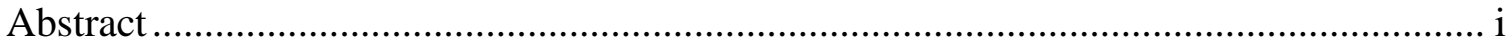

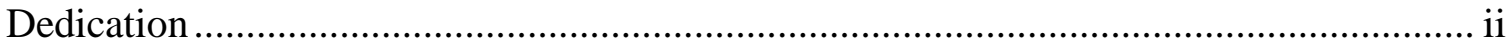

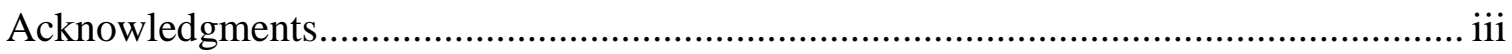

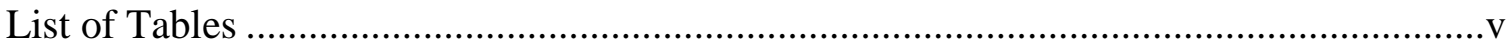

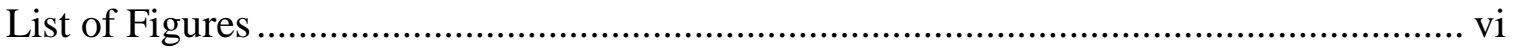

Chapter

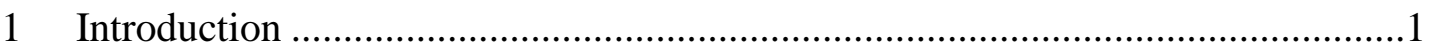

2 Literature Review ............................................................................... 13

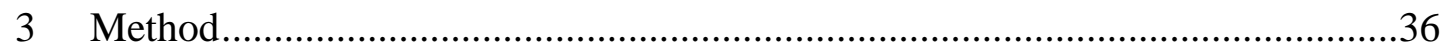

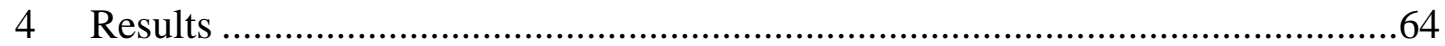

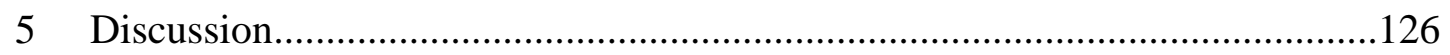

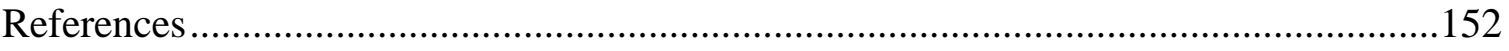

Appendices

A List of Interview Questions From Pilot Study.............................................159

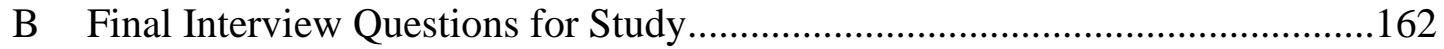

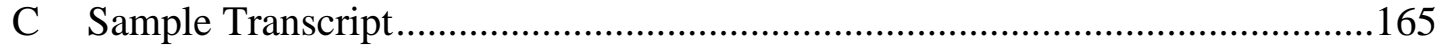

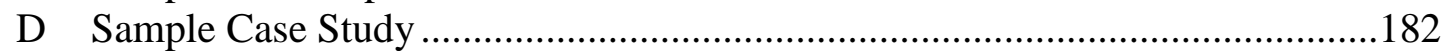

E Directions for Audit Trail .......................................................................... 188

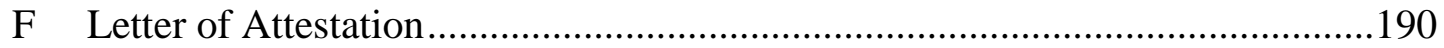


List of Tables

Table

Page

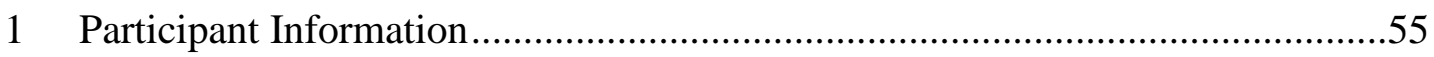

2 Summary of Themes From Research Question 1 .........................................117 


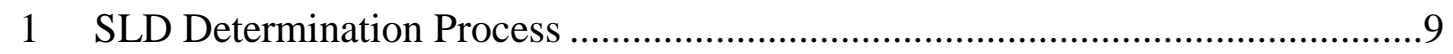




\section{CHAPTER 1}

\section{INTRODUCTION}

The process that schools use to decide which students have a specific learning disability (SLD) as a prerequisite to receiving special education services has been called “muddled and confused” (Bocian, Beebe, MacMillan, \& Gresham, 1999, p. 1) and "haphazard" and "capricious" (Shinn, 2007, p. 603). Lawmakers who developed the Individuals with Disabilities Education Act may well have been influenced by adult disability law, which specifies that recipients of Social Security and other federal benefits needed to meet certain criteria in order to qualify (Berninger \& Holdnack, 2008). As early as 1982, researchers at the University of Minnesota argued that the theory of classification for SLD was "an ill-defined, poorly conceptualized, incredibly popular idea" (Ysseldyke, Algozzine, \& Epps, 1982, p. 21), and that the field needed an era of experimentation, one that encouraged instructional innovation and avoided both “categorical bounty hunting" (p. 21) and "simple-minded compliance" (p. 23). Although some researchers (Flanagan, Ortiz, Alfonso, \& Dynda, 2006) blame the confusion over what constitutes a learning disability on a lack of common vocabulary, McKenzie (2009) noted that the term has so many definitions due to challenges and frustrations in assessing the disability rather than in whether or not such a construct actually exists.

\section{The Discrepancy Model}

After the 1975 passage of the Education of All Handicapped Children Act, the U.S. Department of Education attempted to clarify for school practitioners how they 
could simplify their SLD decision making processes when considering eligibility: There must be "a severe discrepancy between achievement and intellectual ability" (Fed. Reg., 1976, p. 65083). This regulation intended to preserve the concept of unexpected underachievement; as opposed to students with intellectual disabilities, students with SLD had average to above average intelligence with notable deficiencies in academic areas. However, the regulations did not state the degree or amount of difference between ability and achievement necessary for the student's discrepancy to be classified as “severe” (Epps, Ysseldyke, \& McGue, 1984).

The practice of using discrepancy models — which require a significant difference in scores between average cognitive ability (IQ) and below average academic achievement (quantified by standardized achievement testing such as the series of Woodcock Johnson Tests of Academic Achievement)—was not without criticism. Bateman (2005) described it as the reduction of a child to "one dot representing estimated intellectual disability and one dot representing the deficient achievement area” (p. 94). Kavale, Spaulding, and Beam (2009) argued that because there were four different types of discrepancy models (grade level deviation, expectancy formula, standard score differences, and regression formulas), different students were identified as SLD, rendering the definition of the term nonequivalent. Reschly and Hosp (2004) noted that poor readers who had measurable IQ-achievement discrepancies were able to access more instructional (and therefore financial) resources than poor readers whose test results did not reveal a discrepancy, and that these students lost valuable time before becoming eligible for remedial instruction. Moreover, a survey of state educational agencies 
(Reschly \& Hosp, 2004) showed that there was little, if any, agreement between the states as to how discrepancy should be calculated or how large it needed to be before students qualified for special education. In addition, 33 out of 50 states permitted "team override," meaning that students could qualify as having a learning disability even if they did not meet the official SLD criteria. The discrepancy model was "unstable and invalid" (Reschly, 2005, p. 513), did not clearly differentiate SLD from low achievement (Kavale, 2001), and encouraged practitioners to drop the concept of processing deficits from the identification of students with SLD, classifying students with no cognitive-based explanation for their academic challenges (Kavale, Forness, MacMillan, \& Gresham, 1998). Discrepancy models also caused problems with specificity, early identification, and local implementation (Scruggs \& Mastropieri, 2002). Reschly and Ysseldyke (2002) summarized the feelings of many practitioners when they declared, "We have never met anyone who is certain that a 15 or 16 point ability-achievement discrepancy indicates greater need than a 13 or 14 point discrepancy" (p. 8). They also commented that science alone was not enough to shift special education from a correlational to an experimental framework, but that a combination of both science and political influences would lead to the creation of a different model.

\section{The Response to Intervention Model}

Reschly and Ysseldyke's (2002) speculation that politics would provide an impetus for change was correct. Since the 1980s, education reform has focused almost exclusively on accountability, and schools belong to only one of two categoriesimproving or failing (Lezotte, 2005). Student performance on standardized tests is used to 
show not only whether the students have met their obligation to learn, but whether all levels of the organization (the school, district, and the professional educational bureaucracy) have met their as well (Olson, 2003). The No Child Left Behind Act of 2001 and the 2004 Reauthorization of the Individuals with Disabilities Education Improvement Act have increased the pressure to implement scientifically based programs and practices to unprecedented levels (Merrell \& Buchanan, 2006). Accountability reform is also influenced by the evidence-based practice movement, which emphasizes improving human performance (Kowalski, 2009), as well as only using interventions that have been judged to have adequate empirical support (Reschly \& Ysseldyke, 2002).

One educational reform — response to intervention, or RTI—addressed both concerns about using the discrepancy model and the search for more effective ways to improve student performance. The conceptual underpinning for RTI is credited to a 1982 National Research Council study by Heller, Holtzman, and Messick (as cited in Bender and Shores, 2007), which offered three criteria on which to base special education eligibility: Adequate general education instruction, an effective special education program that improves student outcomes, and a meaningful evaluation process. The purpose of RTI is to eliminate the ecological effects that lead to learning problems (Vaughn \& Fuchs, 2006), as well as to identify students who demonstrate "failure to respond" to general education and who require a more individualized approach to learning (Fuchs, 2003). Barnes and Harlacher (2008) described the unchanging principles of RTI as (a) a focus on early identification and intervention, (b) matching student needs 
with curriculum, (c) a problem solving approach and data-based decision making, (d) use of effective practices, and (e) a systems level approach.

The 2004 Reauthorization of the Individuals with Disabilities Education Improvement Act codified this spirit of measurable improvement by including RTI as a method of qualifying students with SLD for special education services. States were no longer permitted to require local education agencies to use a severe discrepancy model. On August 14, 2006, the U.S. Department of Education's final regulations gave further explanation: Students could either be assessed using an RTI process or "by exhibiting a pattern of strengths and weaknesses in performance, achievement, or both, relative to age, State-approved grade-level standards, or intellectual development, that is determined by the group to be relevant to the identification of a specific learning disability" (Individuals with Disabilities Education Improvement Act of 2004).

Yet nearly seven years later, Hughes and Dexter (2013) completed a review of all RTI field studies and noted, "Inconsistencies in identifying non-responders in an RTI model are eerily similar to inconsistencies in the IQ-achievement discrepancy model that RTI purports to correct” (Is RTI Helping to Increase Consistency of SLD Identification, para. 3). Berkeley, Bender, Peaster, and Saunders (2009) also found that there was no consistency between districts or states in how RTI was being applied. Reynolds and Shaywitz (2009) lamented that the arguments for RTI in the face of a limited research base "seem to take a giant step backwards and reek more of educational faddism and political correctness than of science-based, effective educational practice" (p. 132), while 
Kavale, Kauffman, Bachmeier, and LeFever (2008) argued that RTI merely served an accountability function instead of a method for valid SLD identification.

\section{The Patterns of Strengths and Weaknesses Model}

The belief that students with learning disabilities demonstrate a pattern of cognitive strengths and weaknesses, measured by results on standardized tests, forms the philosophy of what Flanagan, Fiorello, and Ortiz (2010) have called the Third Method Approach to SLD identification. The Third Method approach is grounded in Catell-Horn Carroll theory of cognitive abilities. In this model, all human beings have $\mathrm{G}$ (general intelligence), Gf (fluid intelligence, or the ability to solve new and novel problems), and Gc (crystallized intelligence, or what is learned from one's life experience and education). Within both Gf and Gc, there are many narrow abilities, such as VL (lexical knowledge), Grw (knowledge related to reading and writing), and Gq (quantitative, or mathematical knowledge) (Schneider \& McGrew, 2012). In 1990, Richard Woodcock, one of the developers of the Woodcock Johnson Tests of Cognitive Abilities and Achievement batteries, suggested that practitioners use a "cross battery approach" to align their assessment plans with CHC theory (Schneider \& McGrew, 2012). The Woodcock Johnson test batteries are the only ones aligned with CHC theory, so practitioners should start there and then use additional psychological assessments as needed for particular students.

Proponents of this model advocate for a new operational definition of SLD. First, there must be evidence of academic skill deficits and exclusionary factors such as English language proficiency levels, intellectual disability, or autism are ruled out as primary 
contributing factors. Additionally, there must be evidence of cognitive processing disorders and a match between the area of academic skill deficit(s) and cognitive processing deficits. An academic strength is measured by a standardized score of 85 or better; an academic or cognitive weakness is measured by a standardized score below 85 . There must also be evidence of adverse educational impact as measured by classroom observations and work samples (Flanagan, Alfonso, Mascolo, \& Sotelo-Dynega, 2012). However, to date there are no empirical studies of students differentially diagnosed as SLD through the third method approach (Flanagan et al., 2010).

Fletcher, Morris, and Lyon (2003), when discussing the similarities and differences between and the pattern of strengths and weaknesses (PSW) model and RTI, observed that both models preserve the concept of "unexpected underachievement" as a hallmark of a learning disability. Both models focus on specific academic behaviors, and both models attempt to use effective interventions. The intra-individual (PSW) model focuses on discrepancies between abilities within the child, while the RTI model focuses on behavioral outcomes and school context. PSW relies strongly on standardized, normreferenced testing administered at one point in time, and RTI assesses the same ability (i.e., phonological awareness) at different points in time to measure progress. According to these authors, the assumption behind PSW is that better classification of students with learning disabilities will lead to better interventions for students, but the assumption behind RTI is that treatment for reading disabilities, not the classification itself, is the most important thing. 


\section{Science or Service?}

Despite these new, updated identification models, Mellard, Deshler, and Barth (2004) pointed out that if researchers did not consider the non-technological factors that influence eligibility decisions, “our field's unrelenting search for the perfect 'mousetrap' for SLD determination may be in vain" (p. 231). They proposed that "street level" SLD workers had a different concept of who should qualify as having SLD based on the resources and organizational limitations available within their schools. Discussions from focus groups conducted with different stakeholders in the SLD identification process (school psychologists, parents, general ed teachers, resource teachers, and special education administrators) revealed that school teams were more interested in special education services as they related to classroom performance, not to how assessment data aligned with state or federal definitions of SLD. The National Research Center for Learning Disabilities (NRCLD; 2007) cautioned that "any proposed identification tool, process, or model will likely fall short of the goal of improved SLD identification if the problem is only or primarily viewed as a problem requiring better tools. NRCLD considers that SLD determination issues are not methodological . . . the issues involve the decisions regarding the provision of services to students" (p. 10). The diagram below shows their conceptualization of the SLD determination process. Changes on the outside loop (new identification models) will not change over-identification or mis-identification of students unless there are also changes to the elements on the inside loop (school culture, values, roles, and individual interpretations of disability law). 


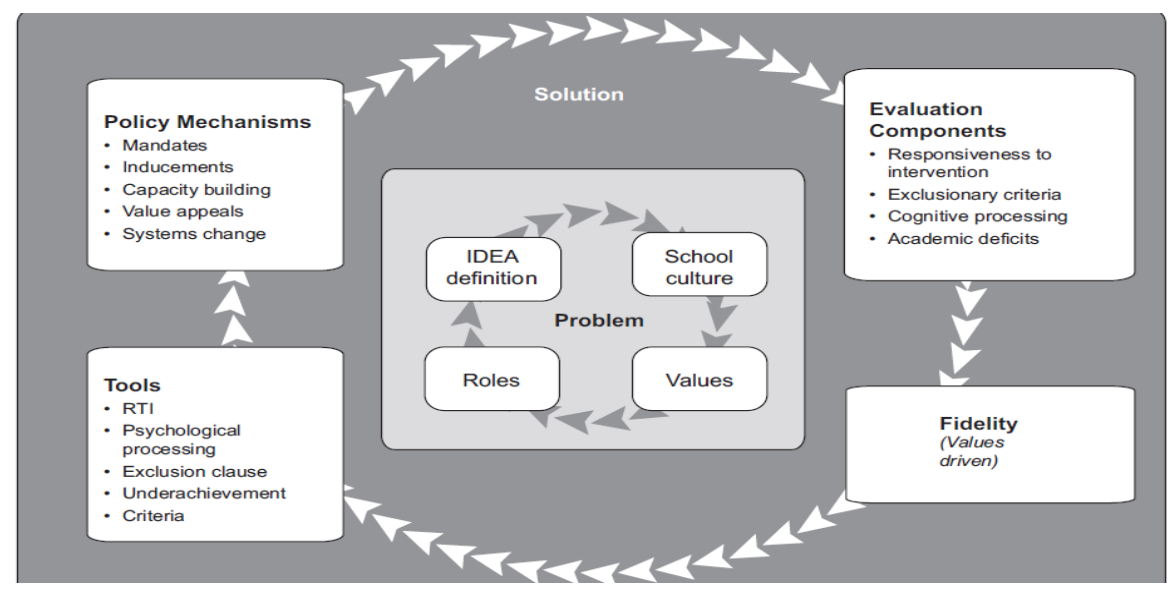

Figure 1. SLD determination process. Source: NRCLD (2007).

Johnson, Mellard, and Byrd (2006) noticed that eligibility teams appeared to weigh classroom needs more heavily than district or state guidelines, but that the desire to serve low performing students through the process of labeling them as SLD represented "an improper use of federal funding and denies those with actual disabilities a chance to progress by virtue of the federal protections and civil rights that have been granted to them" (Stakeholder Values section, para. 3). Kavale et al. (1998) agreed that schoolbased eligibility teams placed more importance on "what a child needs' rather than on 'what kind of child they are' .... With the prevailing attitude emphasizing service, science, defined as an understanding of the phenomenon question, becomes secondary" (p. 309). Kavale et al. cautioned that, if science was ignored in favor of service, "special education must be prepared to serve one half of the school population, all those who fall below average" (p. 310). 


\section{The Theory of Competing Paradigms}

Another team of researchers completed a series of studies at the University of California, Riverside, in the early to mid-1990s, examining the overlap between legal guidelines for eligibility teams and school-based decision-making. Bocian et al. (1999) proposed that schools use three competing paradigms when making decisions about special education services for students with learning disabilities: Relativity, operationalized by the teacher's perception of how the student performed as compared to their peers using local norms; acceptability, operationalized by use of an abilitydiscrepancy based formula recommended by the state of California; and profitability, the final decision whether an individual student would benefit from special education services. The impressions and data generated by one stakeholder may indicate that a student needs special education services, but those views may not be held by other stakeholders or sustainable within the school environment.

These competing paradigms occur sequentially throughout the special education process, beginning with the general education teacher referring the student for special education evaluation. During the testing process, the special education team's primary concern is with whether the data shown by standardized intelligence and achievement tests demonstrates an acceptable level of discrepancy to meet the district or state recommended criteria. At the final stage, the evaluation team analyzes the test results and makes a placement decision. However, this decision is also influenced by socio-cultural factors such as the personalities of team members, their perceptions of both special education and general education services within the school, openings in special education 
classrooms, English language learner status, and caseload of resource teachers (Bocian et al., 1999), although researchers acknowledged that there was no real way to measure these factors within the context of their study other than to count the number of students who qualified for services.

MacMillan and Siperstein (2001) explained that, as a school-based decision making team moves through the paradigms, extra layers of subjectivity are added to the process. Teachers' decisions about which students are referred are influenced by their personal beliefs about how effective they are as educators, as well as comparing the student's performance to that of his or her peers. Although the assessment phase appears objective on the surface, special education decision makers can and do employ "creative testing" to justify why a student qualifies as SLD rather than under the category of mental retardation (now called intellectual disability). At the final stage, where team members determine profitability, knowledge of the particular resources at that school site, the particular chemistry of team members, and team perceptions of teacher efficacy all influence whether a student will be classified as SLD. MacMillan and Siperstein argued that schools "are serving those most in need by using the SLD category as the vehicle for providing the help they perceive as needed" (p. 8). Researchers and school practitioners do not identify the same population of students as having learning disabilities; however, policymakers are attempting to address issues of over-identification in the public schools, not those in research studies, and "the only way to understand the SI (school identified) SLD population is to understand how the public schools function and to acknowledge the various reasons that schools have for identifying individuals as LD” (p. 3). 
Despite the introduction of two new SLD identification models since the 2004 reauthorization of the Individuals with Disabilities Education Improvement Act, there have been no studies documenting local, school-based special education team decision making and the interplay between statistical requirements of the model and concerns about diminishing resources and organizational limitations.

\section{Research Questions for this Study}

This qualitative interview study attempted to fill a gap in the existing literature base about how schools are now identifying students after implementation of new SLD models. The first research question was: To what extent do interviews of secondary resource teachers reveal the concepts of relativity, acceptability, and profitability as they reflect on the SLD process? The second research question was: What other themes regarding SLD eligibility determination emerge from interviews with secondary resource teachers?

This study focused on data generated at the middle school level, since both PSW models and RTI models have little research in secondary schools. The study explored and attempted to extend the theory of competing paradigms as proposed by Bocian et al. (1999). Did interviews of middle school resource teachers reveal that teams consider all three paradigms to be equally important, or was one more important than the others? 


\section{CHAPTER 2}

\section{LITERATURE REVIEW}

Many studies of special education student evaluation teams and the processes they use to classify students as having learning disabilities are quantitative, concentrating on discrepancy formulas or scores derived from curriculum based measures. However, some researchers are beginning to question the almost exclusive use of quantitative methodologies as a way of answering the many questions surrounding special education practice, particularly as it is applied in school settings. Ferri, Gallagher, and Connor (2011) conducted a content analysis of all studies published in four professional LD journals during 2008 and found that $91 \%$ of articles used either quantitative or metaanalysis methodologies. Because the political research climate influenced by No Child Left Behind Act of 2001 placed a premium on intervention studies and scientifically based research, "in this almost unilateral focus on what works we may inadvertently lose sight of what matters" (p. 223). They called for a diversification of research methodologies in special education, particularly qualitative and mixed methods techniques, as a way to study how local and contextual factors shape effective practices of teachers, psychologists, and others working with individuals with learning disabilities.

Shinn (2007) discussed that there were two parallel tracks of research into how schools decided which students were classified as LD. He described the first line of research as both deductive and as "do as I say research" (p. 602), meaning that investigators were primarily interested in whether school adhered to federal guidelines 
when determining eligibility. He described the second line of research as inductive and "do as I do research" (p. 603), meaning that investigators were searching for patterns in test results and in ways that schools used those results to classify students as LD. This second line of inquiry depended upon curriculum-based measurement (CBM), which was first developed as a method to measure progress of special education students, but more recently has been explored as a tool to predict which struggling students will pass highstakes state assessments (Deno, 2006).

This literature review does not include studies that examine school-based decision-making using either an RTI or PSW model because none exist (Flanagan et al., 2010; Raths, Kotch, \& Carrino-Gorowara, 2009). Studies of RTI seem to fall into one of three categories: Technical issues, which focus on screening instruments, cut scores, and different ways to determine responsiveness (Fuchs, 2003; Jenkins, Hudson, \& Johnson, 2007); political purposes, such as using RTI as a strategy to raise proficiency and meet goals under the No Child Left Behind Act of 2001 (Fuchs, Fuchs, \& Stecker, 2010; Ikeda et al., 2009; NASDE, 2006, p. 7); or organizational structure and implementation of tiered instructional models (Barnes \& Harlacher, 2008; Glover, 2010; Kovaleski \& Black, 2010; Sugai \& Horner, 2008). The goal of these tiered instructional models is to provide prevention and remediation at the same time (Stewart, Benner, Martella, \& MarchandMartella, 2007). There is no agreement between RTI practitioners and researchers as to the number of instructional tiers, the type of protocol to follow when making decisions about students, or at what tier special education services should begin (O'Shaughnessy, Lane, Gresham, \& Beebe-Frankenberger, 2003). Furthermore, because there is no 
research on using a standard protocol approach in secondary schools, many districts are using a problem-solving RTI approach instead (Johnson \& Smith, 2008). This has led to a wide variety of measures used to define the model's success, including the number of homework assignments submitted (Burns, 2008), improved scores on state math tests (Canter, Klotz, \& Cowan, 2008), and student grades (Samuels, 2009). Because of these challenges and a lack of research about school based decision making that considers all aspects of Bocian et al.'s (1999) theory of competing paradigms, it is necessary to go further back in special education history to examine studies conducted under the discrepancy models widely used through the 1970s-1990s.

This literature review includes studies that both assess compliance to definitions of SLD and contextual variables that can influence the eligibility decision. Researchers studying the SLD eligibility process have employed a wide variety of methodologies, including both quantitative and qualitative designs. Early observational studies described the process of team decision making and the types of data considered as parents and professionals determined SLD eligibility (Richey \& Graden, 1980; Rostollon, 1980). Case study methodology enabled researchers to collect longitudinal data as students moved through the entire special education process, from initial referral through eligibility to provision of services (Christenson, 1980; Mitchell \& Poland, 1980). Researchers used quantitative analysis of psychometric evaluation data to study how the application of different discrepancy models produced different groups of students identified as SLD (Ysseldyke, Algozzine, \& Epps, 1982; Ysseldyke, Algozzine, Shinn, \& McGue, 1982); Algozzine \& Ysseldyke, 1983). Other researchers used quantitative 
methods to draw comparisons between groups of students identified when following legal guidelines versus groups identified by school staff (Bocian et al., 1999; Gresham, MacMillan, \& Bocian, 1998; MacMillan, Gresham, \& Bocian, 1998). Finally, researchers have also used quantitative analogue designs as a way to gather data on decision making based on vignettes presented to school professionals (Ysseldyke \& Algozzine, 1982; Epps, Ysseldyke, \& McGue, 1984).

\section{Observational Studies of Student Evaluation Teams}

Much of the early research of special education eligibility was conducted at the University of Minnesota at the Institute for Research on Learning Disabilities. Between 1980 and 1983, the Institute produced several studies investigating practices in special education referral, identification and classification, intervention planning, progress evaluation, and outcome evaluation. At this time, the special education team process for determining eligibility was fairly new, having been stipulated in the 1977 regulations of the Education for All Handicapped Children Act of 1975, and some of this research attempted not only to explore the relationship between federal regulations and school based SLD identification, but simply to document what went on during eligibility team meetings. In 1980, the Institute videotaped 38 special education placement team meetings and used their observations to answer several different research questions regarding practices in schools.

Rostollon (1980) studied dialogue from 32 of these meetings in order to identify categories of statements made about the children under consideration for special education eligibility. For every 10 second interval, an observer coded each statement 
made during the meeting as belonging to one of three distinct categories: Academic, behavioral, or physical. A second observer re-coded random segments of meetings (20\% of total meeting time) in order to establish interrater reliability. Rostollon found that $20 \%$ of the comments made were about academic data, and that much of those data was drawn from norm-referenced, standardized tests. Ten percent of comments were classified as behavioral, and only $1 \%$ of comments related to physical functioning.

Richey and Graden (1980) studied 20 videotaped meetings in order to answer a different but related research question: What kinds of data are presented at eligibility team meetings and to what extent did the data relate to the eligibility decisions that were made? Observers listened to teams discuss whether or not a child qualified for special education under the category of SLD and recorded two types of statements: Expected levels of academic performance (i.e., grade level, age level) and actual level of performance (scores on assessments, observational measures, or classroom data). Using an observation sheet, each statement was also coded as to whether it supported, did not support, or was irrelevant to LD eligibility using three different definitions: A discrepancy between intellectual ability and achievement; a discrepancy between performance IQ and verbal IQ scores; or the current federal definition of learning disability. To improve reliability of the coding measures, two observers watched the videotapes and researchers calculated interrater agreement as to whether the data supported one of the three categories of eligibility. Agreement was .95. Researchers found that $83 \%$ of statements made by team members were irrelevant to determining eligibility under any of the three definitions and that only $5 \%$ of statements were not 
supportive. Richey and Graden concluded that the teams they observed did not appear to use specific criteria in determining which students were classified as having learning disabilities, but that 14 out of the 20 students were found to have learning disabilities and qualified for special education services.

\section{Case Studies}

A second research team, also working through the Institute for Research on Learning Disabilities, employed a case study methodology in order to study the entire special education decision making process, from initial referral through eligibility determination and provision of services (Ysseldyke \& Thurlow, 1980). Focusing on seven students referred for special education services during the 1979-1980 school year, researchers attended meetings, reviewed written documents about the student, and interviewed key school personnel and parents to gather feedback about the special education process. Subjects attended a variety of school settings (suburban, inner city, and rural). Research teams studied the sequence of activities in each case to determine if it was consistent with recommended district procedures.

This longitudinal approach not only gave researchers insight into how decision making affected individual students, it also gave them perspective to comment on the results of those decisions. Reflecting on one case where a student was not found eligible for special education, but where she went on to experience considerable success after engaging in the evaluation process, Mitchell and Poland (1980) wrote, "It is interesting to speculate what might have happened if Susie had been identified as LD. Would the teacher, parent, and child have taken the same active role in remediation, or would the 
responsibility have been handed over to the "specialists'?" (p. 32). Mitchell and Poland (1980) discussed the "reassignment of responsibility" that occurs when a student is made eligible for special education and that "the team must be aware of the resources of various parties when designating such responsibility" (p. 48).

A second issue involving decision making and building resources was apparent at a suburban middle school where team members did not appear to use any specific criteria for determining who had a learning disability. The team (without parents present) voted on whether a student needed special education services, and if they did, the next question was, "Who has an opening to serve the student?" (Christenson, 1980, p. 74). In order to provide services for one student, the special education teacher said she would have room for him only if she moved another student to monitoring status. For a student transferring from another district with more services than the current school could offer, the team reassigned him for case management purposes to a teacher who taught students with much more severe needs. Mirkin (1980) concluded that the team decision making process was "situation centered" (p. 109), often heavily influenced by the availability of resources at that school site, and "idiosyncratic" in nature. Because all of the participating districts used different criteria for determining which students had learning disabilities, eligibility in one district did not necessarily mean a student would receive services in another district.

\section{Quantitative Research Studies of the Discrepancy Model}

The fact that districts used many different models for determining SLD eligibility was the impetus for several additional research studies as well. Ysseldyke, Algozzine, 
and Epps (1982) conducted two studies to determine how 17 different discrepancy methods resulted in groups of students being classified as having learning disabilities (LD). Their first study analyzed psychometric data for 248 regular education students attending either third, fifth, or twelfth grade in a large suburban school district. The assessment instruments used were the Woodcock Johnson Test of Academic Achievement, the Weschler Intelligence Scale for Children, Revised, and the Woodcock Johnson Test of Cognitive Ability, which nearly 30 years later are still frequently used in many school systems for diagnostic purposes. When student test scores were classified according to one of the 17 different discrepancy methods, $85 \%$ of students met the criteria for $\mathrm{LD}$, although none of them qualified for special education in their respective schools. The average number of students identified under one of the various methods increased through the grade levels, from $16 \%$ of third graders to $28 \%$ of twelfth graders meeting the specified criteria. The researchers noted that more students qualified when the definitions of LD were based on mild ability-achievement discrepancies; the more stringent the criteria, the fewer students qualified.

Ysseldyke, Algozzine, and Epps' 1982 study used the same 17 discrepancy formulas, but applied them to a set of psychometric data belonging to 50 students identified by schools as SLD and those belonging to 49 students who were low-achieving but not SLD. Only 8 of the 99 students were not identified as SLD when all 17 methods were explored. The formulas and methods used by the school district tended to over identify as well as not discriminate between students with SLD and those students who were described as low achievers. Eighty-eight percent of the low achieving students were 
classified as meeting SLD criteria, although none of them were identified by their respective schools, and two of the students that schools had identified as having a learning disability did not meet the criteria under any of the 17 discrepancy formulas. Because all of the students attended fourth grade, it was not possible to draw conclusions across age groups as it was in the previous study. The same pattern existed, however, with a wide variability of classification depending on whether the formula applied required a mild or a severe discrepancy between ability and achievement.

Another study, conducted by Ysseldyke, Algozzine, Shinn et al. (1982) searched for significant differences between test scores of 50 fourth-grade students identified as SLD by their schools and 49 students who were low achievers attending those same schools. Researchers selected assessments that were commonly used by school districts during the special education evaluation process and each student was given a wide variety of tests, including the Weschler Intelligence Scales for Children-Revised, as well as the Woodcock Johnson Tests of Cognitive Ability and Achievement. They operationalized the concept of a severe discrepancy in two ways: As an absolute achievement discrepancy, based on low academic achievement alone and not including the intelligence measures as part of their classification procedures, and as an intraindividual discrepancy, where cognitive scores were compared with achievement scores. Although students in the school-identified SLD group performed poorly on many subtests, including those measuring reading comprehension, word attack, and semantic memory, the researchers discussed that because individual scores were used to make SLD 
decisions, average means between scores from the SLD group and the low-achieving groups were to be noted but not considered for their purpose.

When researchers examined which students performed at least one standard deviation below average, 37 SLD students and 35 low-achieving students were identified as SLD. However, there was only 50\% agreement between research-based and schoolbased classifications of SLD. When the criterion was increased to 1.5 standard deviations, 24 SLD students and 17 low-achieving students were classified as SLD by researchers, with a 56\% agreement rate between research-based and school-based classification. Ysseldyke, Algozzine, Shinn et al. (1982) pointed out that for every student receiving services as SLD, there was a second student whose academic performance was just as poor, but who did not receive services. Overall, 40 of the 99 students had been misclassified by the schools as SLD, but the individual students within that group of 40 changed depending on the severity of the discrepancy that was applied. Ysseldyke, Algozzine, Shinn et al. concluded that they were not able to find psychometric measures that differentiated between students classified as SLD and those who did not qualify for special education services but struggled academically.

Algozzine and Ysseldyke (1983) conducted a similar study examining whether low achievers and students classified by their schools as having learning disabilities exhibited any significant differences in psychometric test scores. They analyzed scores from two samples of fourth-grade students. Sample 1 had 40 students identified by their schools as SLD and 40 students identified as low-achieving, based on scoring below the $25^{\text {th }}$ percentile on the Iowa Test of Basic Skills. Sample 2 comprised 51 children referred 
for possible learning disabilities. As they did in the previous study, they operationalized SLD by looking at three different scenarios for eligibility: One standard deviation, one and a half standard deviations, and two standard deviations between each student's achievement scores on the Peabody Individual Achievement Test and their cognitive scores on the Weschler Intelligence Scale for Children, Revised. In the first group sample, 28 of the 40 school-identified students with SLD were re-identified by the researchers as meeting criteria, but 12 students who the schools had classified as SLD were not re-classified by researchers. However, in the second sample, where students did not qualify for special education based on school judgment, 6 students met the researchers' standard of SLD by demonstrating that their overall achievement score on the PIAT was 30 points lower (2 standard deviations) than their overall IQ score. Although students in the SLD group performed lower in some achievement areas than the students who were described as low-achieving, Algozzine and Ysseldyke noted that many students who did not qualify also demonstrated a discrepancy, and that decisions made by school personnel as to whom was classified as SLD were inconsistent. They criticized the current practice as being "over-sophisticated" (p. 246) because practitioners had to rely on "statistical concoctions" to conduct eligibility meetings, yet they still did not consistently explain which students were eventually placed into special education.

\section{Analogue Studies}

Another type of quantitative design used by special education researchers as they have studied the eligibility process is the analogue study. This type of study asks teachers to read information about students and then respond to survey questions. A strength of 
this particular design is its ability to provide insights into processes used by stakeholders as they make decisions about students with disabilities (Rumrill, Cook, \& Wiley, 2011). However, a weakness of this type of study is that information cannot be generalized outside of the vignettes generated by the researchers.

Ysseldyke and Algozzine (1982) conducted this type of study that examined biases in eligibility decisions made by professionals working in the public schools. A total of 159 school staff members (school psychologists, special education teachers, general education teachers, administrators, and 10 other non-identified school personnel) were given one of 16 different case studies and asked to decide if the child (a fourth grader) qualified as having learning disabilities. The researchers varied four different characteristics when preparing the 16 case studies: Physical attractiveness (photographs were included in the folder), whether the child was male or female, whether the child was from a high socioeconomic status (SES) or a low SES, and whether the referral was primarily for academic or behavioral concerns. In half the case studies, participants read that the child's parents were a realtor and a bank vice-president; in the other cases, the child's parents were described as a janitor and a supermarket check-out clerk. In addition to information in the referral data, participants also had access to a computer archive of seven different assessments of cognitive, academic, and perceptual-motor skills, and were able to choose among assessment data to consider as part of their decision making process. Regardless of which measures were chosen by participants, all assessment data were within the average range of performance for a fourth grade student. 
After reviewing all of the case data, participants completed a Likert-type scale that indicated how certain they were that a child was either intellectually disabled, had a learning disability, or was emotionally disturbed. A score of 1 meant "very likely" to have a learning disability, while a score of 5 meant "very unlikely." The researchers used a four factor multivariate analysis of variance design to analyze the Likert scores. SES, whether the child was male or female, whether the referral was academic or behavioral, and whether the child was physically attractive or unattractive were the four independent variables. The dependent variables were whether the child was categorized as having a learning disability, an intellectual disability, or an emotional disability. The profile least likely to be considered as having a learning disability was an unattractive, low SES girl with behavior problems, while the most likely profile was an unattractive, low SES girl with academic problems. Despite all assessment data showing performance in the average range, half of the participants (52\%) found the child eligible for special education. None of the students were found eligible as having an intellectual disability, but the research does not break down the group as how many were classified as having learning disabilities compared to how many were classified as having emotional disturbances. SES was mixed throughout the results; an unattractive, high SES boy with academic problems was very likely to qualify as having learning disabilities, while an attractive, high SES girl with behavior problems was less likely to qualify. Ysseldyke and Algozzine (1982) commented that certain children were much more likely to be qualified than other children, but that this was a function of child characteristics in the referral, not based on actual assessment data. They speculated that school examiners may form their opinions 
about the child's eligibility based on the characteristics presented at the referral meeting and then just go through the motions of confirming their preconceived notions regardless of the evidence.

Epps, Ysseldyke, and McGue (1984) further investigated the complexities that practitioners struggled with when differentiating students with learning disabilities from students who were low achievers by utilizing an analogue design. Sixty-five school psychologists, 38 special education teachers, and 21 university students, who were not education or psychology majors, participated in the study. Subjects were given psychometric test data on 18 fourth graders; 9 were qualified as SLD by their home schools and 9 were classified as low achieving since they had scored at or below the $25^{\text {th }}$ percentile on the Iowa Test of Basic Skills. As in previous studies, students were classified as SLD if they met either a 1.0 standard deviation between ability and achievement scores in any of five domains (math calculation, basic reading skills, reading comprehension, math reasoning or written expression), or a more "severe discrepancy" of 1.5 standard deviation. Each judge received a packet of test data and was asked to indicate which students had learning disabilities, as well as a rating scale to indicate how certain they were of their decision. A greater percentage of the university students $(81 \%)$ were able to identify one particular student (\#17) who met both operational definitions of SLD, but only $63 \%$ of teachers and $64 \%$ of school psychologists were able to correctly identify the student. Another student, who was in the low achieving group and did not demonstrate ability-achievement discrepancies, was classified as SLD by $34 \%$ of teachers, $23 \%$ of school psychologists, and $66 \%$ of the university students. All three 
groups only agreed about a third of the time with the classifications previously made by school staff using the same data. There was a higher level of agreement between ratings of school psychologists and teachers than between the university students and the two professional groups. However, researchers concluded that just because judges had access to test information did not mean that their decision-making ability was enhanced, and that if judges had so much information that they experienced "cognitive overload," they may just make an initial hypothesis as to whether the student is eligible as SLD and then use data to support their impression, rather than examine all the information and then draw a conclusion. They called for a simplification in assessment procedures and possibly placing students into special education based on their current behaviors rather than results from psychometric testing and the identification of learning disability.

In a commentary summarizing many of their findings, Ysseldyke and Algozzine (1983) wrote that "to ponder, argue, quibble and mix about exactly what to call them (students who need remedial support in school) and who they are has merely served to sidetrack interest from the bigger, more important question: What do we do with them?" (p. 29). Because their research showed few differences between students who were identified as SLD and those who were not, and because school-based decision making was so inconsistent, they believed that the question should become what system of service delivery could address the needs of students who struggled academically.

\section{Theory of Competing Paradigms}

Out of all the studies examining school based decision making and the SLD eligibility process, only one group of researchers has proposed a theory that attempts to 
explain the reasoning behind those decisions. Bocian et al. (1999) proposed that school staff use three competing paradigms - relativity, or how a student performs in relation to their peers; acceptability, or how closely a student's academic and cognitive data align with the criteria for eligibility prescribed by the school district; and profitability, or the decision as to whether a student will benefit from special education services-when determining which students will qualify as SLD.

Interpreting their results through this theory, Bocian et al. (1999) studied how school-based eligibility team decisions varied from those made by researchers applying the legal guidelines dictated by the state of California for determining SLD identification. Out of a sample of 76 elementary aged students referred in 24 California schools, $78 \%$ of the students scored within the lowest $20^{\text {th }}$ percentile on the Wide Range Achievement Test, and $62 \%$ of total students met the acceptability criterion of demonstrating a discrepancy between academic and cognitive achievement. Out of the $78 \%$ of students who performed within the lowest $20^{\text {th }}$ percentile, $77 \%$ of them also met the requirement of having a severe discrepancy. However, only $37 \%$ of the total sample (28 students) met all three criteria (performance below peers, severe discrepancy, and eventual eligibility as a student with a learning disability). When local norms (which were operationalized by scores on the Wide Range Achievement Test, rather than curriculum based measures) indicated a need for special education services but there was no discrepancy, $39 \%$ of those students were labeled as having a learning disability. When there was a discrepancy, but the student was performing in the average range when compared against his or her peers, $45 \%$ of those students were classified as having a learning disability. 
Bocian et al. argued that teachers had a good sense of which students to refer for special education evaluations and that their judgment should be given at least as much weight as objective, standardized measures of ability and achievement when considering eligibility. Two groups of students - lower achieving females who did not have externalizing behaviors, and higher-achieving males who did exhibit behavior problems as measured by number of classroom referrals - did not qualify for special education services in this study.

\section{School-Based Versus Research, Definitional-Based Classifications of SLD}

Gresham et al. (1998) conducted a similar study that examined whether their classification system for mild disabilities, derived from state definitions, was in agreement with the decisions made by eligibility teams. They analyzed special education data (cognitive and standardized achievement scores) from a random sample of 150 second, third, and fourth grade students from 24 Southern California schools. Students were referred to their Student Study Teams during the 1992-1993 and 1994-1995 school years. Researchers divided the 150 students into three groups: Those classified as having a learning disability (severe discrepancy between ability and achievement scores), those labeled as low achievers (IQ of above 76 or higher, but no severe discrepancy between test scores), and those classified as having mild mental retardation (full scale IQ of 75 or less and sub average performance in the classroom). Doctoral students administered both the Weschler Intelligence Scale for Children III and the Wide Range Achievement Test to all subjects in the study and then gave these test scores to Student Study Team members for use in eligibility discussions. The researchers found that there were 
relatively low levels of agreement between the research-classified groups and those identified by the schools, even with identical test data. Forty-seven students in the research group were classified as meeting SLD criteria, but the schools only identified 28 of them, and 8 were found ineligible for services. Of the 43 students meeting the research definition of mild mental retardation, only 6 were identified by the schools under this category, with 19 misclassified as having learning disabilities and 4 misclassified as having specific language impairments. Out of the research-classified low achieving group of students, 14 were classified by student study teams as SLD, 12 with specific language impairments, and one with severe emotional disabilities. Gresham et al. concluded that the relatively low levels of agreement (59\% for SLD and only 14\% for mild mental retardation) between the research-based and school-based classifications meant that student study teams were not significantly influenced by psychometric testing data, and that instead perhaps the data were just used to confirm the teacher's perceptions that the student needed special education services.

In a third study exploring school-based versus definitional, research classifications for SLD, MacMillan et al. (1998) studied two state-mandated criteria for identifying students: A severe discrepancy and exclusionary factors for mental retardation. A sample of 150 children in grades 2, 3, and 4 were selected from 24 different schools in Southern California. All of the children had been referred to the Student Study Teams at their home schools for special education evaluation. However, due to student mobility and other factors, student study teams had determined eligibility or non-eligibility for only 113 students during the period in which the study was 
conducted, so there were a smaller number of decisions to examine compared to the total number of students in the research sample. Researchers administered the Weschler Intelligence Scales for Children III and the Wide Range Achievement Test to all students, and teachers completed social and behavioral rating scales for all participants. All test data, with the exception of cognitive measures for African American students, were given to school staff for use in eligibility discussions. Researchers classified students as either meeting SLD, MR, or not eligible for services based on the following state guidelines: If a student had an IQ of 75 or below, they were classified as having mild mental retardation, and if they had a 22 point discrepancy between their academic scores on the Wide Range Achievement Test and their IQ score, they were classified as SLD.

In the research sample of 150 students, 46 students (30\%) had at least a 22 point discrepancy between their IQs and academic scores. However, out of the 113 students classified by student study teams, the school-identified SLD group was 61 students (51\%), Out of these 61 students, 32 of them did not meet the state guidelines as operationalized by researchers for having a severe discrepancy between ability and achievement. Eighteen of these students had IQs below 75, yet were classified as SLD rather than MR by student study teams, leading researchers to conclude that SLD was a more socially acceptable label to school staff and parents, and that the schools were using SLD as a cross-categorical designation that encompassed students with mild mental retardation, discrepant low achievement, and no discrepant low achievement. They were concerned that the schools were interpreting absolute low achievement as a characteristic of SLD, rather than low achievement with average to above average intelligence, and 
wondered whether findings from intervention studies where participants met the "classic" definition of SLD would apply to students who were low achievers but did not meet research criteria for SLD.

\section{Comparing Discrepancy Models Using CBM}

Peterson and Shinn (2002) also examined discrepancy and school-based decisionmaking for SLD. They compared scores of students identified as having learning disabilities in a high-achieving, suburban school versus scores of students identified as having learning disabilities in a low-performing, urban school to examine which evaluation method best matched eligibility decision making in two different contexts. They used CBM as a critical assessment component when they compared three discrepancy models (absolute discrepancy, relative achievement discrepancy, and intraindividual achievement discrepancy) to see which one most closely reflected school SLD eligibility decisions. Their sample consisted of 48 fourth-grade students from Minnesota, all of whom had been identified as having a learning disability in the year and a half before the study began. Twenty-seven students attended a school in a high-achieving, suburban district where state reading scores were described as "Above Average" and 21 students were enrolled at a school in a low-achieving, urban district where state reading scores were classified as "Below Basic." Thirty-nine fourth grade students who were described as typically achieving were also selected as a comparison group. The researchers administered both the Woodcock Johnson Broad Reading cluster and curriculum based reading measures to both groups of students; students who also qualified for special education also received select subtests from the Weschler 
Intelligence Scale for Children III. Students from both the SLD group and the typically achieving group earned higher scores on all measures than students who attended school in the lower-performing district; SLD students from the higher-achieving district averaged 16 points higher on the Broad Reading cluster of the Woodcock Johnson than the students who were identified as SLD in the lower-performing district. When just the national norm was used (the absolute achievement discrepancy model, where low achievement alone was the criteria for having a learning disability), $81 \%$ of the schoolidentified SLD students from the low-achieving school were re-classified as SLD, but only $22 \%$ of students at the high-achieving school were reclassified. Using the traditional intra-individual achievement model, which required a severe discrepancy between ability and academic achievement scores, $63 \%$ of school-identified SLD students from the highachieving context were reclassified as SLD, but only $48 \%$ of SLD students from the low achieving schools were reclassified. Peterson and Shinn argued that because a relative achievement discrepancy model using curriculum based measures identified $88 \%$ of the SLD students at the high-achieving school and 95\% of SLD students at the low achieving school, it was a more satisfactory explanation of how schools actually decided which students received the label of learning disability.

\section{Summary}

In conclusion, researchers in the field of special education have used a variety of methods to examine the ways in which schools qualify students as having a learning disability. They have used quantitative methods such as statistical comparison and analysis to explore the relationship between legal guidelines for establishing learning 
disability eligibility as well as to examine how different discrepancy models resulted in different groups of students identified for special education services. They have also used analogue studies as another type of quantitative design in order to simulate the decision making process and to examine variables that may affect determination of eligibility. Researchers have also used qualitative methods, such as case studies and observation, as other ways to gather information about the SLD eligibility process.

As the previous literature review establishes, the process that special education professionals engage in to determine which students qualify as having learning disabilities is complicated, fraught with challenges, and can be easily influenced by professional bias, team chemistry, and available resources. The NRCLD (2007) stated that challenges related to SLD identification are not only related to assessment, but involves contextual factors as teams decide whether students need services. Their model, presented in the introduction, presents four interrelated factors occurring in the identification process: IDEA definition, school culture, role played during the SLD determination process, and values held by stakeholders. Bocian et al. (1999) also discussed that school culture and values play a part in profitability — the team's consideration of whether the child will benefit from special education services as provided at that specific school site. The concept of profitability also includes availability of local resources.

However, all of the existing research was completed before the 2004 Reauthorization of the Individuals with Disabilities Education Improvement Act, which permitted local education agencies to use new identification models for SLD evaluations. 
RTI focuses on organizational structure, prevention, and scientifically based reading instruction. PSW focuses on an individual's ability and achievement as measured by norm-based, standardized testing and searches for a cognitive weakness that explains academic difficulties and low achievement. Both models arose in part due to concerns that public schools were using the traditional IQ-discrepancy model to over identify students. 


\section{CHAPTER 3}

\section{METHOD}

This qualitative interview study attempted to fill a gap in the existing literature base about how schools were identifying students after implementation of new SLD models. The first research question was: To what extent do interviews of secondary resource teachers reveal the concepts of relativity, acceptability, and profitability as they reflect on the SLD process? The second research question was: What other themes regarding SLD eligibility determination emerge from interviews with secondary resource teachers?

The first conceptualization of this doctoral study attempted to analyze actual files of middle school students identified as SLD by school eligibility teams as a way of answering the first research question. However, after an extensive recruiting effort in Fall 2013, only two consent letters were returned. Because of the low rate of return, this option could not be pursued.

Lee (1999) cited a list of questions by Marshall and Rossman (1995, pp. 41-43) and suggested that a qualitative study should be chosen by the researcher if the answer to the following six questions was yes:

1. Is it important for the researcher to understand the in-depth processes that operate within the organization or industry?

2. Do the research issues involve poorly understood organizational phenomena or systems?

3. Is the researcher interested in the differences between stated organizational policies and their actual implementation? 
4. Does the researcher want to study ill-structured linkages within organizational entities?

5. Does the study involve variables that do not lend themselves to experiments for practical or ethical questions?

6. Is the point of the study to discover new or thus far unspecified variables?

The answers to questions $1,2,3,5$ and 6 as they pertain to this doctoral study are yes. Bocian et al.'s 1999 theory of competing paradigms is the only existing theory of how school-based special education eligibility teams determine which students qualify as having specific learning disabilities. It is important for researchers to understand the indepth processes that operate during school-based SLD identification and for that information to be shared with decision-makers within the participating school district, as it can affect the lives of students, teachers, and parents (question 1). The current state of identification as practiced by schools is not well understood (question 2), and the differences between the prescribed SLD criteria by the cooperating school district and the actual implementation of that policy is of interest to service providers and those who make policy and administrative decisions (question 3). Although there is much advice and theory published in the last 10 years surrounding and following the changes in federal law including RTI and PSW, there have been little to no studies of how actual teams are implementing these new policies with real students. The restrictions involving the review of student records and parent consent (FERPA) and the difficulty of obtaining parent consent to review a confidential file limit the current investigation to an interview study. Furthermore, it is not possible to design experiments regarding SLD eligibility determination (question 5); it would be unethical to withhold special education services from students who need them. Previous analogue studies have examined stakeholder 
decision-making using standardized testing data (Ysseldyke \& Algozzine, 1982; Epps et al., 1984); although the scores from psychometric evaluations provide a critical piece of eligibility determination, the theory of competing paradigms is broader than just the concept of acceptability as it is defined in state or district procedures for determining SLD eligibility.

Finally, the second research question asked if there are other themes that emerge from the interview data that affect identification of students with SLD. Bocian et al. (1999) argued that there were practical considerations that influenced classification decisions, including available space on caseloads, second language issues, and how strongly the parents advocated for services. Although the point of this study was to look to see if an existing theory can be grounded in specific statements by secondary resource teachers, there was the possibility that other contributing factors to the SLD decisionmaking process could be identified.

\section{Methodology}

The method selected for this study followed the naturalistic paradigm. Lincoln and Guba (1985) described the first step of a naturalistic inquiry as making a decision upon a problem or phenomenon of study. Their definition of a problem is "a state of affairs resulting from an interaction of two or more factors that yields a perplexing or enigmatic state" (Lincoln \& Guba, 1985, p. 226). In this study, the problem was why school-based eligibility teams identify different students as eligible for special education services under the category of SLD than do researchers (Bocian et al., 1999). Their theory of competing paradigms identified three different concepts that create tension 
throughout the SLD determination process: Relativity, acceptability, and profitability, which include a host of other variables, such as team chemistry, parental advocacy, and local resources. Lincoln and Guba stated that the purpose of a naturalistic inquiry is resolution, in the sense that enough information is gathered to develop a sufficient explanation or understanding of the problem.

According to Lincoln and Guba (1985), there are 14 characteristics to a naturalistic study. The first is that it be conducted in a natural setting rather than an experimental one. Because FERPA restrictions on consent did not allow for direct observations of student evaluation teams or direct review of records produced during those meetings that documented SLD decision-making, interviewing participants who had served on secondary eligibility teams and documenting their experiences did permit a window into the ways in which the theory of competing paradigms interacts in real-life eligibility decisions.

The second and third characteristics of naturalistic inquiry are that the instrument be a human, because "only humans can identify biases that exist within a local system" (Lincoln \& Guba, 1985, p. 39). The SLD decision-making process, as stated before, is complex, nuanced, and heavily influenced by local factors through the initial referral right up until eligibility determination. Although school staff have their biases, only humans can reflect on and identify those pre-conceived ideas that can influence their decisions. The third characteristic, utilization of tacit or "intuitive" knowledge in addition to propositional knowledge, is also key in the design of this study. Teachers may know and have been trained in their district's procedures for determining eligibility, but each of 
them also have an internal concept of what a learning disability is, and each of them can be susceptible to either persuasion or coercion by other players on the eligibility team that "the student needs the help" even if they do not meet SLD criteria within the district's prescribed model.

The fourth and fifth characteristics are employment of qualitative methods and purposive sampling. This study used a qualitative method (interviews with secondary resource teachers) as a way to gain insight into the SLD eligibility process, in part because other methods (direct observation and review of student records) were not accessible due to complications with gaining district participation and concerns with FERPA regulations. Interviews are "particularly well-suited for studying people’s understanding of the meanings in their lived world" (Kvale \& Brinkmann, 2009, p. 116). Interview questions were "thematized" (Kvale \& Brinkmann, 2009, p. 107) as a first step in designing the interview, meaning that several questions were written in order to reflect certain elements of the theory of competing paradigms. Building the theory to be tested into the questions themselves increased the probability that the interviews would contain relevant information to be used during the data analysis stage (Kvale \& Brinkmann, 2009).

The fifth characteristic of naturalistic inquiry according to Lincoln and Guba is purposeful, or theoretical, sampling. Creswell (2008) defined this type of sampling as occurring when researchers intentionally select their participants and sites in order to explore the phenomenon in question. Naturalistic researchers prefer this type of sampling 
as opposed to random or representative sampling, which can suppress outlier cases. Secondary resource teachers were recruited and gave informed consent to participate.

The sixth and seventh characteristics of naturalistic inquiry go togetherinductive data analysis and grounded theory. Lincoln and Guba (1985) argued that inductive data analysis was more able to identify the multiple interaction of factors that affect the phenomenon under study, and because "values can be an explicit part of the analytic structure" (p. 40). In this study, multiple factors influenced SLD eligibility decisions. Bocian et al.'s (1999) concept of profitability — the idea that school staff may weigh the benefits of special education services at their local site when identifying a student as SLD - is an example of a value that was explored during data analysis. Grounded theory is preferred by naturalists because no previously existing theory can encapsulate all possible realities interacting within the central phenomenon. This study used the theory of competing paradigms as a "jumping off place," with questions that examined elements of the theory, and then expanded the inquiry to look at other influences that may be affecting SLD eligibility.

The eighth and ninth characteristics both relate to flexibility of study design and using the insights of human participants as the inquirer moves further along in their research. The eighth characteristic of a naturalistic inquiry is emergent design, because naturalists believe that there are too many unknown variables to plan the research design in advance and stick with one linear plan throughout the entire investigation. This is true of the current study in that a pilot study was conducted to field test interview questions to ascertain whether the information obtained was relevant to the theory being examined. 
Based on the responses of four secondary resource teachers, the wording of questions was adjusted or combined with other questions in order to elicit better information during the dissertation interviews. The ninth characteristic, negotiated outcomes with participants, involved both an immediate member check (completed after each question while interviews were taking place) and a more thorough, case study report that was checked with participants for accuracy a few months following their interviews. These interactions with human sources permit the naturalistic inquirer to better reconstruct the lived realities experienced within the settings of interest — in this case, the public schools — as participants reflect on the SLD eligibility determination process.

The tenth characteristic is the use of case study reporting to share information gathered throughout the research, because this style of communication is able to provide a thorough description of the site in which the research occurs. Although case studies were used during the member check process in this study, they were not full of the "thick description" of the actual school sites where participants were employed; rather, they were used to check information for accuracy. While subjects did provide some context for making SLD decisions and described some of the structural and organizational elements present in their school buildings, this study used description less than a naturalistic study that employed observational methods rather than interviews.

The eleventh characteristic of naturalistic inquiry is idiographic interpretation, which means the naturalistic inquirer is more inclined to interpret data in terms of specific details of that case because the realities in one setting may or may not be the same as in a different setting; drawing generalizations between cases is likely to be less 
reliable given that local factors affect interpretations. In this study, I did search for common themes among sites given that although each school had its own distinct and unique local culture, and each eligibility team was influenced by the personalities of its composite members, there is an overall district policy in place that was being implemented throughout all schools. The three steps (referral, testing, and eligibility determination) and the three competing paradigms (relativity, acceptability, and profitability) were the same throughout all of the public schools, but how they were implemented may be slightly different from site to site because of the three competing paradigms (relativity, acceptability, and profitability). Because of these differences, characteristic number 12 - tentative application of the findings - is true of naturalistic inquiry as well. The findings are somewhat dependent on the rapport between the investigator and the participants, which may be difficult to duplicate in a similar study; the fact that I have been employed by the school district for 14 years and am known as a district employee may have influenced the participants' responses, where they may or may not have shared other information with an investigator who was not perceived as experienced in the culture of the district special education process. Local factors, such as value systems, can also affect whether the generalizations at one site can transfer to another site.

The thirteenth characteristic of naturalistic inquiry is focus-determined boundaries, meaning that the inquirer is more likely to set boundaries on the inquiry based on the emergent focus rather than on the pre-conceptualizations of the inquirer. In this study, boundaries were set around the elements of the theory of competing paradigms 
and questions related to the eligibility process. Although information from the pilot study was used to re-formulate and select the final questions used for the dissertation interviews, the theory under investigation was the guiding force in which questions were developed and retained. The focus was not so much emergent as pre-determined given that the first research question is whether the theory of competing paradigms could be grounded in the realities of secondary school SLD eligibility practices; however, the second research question searches for other emergent themes that may not be represented by existing theory.

The fourteenth and final characteristic of naturalistic inquiry according to Lincoln and Guba (1985) is that there are special criteria for trustworthiness. In a qualitative study, the concept of trustworthiness refers to whether or not the research findings are valuable or worthy of attention from stakeholders. For quantitative, conventional research studies, the criteria that have emerged to judge the worth of a study's findings are internal validity, external validity, reliability, and objectivity. However, conventional research is based upon the idea that there is an objective reality "out there" that can be fragmented into individual pieces for study; naturalists believe that there are multiple constructions of reality, that it is impossible to separate the "known" from the "knower," and that at best, the results of study will yield a general understanding of the phenomenon rather than a definitive truth arrived at by controlling variables. Because of these beliefs, the substitute criteria for determining the value of qualitative research findings are credibility, transferability, dependability, and confirmability. 
Credibility is the substitute criteria for internal validity in a conventional, quantitative research study. It is the idea that the researcher will design and carry out the study in such a manner that the findings will be believable by stakeholders and audiences. Major activities for building credibility include prolonged engagement, triangulation of sources or methods of data collection, member checking, peer debriefing, negative case analysis, and referential adequacy.

Prolonged engagement is when the researcher immerses themselves in the local culture before beginning the study in order to build trust and rapport with participants. I have worked for 14 years in the special education resource culture of the participating district and have attended staff development alongside the participants. I am recognized as part of that local culture; Lincoln and Guba (1985) noted that "unless the inquirer began as an accepted member of the group or agency being studied, distortions can never be overcome" (p. 302). I regarded my background as a secondary resource teacher as an asset during the course of this study.

The second technique for establishing credibility is triangulation, or using many different sources of data collection or participants. The investigation included interviews with 10 participants, who had signed informed consent before sharing their insights into the SLD eligibility determination process. Multiple viewpoints gathered from different schools and different individuals with varying levels of professional experience gave depth to the research findings and enhanced credibility. I also took notes during the interviews and referred back to them throughout the development of the transcripts and case studies. 
Member checking is the most critical technique for establishing credibility (Lincoln \& Guba, 1985) and it requires the inquirer to check data, interpretations, and conclusions with participants who supplied the data for the study. The advantages of member checking are that it gives respondents an opportunity to correct errors or dispute misinterpretations made by the inquirer. It also gives participants a chance to supply additional information about the topic, since the act of reflecting on their own responses can trigger them to provide more details, as well as creating a written record of statements for the inquirer to analyze. This study used two forms of member checking: As participants responded to each question, I summarized their responses and asked them if the summary sounded complete and accurate. Later on, each participant received a written report summarizing the results of their interview and was asked to provide feedback on accuracy and whether I had correctly identified the ideas contained within their statements.

Three other techniques for establishing credibility include peer debriefing, negative case analysis, or referential adequacy. Peer debriefing is when a colleague acts as a "devil's advocate," listening to the inquirer develop insights about the materials collected and asking questions about research methods, methodology, decision-making, and other aspects of the study. I did not choose to participate in this process because Lincoln and Guba (1985) specified that the debriefer should be someone who is neither junior or senior in status compared to the inquirer, and it became difficult to find someone who would fit that description, yet would have a solid background in 
understanding both the theoretical and practical processes involved in SLD eligibility determination.

Negative case analysis is the qualitative version of statistical analysis; this involves returning to the working hypothesis each time conflicting information is reached during data analysis and refining it until all available cases are accounted for. My second research question - what other themes emerge during the SLD eligibility determination process - is meant to be an exploration, rather than produce a hypothesis that accounts for all examples provided by interview participants. Therefore, I did not use negative case analysis.

Referential adequacy, or storing some of the interview data until after the rest of the data is analyzed in order to test the hypothesis and see if it holds true, was not done for this study because there was such a small set of interviews. This approach for building credibility "does not recommend itself well to the more practical minded or resource poor" (Lincoln \& Guba, 1985, p. 314) for that very reason; withholding even one of the 10 interviews would have resulted in less data available during analysis.

The second substitute criterion for trustworthiness in a naturalistic study is the concept of transferability, which replaces external validity in a conventional qualitative study. Transfer is the idea that the results of the inquiry can be used to describe actions in a similar setting with a similar population of individuals. The basis of transferability is thick description; however, in the current study, the focus was more about the concepts of relativity, acceptability, and profitability, rather than on describing specific elements of the settings in which individual teachers and teams applied procedural knowledge in 
order to determine SLD eligibility. There is no agreement between naturalistic researchers about how much thick description is enough to constitute transferability. The responsibility of the inquirer is to provide enough background information for another researcher to decide if there are enough similarities between the "sending context" (the sites in which the original study is conducted) and the "receiving context" (the sites where the second researcher would like to make the generalization) to make an argument that the findings hold in other settings.

The third and fourth criteria for trustworthiness are dependability and confirmability. Dependability is a substitute for reliability, the idea that in conventional studies, the same experiment will produce the same result if it is repeated and procedures are duplicated. However, because naturalists believe that reality is not unchanging, and that the phenomenon under study can change over time, dependability is a broader concept than reliability and needs to incorporate both changes in the construction that is studied and changes in the emerging design of the study. Confirmability is the substitute criterion for objectivity in conventional studies; instead of the focus being upon the distance between the investigator and what he or she is studying, the question becomes whether findings developed from the data can be confirmed. Both the tasks of establishing dependability and confirmability can be done using an audit trail, which is an outside review of records generated during the course of the study and the linkages between those data sources and findings. I explain more about the specific audit trail employed in the current study in the procedures section. 


\section{Procedures}

\section{Setting}

This research study took place in a large suburban district in the Pacific Northwest that was in its sixth year of implementing a new SLD identification model. There were more than 2,000 teachers working in the district, with an average of 10 years of teaching experience, and an average of 10 years of experience working within this district. The district's projected enrollment by Fall 2015 was nearly 40,000 students. Thirty-eight percent of students qualified for free or reduced lunch, and nearly 50\% were students of color, with Hispanics and Latinos making up the largest ethnic group. There were more than 90 different languages spoken by students. As of December 2013, 12.5\% of the student body qualified for special education services.

\section{Special Education Eligibility Determination Guidelines}

During the 2008-2009 school year, special education administrators convened a committee composed of both learning specialists and school psychologists to "recommend a process for ... staff to follow in determining SLD eligibility based on OAR 581-015-2170 and to develop tools to assist with process implementation" (personal communication, April 2013). However, due to scheduling challenges and difficulties with resource teachers leaving their classrooms and caseloads for meetings, the final SLD committee included only 11 school psychologists. The committee wrote a position paper titled "Proposed Guidelines for SLD Identification," advocating that the district adopt a balanced practice model that would incorporate elements of both RTI and PSW. Students should receive interventions prior to referral, but eligibility teams should 
still conduct cognitive testing in order to identify processing deficits that may be responsible for lack of academic skills, as well as to design more targeted interventions. Beginning in the 2009-2010 school year, eligibility teams were given the option to identify students under both RTI and PSW. (After this interview study was conducted, in November 2014, another committee of school psychologists changed the criteria for identifying students under the category of SLD. Although the committee declared that schools were to attempt two different interventions before initiating a referral to special education, the results of those interventions were not to be considered during the SLD determination process. The description of the RTI process given below followed the previous guidelines that were in place at the time the study was conducted.

The middle school RTI process used Easy CBM as its universal screening program to identify which students were not performing at grade level in reading or math. Curriculum based measures are short assessments that are designed to be given frequently and are linked to the curriculum (Hallahan, Lloyd, Kauffman, Weiss, \& Martinez, 2005). Three times per year (fall, winter and spring), all students read a 1,000 word grade level passage and answer a 20 -item multiple choice assessment on a computer. In addition, all students also completed the math Easy CBM assessment for their grade level, which is approximately 50 problems. After universal screening, data team members (an administrator, the school math and reading intervention teachers, and the counselors) met and review results to decide which students could benefit from RTI services, which were delivered for a set amount of time every day (the amount varies per school depending on school schedule, but is typically done in place of an elective class). The software program 
assigned a risk level (low, medium or high) depending on the student's performance; low risk meant they were on track to meet the state benchmark for that grade level, while high risk meant that they were not likely to meet the standard. For a student to qualify as SLD using the RTI method, two different research-based interventions needed to be administered and at least seven data points per intervention were recorded showing that the student was not responding to the intervention. However, this presented a significant challenge in middle schools, as not many research-based reading and math interventions developed specifically for older struggling students exist.

Because of this challenge, many middle school evaluation teams used the second eligibility option-PSW — when assessing and considering whether students meet criteria for SLD eligibility. During the first few years of the program, only school psychologists were trained in the model, but other school personnel were not given training. Beginning in the 2011-2012 school year, resource teachers could attend optional staff development sessions explaining the PSW model. At the trainings, staff received copies of the SLD matrix, a tool used by eligibility teams to clarify implementation of the PSW model. It provided school practitioners with a framework for comparing standard scores on cognitive subtests with standard scores on academic subtests as they searched for processing deficits causing weaknesses in reading, writing, or math skills. Standard scores of 85 or above in any cognitive or academic cluster are considered to be a strength of the student; scores below 85 are considered to be a weakness. According to district guidelines, to qualify as having a SLD, the student must have at least three cognitive scores in the average range and at least one score below average; they must also have 
corresponding scores indicating weaknesses in the academic skill related to that cognitive ability.

Regardless of whether the eligibility team uses the PSW model or the RTI model when evaluating a student for specific learning disabilities, the district suggested that teams use a weighted scale, assigning points to each required element of the evaluation. For RTI, there were nine points available, and a student who qualified as SLD needed to earn seven out of nine; for PSW, there were seven points available, and the student needed to earn all seven points in order to qualify as SLD. The file review was one point if it showed academic impact due to a possible disability (i.e., poor grades, negative comments from teachers pertaining to an academic area). The required classroom observation was one point if it shows that the student was struggling with learning. The state testing scores were assigned one point; if a student does not pass them, or has a history of not meeting those standards, they earned a point. The standardized academic testing scores were two points if they were below the average range (standard scores of 85); the standardized cognitive test scores were also given two points if they showed a pattern of strengths and weaknesses. Finally, if the student had been enrolled in at least two different academic interventions, their progress monitoring scores counted as two points if they did not show growth resulting from the intervention.

\section{Instrument}

The instrument used in this study was a list of 13 questions asked of resource teachers in the participating school district. Between January 2014 and March 2014, questions were field-tested with 4 participants (two middle school resource teachers, one 
high school resource teacher, and one middle school resource teacher who had retired during the previous year), all of whom had taught in the participating district. Using their responses, I fine-tuned the wording of the original 13 questions, added one question specific to assessment of English language learners, and dropped one question. Appendix A has the first list of questions; Appendix B has the final list of questions used with those interview participants in the dissertation study.

\section{Participant Recruitment and Selection}

This study focused on gaining information from secondary resource teachers for several reasons. Resource teachers attend all meetings for students being referred and evaluated for special education services, communicating with all members of the child's assessment team. These teachers are in the position of knowing the regular education teachers well, particularly if they are co-teaching classes. They are also in the position of knowing the other specialists on the evaluation team well, as they are part of the special education department. They also have some training in standardized cognitive and evaluation methods through courses taken to gain their special education teaching credential. In addition, they are the most likely to take on extra work for each student who is identified for special education as having a learning disability; Bocian et al. (1999) listed caseload numbers as one factor affecting the team's decision of whether a given student will profit from special education identification. I chose to study secondary resource teachers, as opposed to elementary resource teachers, because my literature review revealed that only two studies (Christenson, 1980; Ysseldyke, Algozzine, \& Epps, 
1982) included information about how school-based eligibility teams were making SLD determination decisions.

During May and June 2014, I mailed informed consent forms to 68 secondary resource teachers at eight comprehensive middle schools, five comprehensive high schools, and eight middle and high school magnet programs in the participating district. All secondary resource teachers were included in this mailing, other than three teachers who were out on personal leave. Twenty-three teachers were employed at the middle school level; the rest were employed the high school level. Thirteen informed consents were mailed back to a post office box reserved for the purpose of the study. Of those 13 respondents, one was an administrator not targeted for recruitment, one declined to participate, and one was a K-8 teacher who did not respond to an attempt to schedule an interview. The remaining 10 teachers who had given signed informed consent were contacted through their district email addresses and asked to provide summer contact information to use for scheduling an interview. These 10 teachers represented one 6-12 magnet school, two middle schools, and three comprehensive high schools. Five taught at the middle school level, and five taught at the high school level. The participants varied both in the number of years of teaching experience and the number of years of employment with the participating school district. Because multiple participants had previous experience with multiple grade levels, they were categorized below by the level (either middle or high) that they had most recently instructed (see Table 1). 
Table 1

Participant Information

\begin{tabular}{|c|c|c|c|}
\hline Interview Number & $\begin{array}{l}\text { Level Taught During } \\
2013-2014\end{array}$ & Years of Experience & $\begin{array}{c}\text { Years Employed by } \\
\text { District }\end{array}$ \\
\hline 1 & middle & 7 & 7 \\
\hline 2 & middle & 15 & 12 \\
\hline 3 & high & 30 & 14 \\
\hline 4 & middle & 24 & 12 \\
\hline 5 & middle & 16 & 5 \\
\hline 6 & middle & 5 & 8 \\
\hline 7 & high & 22 & 1 \\
\hline 8 & high & 14 & 14 \\
\hline 9 & high & 1 & \\
\hline 10 & high & 27 & 10 \\
\hline
\end{tabular}

\section{Interviews}

In early July 2014, I began contacting interview participants and scheduling the interviews at a mutually convenient time and location. Three of the interviews were conducted at a meeting room in a public library; the remaining interviews were conducted at coffee shops. The length of the interview sessions ranged from 20 minutes to 48 minutes. All interviews were recorded using a digital audio-recorder, and I took notes as participants responded to each question. Following each question, I summarized and paraphrased the participant's response as a way of conducting an informal member check (Lincoln \& Guba, 1985). After interviews were completed, participants received a \$20 gift certificate for a store or restaurant of their choice. 


\section{Transcription and Reliability}

During August and September 2014, I transcribed each audio file and developed a transcript by listening to each recording and pausing where needed to type what I had heard. I recorded all words with the exception of the names of the schools where the participants were employed in order to protect their identities. Appendix C shows 1 of the 10 transcripts as an example.

In September 2014, another doctoral student conducted a reliability check on two randomly selected pages of each transcript. Lee (1999) suggested assessing reliability by having one person transcribe the text and another person compare the printed transcript to what they hear on the page; this was the method used for this study. My assistant listened to each audio-file while reading the selected pages of each transcript, and made notations of places in which my transcripts differed from what she had heard. She calculated reliability using the following formula suggested by Miles and Huberman (1994): number of agreements divided by the number of agreements and disagreements. Miles and Huberman suggested that the goal be $80-90 \%$ reliability. For this study, reliability statistics ranged from $97 \%$ agreement (interview number 7) to $100 \%$ agreement with the transcript (transcripts numbers 8 and 9).

\section{Member Check Case Studies}

In October and November 2014, I wrote a series of short case studies based on each transcript and emailed them to participants, asking for their feedback. I specifically asked if there were errors in either factual information or in my interpretation of their statements. If I had questions, I italicized the text within the body of the case study and 
asked for clarification. I also emailed each participant a copy of their interview transcript, so they could refer to it as they read their case study to refresh their memory or crosscheck their statements. I asked participants to keep both documents confidential and to try to respond to my request for feedback within two weeks, or to let me know if they needed more time. After two weeks, if I had not heard from participants, I gave them a telephone call reminding them that I needed to verify their data with them before I was able to analyze it and include it in the study. All but one participant returned written feedback on the case study, which was then used to make changes if they were indicated. One participant gave verbal feedback over the phone that the case study was sufficient and represented her views adequately. One of the case studies is shown in Appendix D as an example of how it was developed from the interview transcript.

\section{Data Analysis}

The method of data analysis selected for this study was the constant comparative method, which was originally developed by Glaser and Strauss (1967). The original intent for this method was to generate grounded theory, or theory that is based in data, in the field of sociology. However, Lincoln and Guba (1985) proposed a modified version of constant comparative method, which focuses more on the usefulness of this approach for analyzing data and does not generate theory as the final outcome. They suggested four steps: Unitizing the data, categorizing data cards, filling in patterns and writing a case study report, and member checks.

The first step of the constant comparative method according to Maykut and Moorehouse (1994) is preparation of data for analysis, which includes unitizing the data 
so it can be sorted into categories. Lincoln and Guba (1985) stated that a unit of data needs to meet two criteria - it needs to be heuristic, or "aimed at some understanding or some action that the inquirer needs to take" (p. 345); it also needs to be able to be understood without any additional explanation except for a general sense of the context in which the study is conducted. A unit may be as small as one sentence or as large as a few paragraphs. Units can be found in interview notes, field notes, or other document; in this study, only the interview notes were unitized. The case study reports were used to check facts and interpretations, as well as emerging ideas, with members, but were not unitized as part of data analysis.

I followed Maykut and Moorehouse's (1994) suggestion that researchers make a set of photocopies for each transcript at the start of the analysis process. I read though the transcripts and drew a line across each unit of text to separate it from the following unit. In the left margin, I indicated where the unit is located within the larger data set. When identifying the data for this study, I used the participant number, question number, and statement number; for example, a margin note reading “2-7a-3” means Participant 2, question 7a, statement 3." The statement number represented the number of responses offered by the participant to that particular question. Underneath each margin note, I wrote one or two words describing the meaning of that particular unit. By the end of the preparation process, I had three sets of transcripts for each interview: the original transcript, which remained unmarked; a complete transcript with identified units, margin notes, and key words; and a final set, which was identified and ready to be pasted onto index cards and sorted into categories. 
Maykut and Moorehouse (1994) argued that using this approach (identifying the units within the whole transcript and labeling them before cutting and pasting onto index cards) allowed inquirers to return to their original transcripts more easily to clarify information if that became necessary at a later stage during analysis. I followed their recommendation that every piece of the transcript be unitized, with two exceptions. Participant responses to questions number one and three (the number of years they had spent teaching, and the number of years they had spent employed by the district under study) were recorded as numbers on the back of each index card, rather than cut and put onto index cards. Both Lincoln and Guba (1985) and Maykut and Moorehouse (1994) advised that inquirers include additional information about the participants on the back of cards, as it may become important later during analysis.

After unitizing each section of each transcript and cutting each transcript into their corresponding units of meaning, I taped each chunk of text onto a 5 by 8 inch index card and sorted cards into 14 different piles, one pile for each interview question. Question 7a and $7 \mathrm{~b}$ were sorted into two different piles; questions $13,13 \mathrm{a}$, and $13 \mathrm{~b}$ were sorted into one large pile, as each one involved participants' impressions of SLD eligibility models. Then, for each data set, I followed the categorizing steps described by Lincoln and Guba (1985):

1. I selected one card out of the set and put it aside.

2. I chose a second card and read it, deciding if it was somehow connected to the first card, or if it needed a separate category of its own. 
3. I repeated this process with all of the cards, using a "look-alike/feel-alike" criterion (Lincoln and Guba, 1985, p. 347) to see whether each card belonged in an existing category, or if it needed to be used to start an additional category.

4. For cards that did not appear to belong to any category, I set them aside into a miscellaneous pile.

5. After I sorted about half of that question's cards, I studied each pile and wrote a statement about how all of the cards in that pile went together. I wrote the rule on another index card and placed it on top of the pile, then re-read the cards to make sure they all fit within that category. Sometimes I restated the "rule," or statement, after re-reading the cards. Sometimes I removed cards from that category if they did not appear to fit with the statement I had written.

6. I continued the process for the rest of the cards that responded to that specific interview question.

7. After I had used the entire pile of unitized cards for that question, I read through the categories to see if any could be combined or if any of the cards in the miscellaneous pile could be included.

I did not complete Step 8 (gather more data for categories if possible), because I did not conduct any more interviews after data analysis was conducted. I then repeated Steps 1-7 for each pile of cards that represented each interview question. I put all cards into large manila envelopes and labeled them with the concept (i.e., profitability) that the 
interview question was designed to explore, as well as the categories that were represented by the cards.

When analyzing data for Research Question \#2 (what other themes emerged from participant data), I looked at the entire set of cards rather than beginning the sort with cards already organized according to their corresponding research question. I returned to Bocian et al. (1999) and reviewed examples they had given for each of the three paradigms, and cards that had similar examples were removed from the pile. For example, when expanding upon the concept of profitability, Bocian et al. gave examples of class size, responsiveness of the child, and resources available in the classroom as influencing factors on whether teachers referred a student for special education. I removed cards that reflected those examples. Then, for each paradigm, I sorted the remaining cards into like categories using the constant comparison method described above. I labeled each card with either an R (for relativity), an A (for acceptability), or a P (for profitability) and then classified those categories under the concepts of either relativity, acceptability, or profitability as evidence of themes that had not yet been discussed by Bocian et al., but that still related to their theory.

\section{Audit Trail}

Both Maykut and Moorehouse (1994) and Lincoln and Guba (1985) describe an audit trail as one way to establish trustworthiness of an inquirer's findings, and allows reviewers to re-trace the steps completed during the study. Lincoln and Guba presented Halpern's algorithm for completing the auditing process. Those steps are: (a) pre-entry discussion of what materials should be audited and explanation of the purpose of the 
study; (b) determination of whether an audit can be completed; (c) a formal agreement between the inquirer and the auditor, including a time limit; (d) determination of trustworthiness, which means examining the findings for dependability and confirmability; and (e) closure, which includes the auditor writing a letter to attest to their findings. However, Lincoln and Guba noted that for many studies, the auditor is not involved until after the research study has already been conducted, and that "while the stages and sub-stages are described in a rational order, it is not the case that the sequence is inviolable; in an actual situation some of the steps may be interchanged and others may be omitted entirely ... It is not the order but the scope of coverage that is important" (Lincoln \& Guba, 1985, p. 320).

In this study, the audit trail was conducted to establish confirmability. The directions I wrote for the audit trail are shown in Appendix E. My assistant read the version of the Results section that contained references to each unitized card, which was also linked with the corresponding number for each unit of text in the original transcript. She reviewed the cards and the transcripts to see if each statement in the Results section was grounded in data and if my categories summarized the information in the cards. In four instances, she found errors, meaning that the card that was referred to in the paper was not with the correct set of cards or I had made an error when recording the card's number in the Results section. For the audit for the first research question, I corrected six discrepancies; for the second research question, I corrected two discrepancies. At the end of the audit process, all information in the results section was linked to cards with 
interview data, and numbers for each statement matched the correct card. Afterwards, my assistant wrote a letter attesting to her findings (Appendix F).

\section{Role of Researcher}

I am a middle school resource teacher with 11 years of experience serving on middle school eligibility teams. I am an employee of the district in which this research study took place. I have attended two district trainings about implementing the PSW model and one district training about implementing the RTI model. I have also participated in a district-facilitated discussion with secondary teachers (both middle and high school) about the challenges of SLD identification.

Because I am employed as a secondary resource teacher by the district in which I conducted my study, I may have a bias that not enough training has been offered regarding new SLD models of eligibility, or that based on my professional experience, student evaluation teams favor one of the three paradigms (relativity, acceptability, or profitability) when making SLD eligibility determinations. However, by conducting both immediate member checks during each interview, and by soliciting member feedback and adjusting case studies, the statements reflected in my results section are based in their experiences. My assistant calculated reliability statistics for each transcript to make sure that the audio versions of each interview had been transcribed correctly. She also conducted the transcript reliability check and the audit trail as ways to counter my own possible biases. 


\section{CHAPTER 4}

\section{RESULTS}

This doctoral study focused on answering two research questions. The first research question is: To what extent do interviews of secondary resource teachers reveal the concepts of relativity, acceptability, and profitability as they reflect on the SLD process? The second research question is: What other themes regarding SLD eligibility determination emerge from interviews with secondary resource teachers?

The results of this study are organized throughout this section. Participant responses to questions 1 and 3 (how long they have been teaching special education and how long they have been employed by the school district under study) were reported in a separate table in the Method section. Interview data for question 2 (descriptions of participants' university and district training experiences) and question 13 (participants' comments about implementation of SLD models) are reported under two separate headings. However, other questions are grouped according to the element of the theory of competing paradigms that they were meant to explore. Questions 5 and 10 were designed to explore the concept of relativity, while questions $7 \mathrm{a}$ and 11 were designed to explore the overlap between relativity and acceptability. Questions 4 and 6 were designed to explore the concept of acceptability, and questions $7 \mathrm{~b}, 8,9$, and 12 were designed to explore the concept of profitability. Then, those participant responses to questions related to the theory of competing paradigms are summarized in a table to answer the first research question more succinctly. 


\section{Question 2: Professional Training Related to Assessment of Specific Learning Disabilities}

Question 2 asked participants to describe their university and district preparation for assessing students with specific learning disabilities.

\section{University Preparation}

Six of the 10 participants stated that they had taken an assessment methods class as part of their university preparation. One of the participants had been teaching since before the concept of IQ-achievement discrepancy had been introduced. Participant 10, who had been teaching for more than 25 years, recalled that when she began teaching, assessments were more informal and classroom-based, but that after the discrepancy model was introduced, she took an assessment class. Other participants described the class they took as focused on administration of achievement batteries like the Woodcock Johnson Tests of Academic Achievement. Participants 2 and 7 also mentioned that they were trained to give intelligence testing as part of their assessment class; however, Participant 7 commented, "The intelligence testing class was mostly to understand the interpretation given by a school psych, because we have no business giving IQ tests to kids. But we do have to understand what they mean." Participant 6 recalled taking an assessment course, but did not mention specific assessment instruments she had been trained to use.

Two participants, 4 and 7, also discussed that their pre-service training included coursework on not only evaluation processes, but on instruction as well. Participant 4 stated that she "had to specifically take classes that not only dealt with identifying students, but also how to teach those students that were identified." Participant 7 
explained that she had separate classes in assessing both math and reading, and that in those classes, she learned about the different assessments "and then using that data to create instructional practices for that particular student."

Three of the participants stated that their university preparation programs did not specifically address eligibility for specific learning disabilities (SLD). Participant 9 stated that her training was "mostly academic," and that although she attended one eligibility meeting during her university preparation, it was not for a student considered under the category of SLD. Participant 3, who had taught for more than 30 years, described her special education credential as one that she "picked up for taking a few more hours ... so I wasn't really well-versed in LD, to be honest." She stated that "the more I evaluated kids and worked with them, the more it's like, okay, this student has a learning disability. So in terms of professional training, not so much. I think it was more, you know, getting to know kids." Participant 1 recalled that her university preparation program discussed the development of an Individualized Education Plan (IEP) for students once they were found eligible, and that her professors did mention RTI and data collection, but did not address the eligibility process itself.

\section{District Training Addressing Model for SLD Identification}

Five out of the 10 participants described attending district in-service training on the PSW model and how it is used to qualify a student for special education under the category of SLD. Participant 4 stated that she had attended pre-service trainings, which were held the week before school began, but that she was not able to remember specifically what had been covered in those trainings. Participant 9, who had just 
completed her first year of teaching, did not attend any in-service training explaining SLD criteria before beginning her new position. Participant 5 mentioned that at the training she attended, there had also been instruction on how to implement the RTI guidelines and data collection for SLD eligibility, and that her team had received "some specific forms that they want us to follow when using those." Participant 6 described the training she received as explaining "the formula that we use in order to determine yes or no."

In addition to these formal trainings, Participants 2 and 3 pointed out that the school psychologists in their buildings were important leaders in the implementation of the new SLD criteria and procedures. Participant 2 said, "Perhaps what they've done, and actually, I think this is what they've done- - they've trained the school psychologists, the school psychs, and then the information is supposed to filter down to us through the school psychs." She described that the school psychologists she had worked with were "very willing to discuss it," and that she "worked with different school psychologists trying to interpret what we are supposed to do, how we're supposed to do it. And I've talked endlessly with other resource teachers about how to do that.” Participant 3 said that following her training, "our school psychologist went over that a little bit with us." Participants also described a variety of other district professional experiences. Participant 7 and 10 said that they had attended periodic sessions in how to administer updated versions of achievement batteries. Participant 3 explained that one year, the district "got rid of the school psychologists" and that many resource teachers, including her, were trained in how to give the Woodcock Johnson Broad Cognitive battery: "They 
put a lot of that on the resource people. We had to evaluate, and they did train us how to give the broad cog." Participant 9, who had just completed her first year of teaching, said that she had been assigned a mentor, but that it "didn't work out" and that "I did most of it by myself." The only training she participated in during her first year was "that awful initial training we go to ... SPR\&I.” This annual Systems Review and Performance Indicators training focuses on paperwork compliance and is required for all special educators employed by the district.

\section{Questions 5 and 10: Addressing the Construct of Relativity}

The purpose of including interview questions 5 and 10 was to assess participants' agreement with the principle of relativity. Bocian et al. (1999) theorized that students are referred for consideration of SLD when their academic performance falls below that of their peer group, and when the teacher feels they are not able to raise their achievement without additional support. However, they noted that other factors, such as the student's home life, native language, or health concerns, can also affect the teacher's decision to refer or not to refer to special education. Question 5 asked, "Researchers have noted that the decision to refer a student for testing for SLD can be tempered by socio-cultural and contextual factors. Do you agree with that observation, and if so, what in your experience are some of the socio-cultural and contextual factors, other than the learning problem itself, that can influence a teacher to refer a student for testing?" Five themes emerged from the participant response data: Behavioral issues, SES, English language learner status, cultural differences, and relative performance of the peer group within the 
student's school were identified as factors contributing to the decision to refer a student for an evaluation.

\section{Behavioral Issues and SLD Referral}

Four participants identified behavioral issues in the classroom as a factor influencing teacher referral. Participant 1, with more than five years of teaching experience, noted that there were two ways that behavior could affect learning: "Maybe the student does have learning problems, and therefore they are acting out, or just that behaviors are getting in the way and preventing them from showing what they know how to do academically." Participant 6 said that both behavior issues in class and difficulties with work completion could lead the team to pursue an SLD referral and evaluation. Participant 7 commented that in her more than 20 years of experience, sometimes teachers assumed that the student's behavior problems are caused by not understanding instructional content or material, "when that's not it at all — they're just behaving badly." She described these students as "conduct disordered kids" and agreed that their behavior may influence a teacher to refer them for an evaluation. Participant 9 said that she had never attended a TAT (teacher assistance team) meeting:

From what I've observed, it's a very squishy process based on loose observations while teachers have overbooked classrooms, and there's no program monitoring students that pops up and says, "This one," so if they're not noted, a staff member doesn't notice it, it just falls through the cracks. So things that make people notice people are cultural differences, or obstinacy, or whatever-like these things we're biased against.

\section{SESs and SLD Referrals}

Only two out of 10 participants noted that SES was a contributing factor for teacher referral. In fact, Participant 8 said that "when it comes to socioeconomic factors, I 
don't think it's as thought about at the high school level." Participant 3, with more than 30 years of teaching experience, listed what she felt were several factors: "Kids from low socioeconomic backgrounds, kids without homework support at home ... kids without homes ... kids with family lives that are highly impacted because they're dysfunctional families." She also commented, "I think teachers look at (what) this kid doesn't have, and they need help." Participant 7, with more than 20 years of teaching experience, said that low income students are "sometimes pegged as LD." However, she also described a different scenario:

Conversely, sometimes kids who are from very good, strong, well-educated families are sometimes missed. Because they think, you know, the kid's just copping an attitude or something. And that's just as sad as the kids who are overreferred when they shouldn't be ... We have a lot of very poor kids and we have some Nike and Intel parents. So those kids who come wearing the best clothes and everything - they could still have a learning problem. And the toughest parents to deal with quite frankly are the ones who are highly educated and have a child who struggles to learn. So the kid gets angry, and they think the anger is an attitude when it's actually, "I don't know what's going on in class". .. And it's hard to tell a high-achieving parent, I'm not very smart (laughs). Which is usually how it comes out.

\section{English Language Learner Status and SLD Referral}

Four participants out of 10 discussed that in their professional experience,

students who were bilingual or English language learners tended to be referred more than their English-only counterparts. Participant 1, who had taught for more than five years, shared that when she had taught previously at the elementary level, kindergarten and first grade teachers wanted to refer students who were not making progress in their English skills, but that

A student learning a new language may go through a period of not really talking at all as they're trying to pick up the new language. And so a lot of times the students would start out as communication disorder and then academic goals 
would be added. So I guess that's not really a SLD . . . . but it was a way basically for them to be qualified . . . which I don't think a lot of them should have been.

Participant 8 discussed that, at the high school level, "we have a lot of hesitancy about referring" English language learners, because the team wanted to be certain it was truly a disability and not just limited English skills. She added, "We don't have real clear guidelines as to negotiating that I think as a district, and certainly not in our building. It's always child by child." Participant 2 did not elaborate, but also said that it seemed to her that bilingual students were referred at a greater rate than other students. Participant 7 said that when English language learners were referred, teachers only considered whether the academic difficulties were caused by a language issue or a learning disability, "but they don't ever consider it could be an emotional issue" caused by other circumstances, such as a family member's deportation.

\section{Cultural Differences and SLD Referrals}

Three out of 10 participants mentioned cultural differences as a possible contributing factor for SLD referral. Participants 2 and 5 both taught at the same middle school, and described a student who had moved into their school after being raised on an island, where there was not a culture of formal schooling:

When students haven't lived in our country long enough to make the testing valid, that's a huge factor. And we just had an example of this last year, and it was a major discrimination issue, of which the teachers couldn't understand, because they weren't - they weren't coming at it from being discriminatory as much as they wanted the child to receive help. But the child would have rated in the intellectual disability range because had hadn't been in the country long enough to do well on the test.

Participant 5 explained that because the student had come from a society with no academic structure, he appeared to have difficulties with learning in his new 
environment. Participant 2 discussed how these differences appeared to the vice principal of the school:

They gave him a nonverbal IQ test, and he was way above average in many ways. But it's just such a different that doesn't value - the vice principal would say, okay, it's time to get on your bus now, the bus is gonna leave. And he'd just run off and play. And she'd say, oh, he just doesn't—-he knows, he's just retarded. I mean, and I'd say, well, on the Marshall Islands it's really not all that important to run for your bus ... that's a cultural difference. Anyway, we did not find him eligible for special education.

Only one participant, Participant 4, said that the contextual factor she saw most

often was a home environment that did not value education, where "there's probably not a lot of reading material other than a cell phone."

Those are students who seem to be delayed in displaying positive learning behaviors .... when a general ed teacher looks at a student like that, they don't have positive learning behaviors, they're immediately falling behind . . . but is it a disability or is it those other factors?

\section{Higher Academic Standards and SLD Referrals}

Four out of 10 participants discussed that in academic contexts where the standards for performance were high, students who were performing slightly below the average range may be referred for special education. Participant 2 worked at a school where "many of the kids are real high-fliers" and "if a student stands out as being below the norm of the kids in the school, they might be right on average nationally." Participant 6 commented that in such a high-achieving environment, students in the "lower end of the bell curve for that group" may be referred for testing, but "if they were in a different school, with a lower socioeconomic pattern, or just lower-performing peers, they would not be referred." Participant 10 said that at her high school, there was a "big push" to place students from disadvantaged backgrounds into accelerated, college-prep classes, 
and that "not every child can do IB classes ... We don't give them a good enough background." Participant 3, with more than 30 years of teaching experience, put it this way:

I think with the standards - and what they require students to do - the bar gets higher and higher and it shows a - for these kinds of kids the gap gets bigger, and more difficult... we need to look at that as well, and what impact it is having on kids.

Question 10 also addressed relativity and asked participants to recall specific interventions attempted by general education teachers before a student was referred for an SLD evaluation. The categories that emerged from participant responses were instructional accommodations, system-wide intervention classes, and time, scheduling, and setting accommodations. In addition, teachers noted difficulties with this step of prereferral process and described a wide range of abilities on the part of the teachers who were asked to implement these interventions.

\section{Instructional Accommodations as Part of Pre-Referral Process}

Four teachers, three at the middle school level and one at the high school level, said that they had observed general education teachers try instructional accommodations before initiating a special education referral. The accommodations they had seen were the use of graphic organizers and sentence frames for writing, reduction in the number of math problems, using differentiated smaller group instruction, peer tutors, simple behavior plans, restating general instructions, seating the student near a positive role model, and checking the student's academic planner if work completion was an issue. The only high school response that involved instruction was the use of multiple opportunities to assess each learning target taught in the class; Participant 3 also noted, 
however, that this applied to all students and was more of a function of the assessmentbased grading system employed by the school district. Participant 5, a middle school teacher, also noted that allowing students to re-take tests was "based on the common core." No other high school participants listed instructional accommodations implemented within the general education classroom in response to this question.

\section{System-Wide Intervention Classes as Part of Pre-Referral Process}

Three high school participants and one middle school participant mentioned that students took skill-based intervention courses before entering the special education referral process. Participant 1, who taught at the middle school level, said that she was aware that students may take an intervention course at her school before beginning the referral process. Participant 7 explained that at her high school, "the structure of our general education program has changed," and that there was a focus on placing lowperforming freshmen into remedial reading and math intervention courses when they first enter high school, rather than waiting until junior or senior year. Both the remedial classes and school-wide study hall class was available to both students who were on IEPs, as well as the general student population. Participant 3 described that at the high school where she taught, there were supportive study halls, a tutoring center available during study hall time, and a specific course focused on remedial reading and writing skills for freshmen who had not passed their statewide assessments as eighth graders. She also explained that both general and special education students who struggled in math could enroll in a course that taught algebra and geometry course material over a longer period of time. These classes had fewer students and were staffed with an instructional 
assistant for more support. Participant 8 said that “at the high school level, I don't think intervention is our strength. Individual teacher intervention, if that makes sense. There's systemic interventions." She added, "It's really hard for a teacher to zero in on a kid and say, 'Wow, you know, she's really struggling with the reading. I'm going to try this intervention.'” In addition to the study halls and intervention reading and writing courses identified by other participants, Participant 8 also shared that at her high school, at-risk freshmen students also attended a summer program before beginning high school in the hope that they might become more prepared.

\section{Time, Setting, and Scheduling Accommodations as Part of Pre-Referral Process}

One middle school and two high school participants said that they had observed teachers attempt interventions that addressed time constraints, setting, and scheduling difficulties. Both Participants 9 and 10, who taught at the high school level, said that teachers would schedule time with students to offer one-on-one or small group assistance, including offering that the student could work in their room during the teacher's plan time. Participant 10 also reported that teachers would give the student a pass to have them come and work with them during the building-wide study hall time. All three participants said that teachers considered extended time to be an accommodation.

\section{Teachers Show a Wide Range of Skill Levels in Implementing Pre-Referral Interventions}

Two middle school and three high school participants discussed that some teachers were extremely good with adjusting classroom conditions to attempt to meet a student's needs, and that for other teachers, this was not as apparent. Participant 7 commented, "Some teachers are great, and some teachers are just not." Participant 5 said, 
"Oh, gosh, they say they try a whole lot, but they also say they try everything with everybody, so it's not really individual. So it's kind of hard to know how much they really try." Participant 4, another middle school teacher, put it this way:

I've seen teachers do an incredible amount of interventions, so many interventions that they don't realize that what they are doing are interventions, it's just good teaching to them...And then I've seen it where there's been interventions where - well, I changed his seat and it didn't get better. What didn't get better? Why did you change his seat? How long did you change his seat? Was there a pattern on a day? And so you know, those are the - those are the interventions where you know it's going to be painful, because they just want the kid out of the room but they know it's not really going to happen, or they should know it's not going to happen.

Participant 10 gave the example of a teacher who permitted students to have access to computers and listed it as a pre-referral intervention, "which was really nice, except for the fact that the class was a computer class." Although computer access can at times be considered an accommodation when students are allowed to type their written work, "that one kind of just stuck out as like ... okay ... that's not what we're calling accommodations or extra help." Participant 8 felt that some of the difficulties with implementing individual accommodations at the high school level were that teachers saw large groups of students each period, and that large classes made it even more challenging.

Participant 4 said she thought the general education teacher's expectations were also an intervention: "And it's not necessarily lowering expectations...but expecting that a student is going to engage in the classroom and finding a way to get them to engage. And good teachers do that." She felt that many good teachers would not even recognize what they do as interventions, because it was just natural for them to incorporate such techniques into their instruction. 


\section{Questions 7a and 11: Overlapping the Constructs of Relativity and Acceptability}

Both questions $7 \mathrm{a}$ and 11 asked participants to reflect on issues that addressed both relativity and acceptability. Question 7a asked participants whether classroombased, informal norms or standardized norms were valued more as part of the SLD decision-making process. Question 11 asked participants how teams determined whether or not a non-native English-speaking student qualified as having a SLD. In response to 7a, two themes emerged: The majority of participants felt that standardized testing norms were valued more than classroom-based norms during the SLD decision-making process, and participants used standardized data to "rule out" SLD as a possibility, but would go on to consider other categories of eligibility.

\section{Standardized Norms Valued More During SLD Decision-Making}

Six out of the 10 participants stated that they felt standardized norms were valued more during the SLD decision-making process. Participant 10, with more than 25 years of teaching experience, explained that at the high school where she taught, "we get a lot of kids who, they're getting A's, B's and C's, but their standardized tests show, oh, this struggling student has processing issues, or whatever ... and we make them special ed, and they don't really need it." She felt that the cognitive weaknesses revealed by the standardized testing became the focus, rather than classroom achievement. Another high school teacher, Participant 3, commented that standardized norms were valued more, in part because they could be used to explain to parents that although a student may not be doing well in their academic classes, individualized testing revealed that their academic skills were intact and they were capable of doing the work. She also added that the 
statewide assessment results were also regarded as valuable during team discussion. Participant 8, a high school teacher with more than 10 years of experience, commented that "usually a student — especially for SLD at the high school—floats up into the referral process because they're struggling, because their grades are really poor." These students were often referred by parents, who wondered whether academic difficulties were caused by underlying disabilities. However, she explained that "then you test them, and the results show that they don't have an area" of weakness, so they would not meet district criteria as SLD.

Three middle school teachers also thought standardized norms were more valued than classroom-based data. Participant 1 felt that during the eligibility discussion, "we look more at the big picture," which were the standardized norms. She thought that once students were qualified for special education, more informal sources of data were used to develop IEP goals. Participant 2 stated that she felt that standardized norms were given more weight, but then also emphasized that they were "one piece of the puzzle," and that other sources of data, such as work samples, attendance records, and observations, were also important. Participant 6 described that when students were doing poorly on their classroom assignments and assessments, but did not do poorly on standardized academic testing when evaluated for SLD, "then the team is really put in a quandary, because what — what is the reason for that?" The team would not be able to qualify the student as SLD. 


\section{Classroom Norms Valued More During SLD Decision-Making}

Two participants (one teaching in middle school and one teaching at the high school level) said that classroom-based norms were valued more during the SLD

decision-making process. Participant 5, the middle school teacher, said:

I think that even if a child shows low levels on the standardized measures, but they're doing fine in their classes, it doesn't make sense to me that (we) would identify them as having a SLD. Because somehow they have-you know, learned the adaptive skills that they need in order to, you know, cope with their education, and with their deficits, and move on from it. And in that case, there isn't anything as a special education teacher that I can teach you.

Participant 1, a first-teacher, said:

At (names high school where she is employed), with my colleagues, what I've seen is classroom needs being more - weighed heavier - than academic testing. That if a kid is performing poorly, then the rest of the file review and the testing will be done in such a way that it supports the opinion of how they are performing in the classroom. I've heard the quote-we have the seven, you have to add the seven point system . .. and ..." Make it add up. If the kid needs it, make it add up." Which is kind of unnerving as a new teacher.

\section{Individual School Sites Affect Which Norms are Valued More During SLD Decision-Making Process}

Two teachers, one employed by a middle school and one employed by a high

school, both felt that the individual school site affected whether standardized or classroom norms were more valued during the SLD decision-making process. Participant 7 felt that at her school, the value placed on standardized and classroom-based assessments were "pretty equal," and she would use the teacher records of whether students were meeting those learning targets when she did her own reports on student progress. Participant 4 said:

I think it depends on the building. If a building is really working their curriculum to learning targets, learning standards, whatever phrase we are going to use this year, and they're - all teachers are very clear about what those learning targets 
are, I think it will be easier there to verify that indeed the student is not meeting than in a building where they just don't necessarily have a lot of buy-in to the standards. And they don't use formative or summative assessments adequately enough, and so what ends up - what ends up happening sometimes is that they'll say, well, the student's not meeting learning targets-learning standards, whatever - but what they're grading on tends to have a lot more behavioral grading in it than true content. So, you know, I think it's very building-dependent and as a result also very district-dependent.

\section{Standardized Testing Results Used as a "Rule Out" for SLD Category}

Four participants, two at the middle school level and two at the high school level, mentioned using the required standardized academic testing as a "rule out" for SLD, but would then consider other categories of eligibility. Participant 7 said that standardized testing was not the "be-all, end-all," and that "if someone knows the skills one-on-one, there's something that's keeping them from performing in that way" in the classroom, which would lead her to investigate issues with attention, communication, and social and emotional functioning. Participant 8 said, "If the student is struggling and they don't meet criteria for SLD, we look at other areas of eligibility, and we always ask that question as a team, what else could be impacting them.” Participant 6 said that if a student was not performing below their peers on the standardized academic testing, her team "might move to looking at the attention piece, and we might or might not find a way to make them eligible." Participant 2 also explained that "if you have a standardized test, and it shows that the student is right on average in reading and math, but not participating in class, then you can say, well, does the student have emotional problems, or does the student have attention deficit problems." 


\section{English Language Learners and SLD Eligibility}

Question 11 asked participants how teams made the decision that a student had a SLD when the student's native language was not English. Three participants shared that this decision was a very difficult one for special education staff. Nine out of 10 participants discussed that standardized academic and cognitive testing should be completed in the student's native language, but several also said that this was not always possible to do. Three participants said that scores from the English Language Proficiency Assessment (ELPA) were important pieces of information to have while considering SLD eligibility. Four participants said that the input of the English Language Development teacher was critical to this process of referring non-native English speakers for special education referral.

\section{Difficulties With Determining SLD Eligibility for Non-Native English Speaking Students}

Two high school teachers and one middle school teacher commented specifically on the challenges with identifying English language learners as having specific learning disabilities. Participant 8, a high school teacher, said, “It's tough. I don't know if we do a good job doing it. We don't want to under-identify. We don't want to over-identify. We want to identify the right kids, and I think that's really difficult." At her high school, there was a sizeable Somali student population, who had lived in refugee camps before immigrating to the United States. These students did not have prior experience with written language or with the American school system, which made it difficult to consider specific learning disabilities as a cause for school failure. Participant 8 felt that her team's "guiding question" was whether the student who was being referred was "learning 
English and acquiring skills at a rate commensurate with their peer group." She added that this would not only be English language acquisition, but also how their skill sets in math and writing were developing as well. Participant 5 said the difficulty with evaluating English language learners “doesn't mean that a student who doesn't speak English couldn't have a learning disability. It's just harder to discern.” Participant 3, with more than 30 years of experience, commented, "It's a difficult thing to distinguishthat's where I think we don't know what we're doing. I think you just have to be referred and not speak English and you're in.”

\section{Standardized Testing in the Student's Native Language}

Nine of the 10 teachers responded that when an English language learner was referred for special education, the attempt would be made to assess the student in their native language. Several participants discussed that testing materials and a trained assessor were available in Spanish. Participant 2 also mentioned that there were nonverbal tests of intelligence available for assessment of non-native English-speaking students as well.

However, it was difficult for participants to access materials other than in Spanish. Participant 7 said that at the high school level, "native language is less important than instructional language," and that most of the students she tested had received the majority of their academic instruction in English. She recalled a recent evaluation:

It's hard to find a kid SLD when they're in another language, especially if it's not Spanish. We just tested a girl from -Ethiopia? - Can't remember . . . anyway, her English was her better instructional language, so we could test her in English. But if not, I couldn't even get a translator for meetings. I don't know how we would have given her an assessment tool in her native language. It becomes very problematic. 
Participant 10 thought a student may have been tested in Russian in her building for a special education evaluation. Participant 9 said that onsite, "we only have easy access to materials in Spanish" and that whether or not the student qualified as SLD “comes down to gut feeling instead of . . . uh . . . actual assessment. Because we're not really able to, even though we are legally required to." She reflected on one evaluation that had occurred at her school:

I know there was one situation where the student was up for eligibility and his parents were, um, Hungarian, maybe? Or Slavic, and there was no easy access. The teacher worked-I don't know what routes he went through, but he ultimately did not get materials or a translator.

\section{Importance of Input From English Language Development Teacher}

Two middle school teachers and two high school teachers said that input from the student's English language development teacher was critical to beginning the SLD evaluation process. Participant 8 said, "Our ESL department, they are really the gatekeeper for referring that population of kids . . . and they do a good job of referring." Participant 3, another high school teacher, said, "Probably the ELL teacher is the one who says, 'You know what, I've had this kid for two years now and we're not getting anywhere.' And so some of that is teacher recommendation in terms of referring them." Participant 2 said that the special education team "rely heavily on what the English as a second language teacher says, how the student looks compared to his peers." Participant 6, a middle school teacher, also said, "We usually get the input from the ELL teacher, as well. The team wouldn't consider doing special ed evaluation until at least a couple of years of language instruction was in place." 


\section{Importance of ELPA (Scores)}

One high school and two middle school teachers said that the student's scores from the ELPA were important pieces of data used during the evaluation for SLD. Participant 4 discussed that graphing the ELPA scores gave her a visual impression of the student's progress:

The state testing for ESL students_-if you look at that, and all the areas over time, and you put it on a grid, you can see, you know, if they kept moving forward through all that, and they didn't plateau out in the middle of elementary school, and they keep moving forward with that, and you couple that with everything else, no, they are continuing to make progress in ESL, and so-it's really- the ESL ones to me are the toughest ones to do.

Participant 6 also said that her team would look at the ELPA scores and the student's growth in learning English over time as measured by those tests. Participant 8 said her team would consider the ELPA scores, but would also look at any other additional assessments that had been given to the student as well.

\section{Questions 4 and 6: Addressing the Concept of Acceptability}

Questions 4 and 6 address the concept of acceptability. Instead of the local norms used during the referral process, this stage involves using national norms generated from the use of standardized academic and cognitive tests. According to Bocian et al. (1999), teachers have limited professional judgment at this stage of the eligibility process, because they are following both legal and district criteria for which student scores demonstrate an SLD. At the time the theory of competing paradigms was developed, the discrepancy model was widely employed as the measure of acceptability; however, since 2004, individual school districts have the option to use either the RTI model or the PSW model, which have further complicated the acceptability stage of SLD eligibility. 


\section{Differences Between Students Classified as SLD and Other Struggling Students}

Question 4 asked participants, "What differences should eligibility teams consider when distinguishing between students with SLD and other students who struggle with academic skills and do not qualify for special education?" Six participants, four working at the middle school level and two working at the high school level, mentioned using the district's PSW model in order to decide which students were eligible for special education under the category of SLD. Participant 8, a high school teacher, said:

We stick to the strengths and weaknesses model ... and if they don't demonstrate that they have requisite strengths and weaknesses, we don't qualify. You know, we count up the point system the district has, and we use some professional judgment, but we try to really adhere to the model the district uses.

However, another high school teacher expressed appreciation for that the district "point system" not only required eligibility teams to consider standardized scores, but other types of information as well:

As for those kids who don't qualify, the district is using a model of LD eligibility that catches a few more of those kids . . . Because it's not just hard numbers. You're expected to look at anecdotal information as well. And it's been given more value than it has been in the past. Because before it was, this is the IQ score, does it have peaks and valleys, do these numbers meet into that - that range? No, they don't qualify. But now these kids who were not LD, but not mentally retarded or - um - developmentally delayed or any of those terms, whatever they are-we can look at those kids and say, yeah, they don't quite fit, but look at this piece of it. And some of the more anecdotal information has more value than it used to.

Two participants, both middle school teachers, offered responses that showed that although they understood the underlying concept of PSW, they were not clear about the particulars:

I think the main thing that as a team that we look at is their cognitive scores, and how many strengths and weaknesses there are within those cognitive scores. So, I think it is you have to have, um, two strengths? You can have all weaknesses but 
you have to have at least two strengths in order to qualify. If you did not have that minimum number of strengths then I've been told you don't qualify because you're working basically within your academic ability, or your cognitive ability ... And if you have all strengths but just one weakness, you can still qualify within that one weakness area.

Participant 1 also commented that "I feel like sometimes-I feel like the cognitive area is the black and white, do you qualify or do you not, and the academic area is a little bit more gray as to where the goals are for the student."

Participant 2, another middle school teacher, described the model this way:

I think what the eligibility teams are trying to do at this point is to look at IQ scores across different areas, like perceptual speed, and I'm trying to think of some others ... oh, visual skills, they divide things up, I can't remember exactly what all the categories are. And so you're looking for a pattern of one area being - two areas being strong, and some other areas being weak. I think it's at least two areas have to be strong. And I think a strength is, like, 87, standard score and above. So it doesn't have to be a very big strength ... I think ... Actually, I think maybe 88 is what it is.

Two participants also discussed the practice of using the student's state testing scores as a "rule out" for SLD. Participant 4, a middle school teacher, pointed out that "what the SLD form states, and that is ... has the student met Oregon state standards in these areas. And if they have, you really can't go forward anymore." She explained that even if these students demonstrated a pattern of strengths and weaknesses on standardized academic and cognitive testing, they would not qualify as SLD because "there is no educational impact," sometimes even when they would struggle in the classroom. Participant 7, a high school teacher, said, "I use (state testing history) as an eliminator to - because the learning disability eligibility takes so long, there's so much testing and they lose so much instructional time in class." She had previously refused to evaluate students for an SLD eligibility if they had a history of meeting the benchmark 
score on their state testing, but would still consider other explanations besides SLD for their struggles in school.

\section{High and Low Areas of Achievement as Marker of SLD}

Three other participants, two middle school teachers and one high school teacher, described that in their conceptual understanding, students with specific learning disabilities should demonstrate some high areas of achievement and some low areas of achievement. Participant 5 said:

It seems to me that when you look at the big picture a student with a specific learning disability specifically struggles in, like, one area. Reading, and sometimes writing together, or math. But when you look at kids that kind of academically struggle, it seems to be more across the board.

Participant 3 posed the question, "I think another area we really need to look at is when a kid comes up as LD in math, reading, and writing, are they truly LD?" She felt that the eligibility team needed to consider other explanations, such as difficulties with home life or lack of exposure to reading materials, as other reasons for school failure. She described these students as "the full meal deal" and said that she questioned whether it was a "true learning disability" if reading, writing, and math were all impacted. She also said that many Hispanic students were "some of the kids that come out full meal deal" and "I'm not sure that's . . truly that they are disabled." She wondered if this was really an issue with learning English, or truly a special education problem, and felt that these students were unsuccessful because general education teachers did not provide enough scaffolding for them to learn in class. These students also tended to do poorly on the standardized academic and cognitive testing used for special education eligibility due to a lack of background knowledge. 


\section{Information Gathered From Standardized Academic Testing}

Question 6 asked participants to reflect on the types of information they received from the standardized academic tests used for SLD evaluations. Five participants said that the results generated from testing permitted them to see the student's academic strengths and weaknesses; four participants said that the benefit was to provide a normbased comparison group for the student away from the local school environment. Three participants discussed using the standardized academic results as part of the overall district model used to determine SLD eligibility. However, four participants commented that the standardized tests also had weaknesses in certain areas.

\section{Standardized Tests Used to Determine Student's Academic Strengths and Weaknesses}

Three high school teachers and two middle school teachers described that the testing results were useful in determining an individual student's academic strengths and weaknesses. Participant 6 commented, "After testing many students with the same instrument, the same questions-I think it gives the experienced tester, especially, a sense of where - where students' strengths and weaknesses are.” Participant 3 said:

In terms of diagnosing, I think it gives you a ballpark. For me, it's more like looking for a pattern, or something that sticks out. Can read every word on the, you know, in isolation, but can't comprehend a lick, or something. Then you know something's going on.

Participant 9 said, "I've done the Woodcock Johnson, and I like that it spits out values, and you can compare the different areas ... I've seen some students that are just incredibly high on some areas, and incredibly low on other areas, and you can't ignore it." 
Three participants, two teaching at the middle school level and one teaching at the high school level, both discussed the standardized testing within the district model used to determine eligibility. Participant 5 said that to her, the previous SLD discrepancy model "made sense in my head" and that "when a student is at or above average intelligence and their math score is two standard deviations below, you know, it makes sense that they have a specific learning disability in math." She said that it was "helpful" to have the standardized test results because "you can see that clear line - their IQ, and their reading, and their writing scores are all around the average area, but their math is much lower." Participant 8 said that the standardized testing results were used by the eligibility team to see whether the student had the "requisite areas of weakness and/or strength" and that those scores were "one of our foundational, kind of decision-making tools." Participant 4 said that all of the information gathered during the evaluation process, including state test scores, standardized academic and cognitive testing, and performance in classroom on learning targets should inform the decision because "the one-on-one academic testing in and of itself is not necessarily-well, it's not the only way to look at an eligibility. It's just not enough.”

\section{Standardized Tests Provide a Norm-Based Reference Group}

Three middle school participants and one high school participant discussed that the standardized academic testing provided a norm-based reference group for the student undergoing the evaluation. Participant 7 said that she did not gain a lot from the testing, but that it provided "the whole student learns commensurate with peer group piece of eligibility." Participant 1 said, "It's basically telling me where they are comparing them 
to students across the country at their grade level." Participant 6 said that the advantage of the Woodcock Johnson was that it gave examiners a standardized, norm-based measure of academic achievement. Participant 2 said, "It gives you a more accurate picture of where the student is academically and also in comparison with lots of other people instead of the high-flying group they are with or the low-flying group they're with." She felt the tests were useful because it allowed the team to see whether a student was performing in the average range or whether "they're not really so far behind in their academic achievement that they are considered disabled."

\section{Weaknesses of Standardized Testing}

Although participants seemed to see the usefulness of the standardized testing, they also reported that the test had some weaknesses, and that in and of itself, it was insufficient to determine whether a student had an SLD. Participant 10 said, "I think some tests are better in some areas than others, so ... I don't always think the standardized tests give a good picture of what the student is capable of." Participant 3 described that although she could use the writing portion to see if students had included correct information, it was not scored on spelling or punctuation, so "it gives you a brief look at their writing skills, but not from a scoring standpoint, typically." She said the math subtests were particularly problematic because "they can't use a calculator ... I don't know that we know what they really know how to do because they're not required in high school to use a calculator for a lot of things, so they don't know long division." Participant 4 also cited difficulties when using the testing materials:

In particular, I think of the math portion of the Woodcock Johnson, where if you look at the calculation portion of it, I can't tell you the last time I had a kid do a 
long division problem. So they're going to score low on that. Or when we get to the problem-solving skill, problem-solving subtest. You can't use a calculator. Well, everything they do in class is with a calculator. So, and even at (mentions school in the district where previously employed), I tested a couple of high school students, got further in the test than I'd been in decades, seems like, and they were lost.

Both Participant 3 and Participant 5 felt that the some of the test items were outdated. Participant 3 said she felt "embarrassed to read it." Participant 5 said:

There are some questions on there that are very bad. Pay phones and such. Kids are like, "What's that?" Go to a service station . . . they don't know that term. You know, it's funny ... Making change ... they can't even identify the coins on there and it's not because - they just don't use change. They use debit cards.

\section{Questions 7b, 8, 9 and 12: Addressing the Construct of Profitability}

Questions 7b, 8, 9 and 12 addressed the construct of profitability. According to Bocian et al. (1999), the eligibility team, which consists of a general education teacher, a special education teacher, a school psychologist, and the child's parents, must bring together different perspectives and data to make the decision that the child should be identified as SLD and become eligible for services. The team considers whether that individual student will benefit from special education services as they are provided at that specific school. Bocian et al. hypothesized that many idiosyncratic factors come into play during this decision-making process, such as the experience and competence of the general education teacher, the nature and severity of the child's learning difficulties, the caseload numbers of the resource teacher, whether or not the student is a native English speaker, and the personalities of the team members, as well as the desires of the parents. Bocian et al. argued that even if two different teams were given identical information to consider, it was likely that they would arrive at different eligibility determination decisions, because the more decisive and forceful team members would argue their side 
more effectively. In their original study, Bocian et al. operationalized profitability as the team's decision to qualify the student for special education services. The quote below from Participant 4 beautifully illustrates the conundrum of science versus service:

I think — well, one of my — one of my concerns just based upon my training is, that when we determine special education eligibility, we are determining to the best that we are possible - without an MRI machine - we are determining that a student has a disability. And that's not to be taken lightly. And I think oftentimes I run into peers that think, well they need extra help. Yeah, okay, but what we're saying here - what we're saying with all this testing is this student has a disability. And by the nature of that, it carries - it carries a lot of baggage for that kid. And there are few things more distressing than to watch a student understand — an adolescent in particular — that we've just said that you have something wrong with you, when in fact they don't. Because what the problem was is they weren't working hard enough, or their home environment wasn't good enough, and now we're saying, there really is something wrong with you, when in fact, there's not ... I think sometimes people just look at things, well, they need extra help. So let's qualify them because they need extra help...but special education can't take care of everyone in the district who needs extra help. Special education should only take care of those students who have a disability.

\section{Competing Recommendations for SLD Eligibility}

Question 7b asked participants,

Has your team encountered evaluations where the data yielded 'competing recommendations' for eligibility (meaning that either classroom performance was good, but standardized testing was not, or vice versa? If so, how did your team resolve that contradiction and was that particular student, not using names, qualified as SLD?

Five participants described that if standardized academic and cognitive scores did not show an impact, then the student was not qualified as SLD. Three participants said that if a student did not show clear academic impact in the classroom on work samples, they would not qualify that student as SLD. Two participants also discussed that at the high school level, the students themselves should be involved in the process, and two middle 
school participants felt that standards for re-evaluation were less stringent than for initial SLD evaluations.

\section{Standardized Testing Results Valued More During SLD Decision-Making}

Four high school teachers and one middle school teacher described that standardized testing results had greater influence over SLD decision-making as they reviewed evaluation results and discussed eligibility. Participant 3 said that the standardized testing would show that the student was academically capable of doing class work and that if "nothing is sticking out," such as low processing scores, then the team would not qualify the student as SLD. Participant 10 said that for two students she had evaluated last year, the testing results showed that there were difficulties with memory and processing speed, but that classroom performance was good, and that because the parents were "extremely demanding" and wanted their children qualified, the team agreed that they were eligible as SLD. Participant 9 described one case where "the numbers didn't quite add up" but that "it was concluded that because I didn't follow the process because I didn't know the process," the team found the student eligible as SLD. In that case, he had testing scores that were lower than average, but the student's performance in the classroom was good because he had good coping skills. Participant 8 said she had not seen many referrals where the pattern was to perform poorly on standardized testing and classroom performance was good; she noted that the premise her team followed was "If we test, they're not doing well." She also said, however, that the standardized testing results were the team's "make-or-break decision-making tool” when considering SLD eligibility. Participant 5, who taught at the middle school level, said that in her building, 
"We never came to an agreement on who bears the most weight on a SET team, you know? Is it the psych, is it the admin, and what do you do if you disagree?" She also said that when students did not meet SLD criteria because their standardized testing was too high, but that they continued to exhibit difficulties in classroom performance, it was particularly challenging: "Because where it leaves the teacher is, well, what do we do? If not special ed, then how do we help them?" She said that in her building, "that happened a lot last year, and — actually we argued over it quite a bit, and there were some that qualified and some that didn't. I think it was about 50-50."

\section{Classroom Academic Impact Valued More During SLD Decision-Making}

Three participants, two who taught at the middle school level and one who taught at the high school level, also said they would not qualify a student who did not show academic impact in the classroom. Participant 4 told a story about an eligibility where the student who had previously qualified as SLD no longer met criteria:

This was a student, a seventh-grade student, who had been determined eligible for SLD in first grade, at her mother's insistence. So she went through and went through her grade 4 re-eval and they just pulled her through. We didn't do any more ability assessments. And then she gets to grade 7, and it's time for her three year review. She has always met every single OAKS [Oregon Assessment of Knowledge and Skills] test in all areas. She is earning As and one B, and has always done that, okay? And her mother was really pushing, anyway ... so wethe school psych and I-looked at it and went, okay, this looks like an exit, but let's do what we need to do. And so it was only in reading. So ... school psych did an additional battery of tests that weren't done but should have been done in fourth grade. I did the Woodcock Johnson, I did the file review, I had collected over the year some easy CBM data as well, from her, and she didn't meet. The team was in agreement, the teachers were in agreement ... parents were not. And it was one of those that you walked away from just feeling awful, because this poor child was in tears because-she was in tears because she was being dismissed from special ed. 
Participant 4 also recalled a different case with another student, who demonstrated a weakness in processing speed on cognitive testing, but "it wasn't showing up anywhere." The student worked hard and teachers were automatically giving time extensions and access to books on tape: "So all this stuff that - the accommodationsthat she needed - were being given anyway ... . that was one of those where did not meet criteria and we did dismiss her."

Participant 2 felt that to qualify a student as SLD, "they pretty much have to do poorly on some academic measure." She said that her team had recently met on a referral for a student with ADHD, and the parents requested testing, but because the student was passing all state testing and had never earned poor grades, the team explained to the parent that they did not see any academic impact. She had seen students perform well on state testing, and not perform well in the classroom, but in her experience, those students would receive special education services under the category of Other Health Impairment, not SLD. Participant 8 said, "We don't tend to qualify if — especially if the student's doing academic - if grades are fine, then we - and classroom performance is fine, we just have a hard time justifying where the educational impact is."

\section{Student Involvement at the High School Level}

Two high school teachers mentioned student self-determination as a factor in SLD identification for older students. Participant 3 described such a situation:

To me, the student has rights too, and to make someone not- - to make some eligible for special education, you're saying you have a documentable handicap. You have something interfering, and sometimes it's not one of our categories. It's not something we do or fix .... And at (names school of employment) sometimes we see kids that, the parents - they're getting C's, and they're like, okay, so you know? ... I think you have to stand up for the kid's rights too, and say, you 
know, we don't think you do. And to label you as such is unfair. It's against your rights.

Participant 7 described a different scenario, where some evaluation data supported continuing the student's SLD eligibility and some did not:

I pulled the parents and the kid in with the team and said, we could go either way, which do you want? The one-on-one test scores show you're still low. The state assessment scores say that you're not. Your classroom performance says that you're not. Are you performing well because of the support of this program, or in spite of the support of this program? And I let them make the decision. Because if there's a history of need, I don't want to cut that off if there is still need. And sometimes the kid is the best one to make that determination.

Participant 7 also described a girl who was a straight A student, but still needed

accommodations, such as additional time on assessments, in order to be successful in the classroom. The student remained eligible in order to receive these accommodations, so "we finagle to make things work for the kid." Participant 7 described one of the difficulties with not continuing an SLD eligibility:

That's what kills me about SLD, is if the kid doesn't need specialized instruction anymore, but they need accommodations, there is nothing for them because they don't qualify for a 504 plan, because that's a medical intervention. And it just breaks my heart. I will do anything humanly possible to keep an LD kid on an IEP if they need the accommodations, because I know they don't get them otherwise. And it's not - it's probably not kosher, it's probably not great to admit this, but until the state, or the law, or something changes to protect these kids' rights, I'm going to keep doing it, because I'm a student advocate and that's what - that's who I'm advocating for.

\section{Re-Evaluation Standards Less Stringent Than for Initial SLD Evaluations}

Two participants, both working at the middle school level, shared that they felt the standards for an initial SLD eligibility were more stringent than for an SLD re-evaluation. Participant 6 described that in one case, the student was not below grade level on standardized individual achievement testing, but that they had continued to fail 
state testing and grades were poor. The team decided to continue the SLD eligibility forward after "we looked at other eligibilities and were unable to get a medical statement from the parent...but the team as a whole felt strongly that the student needed the continued special ed support." Participant 2 commented, "I think if a student has already been found eligible that the - the criteria for being re-eligible as not as strong as the first time. That if they still show a weakness then you continue to-you continue to give them service in math."

Question 8 asked participants to reflect back on cases where the team did not qualify a student as SLD, and if so, explain the reasons behind the team's decision. Responses from participants were nearly evenly divided as far as identifying the reason for not qualifying the student; five participants said that standardized test scores did not show a clear pattern of impact, and four participants said that it was because the student's classroom performance did not reveal clear academic impact of a disability.

Two high school teachers and three middle school teachers said that standardized testing results were the reason that students would not qualify as SLD. Participant 7 said, "If I can't look at all the data and say yes, this kid has - the ability for this kid to take in information and process it is the reason they're not performing — I can't sign off on an LD eligibility." She said if SLD was not a possible category of disability, the team may try to consider emotional or attention issues as a reason for academic difficulties.

However, she also said that parents also limit what the team can consider:

Some parents, when you say it's not really a learning disability, we should look at something else, they say no. Because they don't necessarily want family issues involved. I've had parents refuse to take their kids to the doctor for an attention issue when we know there is, because they don't want that stigma. I don't know 
why LD is a better stigma than health impairment. I can't figure that one out, but you know ... families and their privacy.

Participant 3, with more than 30 years of teaching experience, said that kids who did not qualify did not "show a pattern of strengths and weaknesses that was with any consistency." She said that even if a student had a low grade in a math class, "they didn't have anything else to show that they were, you know, that there was a math issue."

Three middle school teachers also cited standardized measurement as the reason why students would not qualify as SLD. Participant 1 said that "the main reason would first land on those cognitive scores" and if they revealed a pattern of strengths and weaknesses. Participant 5 mentioned that both the standardized testing and Oregon Assessment of Knowledge and Skills scores were part of that deliberation of whether a student could qualify as SLD. Participant 2 also cited cognitive scores, saying that if a student had a "flat profile" with all below average scores, they would not qualify as SLD. However, she also said that if a student did not qualify as SLD, "oftentimes what happens is people come in, and call the student attention deficit after that, just to get them served." She explained:

I think we really work to try and find kids eligible. We want to stay within the law, we try to stay within the rules, but we really - if a student is struggling, we really try to find a way to give them the help they need ... I mean, as much as we can, working within the guidelines we have. We have to fill in the paperwork, we have to answer the questions honestly. And I think that for the most part, I think everybody tries to be as fair and appropriate as they possibly can.

Four participants, two teaching at the middle school level and two teaching at the high school level, said that lack of educational impact was the reason a student was not qualified as SLD. Participant 6 said that at her school, "we had multiple referrals either from parents or from teachers that did not result in eligibility. Typically those students 
tested within the average range and had no academic impact, so there was no- - there was no way we could have qualified them." She said that this was particularly true when the referral was initiated by the parents. Participant 4 , a middle school teacher with more than 20 years of experience, also cited no educational impact as a reason not to qualify the student. Participant 10 said that even if students had scores that were slightly below average on some of the standardized testing, her team did not qualify them as SLD because "everything was okay in the classes," including classroom participation and assessments. She also had worked on two cases the previous year where the parents had had outside evaluation done, and although their students were performing well in their classes, they were not getting A's, "and the parents of both those students were more interested in finding out what they could do to help their kids, than they were to be putting them in special ed." For those students, the team gave a few supplemental tests “to look at specific areas," but the students were not qualified as SLD. Participant 9 said she had worked on a case where the student had previously been found ineligible for SLD at one school because "he was spending 6 hours on his homework and getting by," but the staff at his new school said he was eligible "based on the amount of time he was putting in on homework."

Question 9 asked participants, "What unique services does a student get when they are identified for special education as opposed to students who struggle but do not qualify for special education services?" Two middle and three high school participants listed accommodations as a benefit to students who were identified for services. Four middle and four high school participants said that specially designed instruction (SDI) in 
the area of difficulty was a benefit; however, all four high school participants, as well as one middle school teacher, also emphasized study skills as well as direct instruction in reading, writing and math. Four out of five high school teachers, but no middle school teachers, said that case management was a benefit to students who were identified for services.

Five out of the 10 participants said that classroom and testing accommodations were an important part of services. Participant 1 noted that when a student was eligible, "parents have the right to make sure those (accommodations) are being reinforced, where if a student doesn't qualify they can still receive accommodations but it's not necessarily that the teachers have to give it to them." Participant 6 said that both classroom and testing accommodations would be included, and Participant 3 described the accommodations as very important. Both Participant 9 and 10 said that accommodations were provided, and Participant 9 said they were also available for tests such as the Scholastic Aptitude Test (SAT).

Eight out of 10 participants, four high school teachers and four middle school teachers, said that SDI in the area of academic difficulty was an important benefit for students who were eligible for special education. However, there was a difference in their responses; middle school teachers were more likely to emphasize reading, writing, or math instruction in their answers, while high school participants emphasized study skills. Participant 1, a middle school teacher, said, "When you qualify then you receive the IEP and you have specific goals for the academic areas that you are working on," and added that social, emotional, behavioral, or organizational goals could be added as well. 
Participant 2 said that students who were eligible "have a written plan that corresponds to how they were identified. So, if someone is eligible for reading, has a disability in reading comprehension, that student gets small group instruction in reading comprehension." Participant 4 also said that SDI was the difference between instructing students who qualified for special education compared to those that struggled and did not qualify for services Participant 5 had a different perspective:

With the RTI model ... . you know ... it's those particular classes_—we had a math and a resource class for students who struggled in those areas. Those classes were similar to a learning strategies class. It was kind of hard to differentiate, you know, between the two.

Participant 5 also felt that the difference was that special education classes had a "more well-rounded model" that did not focus just on skills instruction, but also on organization and self-advocacy She also reported on an interesting phenomenon occurring at her school:

At least at my school, the RTI classes were much smaller that our learning strategies classes. So in some cases, we kind of recommended not making the student SLD, because they were going to get more individual support in an RTI class than in our special ed class ... And I think that's not how it's supposed to be, but that's kind of how it ended up being.

High school participants described a special education delivery model that encompassed study skills and self-advocacy skills. Participant 7 said that she taught lessons on how to take lecture notes because many general education teachers in high school expected students to be able to demonstrate that skill. She commented, "Not all of the instruction is reading, writing, and organization. I mean, there's a lot of stuff that goes in it that's not on the IEP. And when you start listening to kids, you're like, 'Oh, you don't know how to do that. Okay."' Participant 9 said that at her high school, students 
took a study hall class with their case manager and had assistance with monitoring their grades and homework, as well as having the option to take an elective class that supported English and social studies content. Participant 10 said that the elective class “offers students an additional support besides what their case manager does." Participant 8 described the study halls at her school:

You have nine through twelfth-graders, so it's not divided by grade. And the class itself is divided up so there's a lot of small group work going on...because you'll have ninth through twelfth graders with a range of disabilities in the room .... You tend to have small pull-outs, so you'll have - the teacher will focus on students who have a reading goal, or a writing goal, and do small group work with them. There's also a large component of study skills support. So working on homework, preparing for tests.

Four high school participants said that a benefit to students who were eligible for special education services was case management. No middle school participants gave case management as an example of a benefit to students. Participants 3, 9, and 10 all mentioned that students would receive case management, and Participants 9 and 10 also said that the student would take their study hall class with their case manager. Participant 7 described the relationship between the case manager and student:

There's someone in the building who knows them very well, who offers help, instruction, a kick in the backside . . . is sort of managing their lives until they can take over for themselves, their educational lives, at least ... When we get a freshman, unless there's some extraordinary reason, they're with us for four years. So we know them literally better than anyone else in the building.

Participant 7 described two advantages to this relationship. Students who felt comfortable with their case manager would share problems with them and come to them for help. She also said that administrators and other teachers were starting to recognize that case managers knew their students well and could offer valuable instructional advice about how to help the students pass required graduation examinations. 
Question 12 asked participants if they had ever served on an eligibility team that practiced "team override," meaning that the student's scores did not qualify them as SLD according to the district model, but that the team qualified them as SLD anyway. Six out of 10 participants (three at the high school level and three at the middle school level) said they had participated in team override, and four participants indicated that they had not. Participants gave various reasons for using the override option. Four participants said they had used override when the team felt that the student needed the support of an IEP. Three participants said that they would use SLD as a category when the team was unable to obtain a medical statement, which is needed to consider the category of Other Health Impairment. Two participants indicated their teams had overridden SLD criteria when a student moved in with an active SLD eligibility from a previous district and had a history of receiving special education services. Finally, two participants said they would use team override on a re-evaluation for SLD, but not an initial evaluation.

Four participants said they had not engaged in team override. Although she said she had not done so herself, Participant 2 said she had seen paperwork for students where teams had overridden SLD criteria in order to qualify, and that in her experience, it seemed to happen more with students who had attention issues. Participant 8 said that she felt the school psychologist "set the tone" for which students would qualify as SLD given the district model and that it "helps to have good boundaries about who we are finding eligible and who we are not." She said,

I've worked on teams where I would have liked to make the student eligible, but they just don't - they just don't meet the criteria. And, you know, you're like, I really like the kid ... I really want to help the kid, but we try to be authentic and well-boundary (sp) to the model. 
Four teachers, two working at the middle school and one working at the high school level, said that they had participated in team override of SLD criteria when the team believed the student would benefit from support. Participant 3 said that her team had made students eligible when they felt "the kid would never make it through high school without the support." Participant 6 explained that on her team, the override option was used "only in a choice where it was a sink-or-swim thing where we knew if we didn't continue the eligibility of SLD forward, the student was going to be completely without supports and was clearly in need of those supports." Participant 9 said that she and a school psychologist intern felt that even though a student "did not necessarily get there" for reaching the criteria, "we felt he needed the support," but that she felt the testing results were "inconsistent" and that "somebody else could have looked at it and it could have gone either way." Participant 1 said the reason that her team had overridden the criteria for SLD was because "it's just hard when you see a student struggling so much academically and knowing that you're not going to give them any support." She also described the completion of additional assessments:

I worked with a school psychologist that was very - she would do everything she could to try to find - if we really felt a student would benefit from services, you know, she would find a way to do an additional cognitive testing - basically, you know, to see if that would bring scores to where it would be more official for the student to qualify.

Three participants said they had overridden SLD criteria in order to qualify a student when the team was unable to get a medical statement, which is required for considering the categories of Emotional Disturbance and Other Health Impairment, but not SLD. Participant 5 said that her team had qualified a student as SLD in math because they were unable to get a medical statement "and so we wanted to get the student some 
help." Although the student's scores on the individual standardized achievement testing were low, he had met the state benchmark in math, but the team qualified him as SLD in math anyway "just based on getting him some help." Participant 3 said she had used team override more when she taught at the middle school rather than at the high school level, but that one reason it was used was “we didn't have an ADHD or attention deficit diagnosis." Participant 6 also said that override was used when the team did not have a medical statement and "was unable to get another eligibility category confirmed."

Three participants said they had qualified students as SLD when they had previously qualified as SLD, either in this district or in another school district, or when they were considering re-evaluation. Participant 7 said she had done so because the student was currently successful because of the IEP services and accommodations, and if that support had been dropped, "he would not enjoy the same level of success." Participant 3 said she had done this with students both in middle school and in high school, and that because the student had already received special education support, "we're going to continue with them." She explained:

We've grandfathered kids in, like, come from a different district with an LD diagnosis and they don't really qualify in (district under study), or in Oregon . . . I've probably grandfathered kids in when we look at a re-eval and think, what in the heck, wow, but we say okay, he's had services and we'd better not pull them. So those would be the reasons.

Finally, two teachers said that they would not use team override on an initial SLD evaluation, but that they would for a re-evaluation. Participant 7 said she could not remember overriding the SLD criteria for an initial evaluation, and that if a student was being referred for the first time for SLD in high school, “you've got so many years of failure to look at" and "you've got a very long failure of yup, there's something wrong 
here." Participant 6 said, "I can't imagine a team deciding to make a student eligible as an initial evaluation unless all the pieces were already in place to start with," but that she had used team override occasionally for re-evaluations.

\section{Question 13: Exploring Implementation of Policy}

Question 13 asked participants whether they had served on student evaluation teams prior to the implementation of RTI and PSW models, and if they had, asked them to give their opinion about these new processes for SLD identification. In addition, there were two follow up questions; question 13a asked participants whether they thought parents, students, and teachers benefitted from the model used to determine SLD eligibility, and question $13 \mathrm{~b}$ asked them to identify difficulties with implementation of these new models. Out of the 10 participants in this study, seven of them began their careers before the use of PSW and RTI models, and only three participants did not serve on student evaluation teams when the discrepancy model was in use. Five participants, all with 14 years or more of teaching experience, said they liked the PSW model because it allowed for a more complete learning profile of the student being evaluated, but three participants noted that the discrepancy model had been easier for them to use.

\section{PSW Model More Complete, But More Difficult to Use}

Five participants, four high school teachers and one middle school teacher, liked the PSW model because they felt it gave them more information about the student than the discrepancy model. Participant 10 said that "it was easier doing the discrepancy model because you could look at numbers, and you could see, but I think the new model if better because you look at more than just numbers and you look at different tests to see 
where students are really struggling." Participant 3 said in the old model, "where you had a score and you had to either hit it or you didn't—I know we've probably . . . missed some kids that maybe should have been LD but weren't." She added that with the new PSW model, "we really have to do it correctly, you have to be very thorough in looking at all the factors, you look at their academic history. I think it encompasses more so it maybe gives a better picture." However, she also reflected on the differences between PSW and discrepancy:

It's not as cut and dry. And again, I think ... what we laugh about is that if you give anyone the math Woodcock Johnson, they show a weakness . . . . So that's hard, because, you know, they're showing a weakness here, and then the other thing that I don't think between the two models, I think again before it was a little easier, you were a little more clear-cut, and now it's not as clear-cut.

Participant 7 said that she liked that the PSW model "was more inclusive. It's not just a numbers game." She added that another advantage was that it was easier to bring in anecdotal information instead of just only examining the student's standardized scores. Participant 8 said that she liked the PSW model "because it does allow for more information" and that "you have a better picture of the student." She said that to her, the discrepancy model was more "cut and dry." Participant 2 said that for her, the transition to PSW after finding students eligible under the discrepancy model was not a difficult one because "I see a lot of similarities between the pattern of strengths and weaknesses and the comparison between ability and achievement ... It's not exactly the same, and it's a more complex, more interesting process, I think. But I didn't find it jarring to change." Participant 5 liked that the PSW model "is a bigger picture of the kid, rather than looking at him in isolation on testing." However, she also noted that there were things she missed about the discrepancy model: 
I liked the discrepancy model, because for me, it was concrete. You know, now with these other models, anybody who walks into the school system who doesn't know anything about special ed can put their little tidbit in and say, well, how about this, it seems like a weakness? And it does seem like a weakness, if you look at 105 to 86, if you don't know what you're talking about. So ... I need something more concrete.

\section{Reflections on the RTI Process}

At the time these interviews took place, in the summer of 2014, district policy was that RTI could be used to determine SLD eligibility at the elementary level, but not at the secondary level. However, at all middle schools, reading intervention classes were offered to students who were performing below benchmark on state testing. Although the RTI model was not used at the middle or high school level to determine SLD eligibility, four middle school teachers offered their impressions of the process as it related to special education eligibility. Three of these teachers liked the concept of RTI because it gave information on how the student responded to instruction, because it helped teachers work with struggling students, and because it gave students additional support. Challenges with the interventions classes were tracking data, uncertainty over how long the intervention needed to last or how many data points needed to be collected, and communication between team members.

Both Participant 5 and Participant 6 said that at their school, there were issues with tracking data and understanding of the basic RTI model. Participant 6 said, "There's still a lot of uncertainty with the RTI model, at least in our building, for how long interventions need to be in place, how many data points, and what those kinds of data points need to look like." She also said that it was not clear how frequently data points needed to be gathered. She explained, 
We have some students who have been in the response to intervention class, which is the literacy workshop class, and they've been in there for sometimes two, three years without having a referral, so it's questionable ... it's just not completely clear how the-how the RTI process should work in the middle school related to special ed evaluation.

Participant 5 said that in her opinion, the "the newer models with the data points and the aimline ... they're not user-friendly." She said that at her school, "RTI just seems to make parents mad ... because it slows the process way down with those data points." She described difficulties with data collection:

You know, you're talking to counselors and teachers who are supposed to be taking these data points before and taking them for seven to 14 weeks, or whatever it is, before we can even go forward with an eval, when if you've seen students over time, and you can kind of identify-you know-you can sometimes identify someone right off the bat, and I'd like to be able to get those kids help sooner, but you still have to follow through this process, you know, these data points, and even when people say that we have them, then we go to the SET team and they say no, they didn't do it long enough, or we just had a lot of problems with that. Tracking it, and whether or not they were accurate data points.

Participant 5 also had mixed feelings about the extent to which general education

teachers were required to collaborate within the RTI process:

You're already asking enough of these regular ed teachers. Now they're a huge part of the evaluation process, which I'm not thinking they should be away from but - they're too much a part of it. I can't do anything until they've done their part, and in the meantime, the kid sits there and fails.

Participant 2 noted that in her experience, the RTI teams "have not been a very efficient gatherer of information" and that "the hard data that resource teachers need in order to complete an eligibility on a student doesn't seem to get passed on."

\section{Identifying Which Stakeholders Benefit From the Eligibility Process}

Question 13a asked participants, "Do teachers, parents, or students obtain a benefit through the model used to determine eligibility?" Six participants, two at the 
middle school level and four at the high school level, felt that there were some benefits to parents if a student was found eligible for special education. Three high school teachers noted that special education services could benefit the student, but it depended very much on the particular student and their reaction to being identified for services. Two high school participants said that general education teachers seemed to benefit only to the extent to which they were interested and involved in the special education process.

Six participants said that parents were possible beneficiaries of the evaluation process. Participant 6 said that in her opinion, the model used to determine eligibility was less important than the actual outcome, which were special education services, and that those services benefitted not only parents, but the students and teachers as well. Participant 10 said that she thought that the fact that a parent could learn that their child's poor grades were a result of a disability could be helpful because they could look at other ways to support the student, such as tutoring or additional help at home. Participant 2 said that the parents benefitted from the team discussion, and that sometimes parents did not realize that their student had been absent or tardy for so many days and that it was impacting their education. She felt that the student really benefitted after the evaluation process, when the IEP was developed from the information gathered during the evaluation. Participant 3 said that whether parents benefitted depended on whether the referral resulted in the desired outcome:

Some of them, I think, it's, oh, okay, that's what's going on ... especially the ones that have referred and have legitimate, they are looking for help and answers, I think it does help them. I think through the ones that refer a kid who's not a good referral, they are frustrated because it, it doesn't tell them what they want to hear, probably? 
Both Participants 7 and 8 felt that the PSW model allowed them to discuss data

with parents in a way that was clearer and more optimistic. Participant 8 commented:

The way that you frame the discussion about the student, even the language about strengths and weaknesses - it helps the team, and you've got your gen ed teachers and the family - it helps articulate what's going on with the student in a way that's roughly positive. You know, these are your strengths; these are your areas of weakness. And so I think that's beneficial.

Participant 7 said that she felt the new PSW model had "probably helped those people who go into a meeting and say, well, this is the score, this is how low it has to be, we're not there, he's done," but that because she had always had thorough discussions with parents, it hadn't changed how she approached conversations surrounding eligibility. However, she felt the worksheet provided by the school district was helpful because "it might be an easier way to look at the data, because data is really confusing for everyone."

Three high school teachers discussed student involvement as it related to special education eligibility. Participant 7 said she had had students "completely refuse" special education services, with parental agreement, and then return to her later on to ask for those same services. Participant 9 noted that "there isn't a formal step for consulting with the student" and that "most of us talk to our kids, but it's not part of the system." She said that "you can go through the entire process without having real conversation with the student" and felt that this step was lacking. Participant 3 said that whether or not services were helpful depended on the individual student:

I had one kid and he was just made eligible this year. And he knew ... we went and did ADHD, and he was ED, but he knew what was going on with him. $\mathrm{He}$ was smart enough to know. So then we helped him . . . But for some of them, I don't know that they understand what they-some of them still don't know they are in special ed, or-like-it's interesting, and that includes some of the parents .... When they call and say, we'd like to get him on an IEP ... well, they are! So I think it's a mix ... it's kind of a mixed bag. 
Two high school teachers expressed that the extent to which general education teachers benefitted from the special education evaluation process depended on the degree to which they were engaged and involved. Participant 10 said that it was challenging because often teachers were given information about a student's cognitive functioning, such as that they had slow processing speed, but did not know how to adjust their instruction to meet the student's needs. She also observed that there was a great deal of difference between individual teachers and how they responded to the information generated from the evaluation. She said some teachers would adjust their lesson plans or teaching strategies to adapt to the student's needs, and that others “don't really have the time to figure out every special ed student in their class, unfortunately." Although the resource department at her high school offered workshops to general education teachers focused on discussing types of accommodations, she said that very few teachers attended, and that teacher attitudes also affected how evaluation data was perceived:

I think it's because a lot of times I know that there are teachers in our building who say, "The kid just needs to work harder." So they're not willing to go any further. "Okay, so they have this problem. Tell them to work harder. They should study more. They should study harder. They should do . .." But the kids don't know how. And I think a lot of it is apathy towards the whole . . they don't really have a disability.

Participant 3 also discussed that teachers may have a different motivation behind referring a student for help beyond making instructional adjustments and accommodations:

If they've referred or they're the ones who have been pushing hard, they really at the high school level (are) not so interested in what's going on with the kid but that he gets help. Okay, here's your problem, you're going to get help over here. They don't really take the information because they don't come to the meetings, so they don't take the information, nor are they given it, really, because the only thing they get is an accommodations page on an IEP when it's all over. So, I don't 
think they-I don't think teachers or they know what they do with that information if they got it ... We can say, you know, this kid needs everything written down for him. They still don't get what that means.

\section{Difficulties With Implementation of Eligibility Models}

Question 13b asked participants, "What are the difficulties with implementing these models?" Four participants discussed that the PSW model was time-intensive and labor-intensive, including the effort to coordinate with other stakeholders, such as general education teachers or parents. Two participants discussed that there was a wide variation in level of training between staff members. Two participants said that there were challenges when students had been identified for SLD under a different eligibility model at a younger age, and then were re-evaluated at the middle school or high school level using the PSW model. Two participants discussed that specific elements of the PSW model were difficult to use.

Four participants said that the evaluation process was time-consuming and that it was difficult for them to coordinate the people who needed to be involved. Participant 5 did not elaborate, but said that time was a factor that caused difficulties during the evaluation. Participant 7 liked that general education teachers and counselors were part of the eligibility process, but that "sometimes it's herding kittens." Participant 3 said that the process was difficult no matter which model was used to determine eligibility:

We've had parents call. They don't want their kid being pulled out of class to be tested. They want him tested but they don't want him pulled out of class to be evaluated. So then when do you do the evaluation? Well, you have to do it when you're free, so guess what? ... And then the teachers get mad when you pull them out of class. So not only the parents get mad, the teachers get mad. And you take a kid that already is probably behind and you pull them out of class to give an eval. And ... they are missing more. 
Participant 3 also said that because of paperwork requirements, it could be difficult to consider additional information or categories of disability once an initial evaluation has started. She said that there's "just not enough time" and "when you have so many things to do, it's, oh, another eval, so we have to get through this." Participant 7 said she did not know whether the additional testing required by the PSW model was always necessary to determine eligibility:

I think sometimes the eligibility process is really cut and dry, and I don't know that you need to go through the entire process for every kid. Sometimes it's like ... I know you're not passing your classes, but I want to take you out of these classes so I can give you three more tests that I really don't need the information from because I already have enough. It - it seems ridiculous. I think at younger ages, it's probably much more vital, but again, we've got so much history with high school kids — we know — we know where they’ve been. We know how they've progressed.

Participant 7 said that at times, practical considerations, such as school closures for snow days or student attendance problems, interfered with completing the entire required testing recommendations for PSW. She commented:

It seems that it - we're all professionals, our professional observations should play a role in it and this helps. But when you're still saying you have to do every test on here, whether you need it or not, professionalism is set aside forfollowing the rules? And rules have a place, but come on.

Both Participant 3, a high school teacher with more than 30 years of experience, and Participant 4, a middle school teacher with more than 20 years of experience, said they thought training was also an issue with the new SLD models. Participant 3 commented, "I don't think we're as trained as they think we are.” Participant 4 said, "I think there are a lot of people on —all over the map on it, as far as level of training." Three participants, one working at the high school level and two working at the middle school level, mentioned specific challenges when working within the PSW model. 
Participant 8 said that because the high schools were not following an RTI model, it was difficult to document academic interventions that had occurred before a special education referral: "It's really hard beyond the systemic school-wide, they did the math intervention class. That's kind of it." She also said that conducting re-evaluations at the high school level were difficult and time-intensive because "often these students were identified using the discrepancy model, and then to use-it's like doing an initial," meaning that cognitive testing needed to be completed for the student. She said that at times, if the student's numbers "did not align," the team would override the SLD criteria for re-evaluations, particularly for those cases where the team felt the student's academic progress was improved by the IEP services and accommodations. Participant 1 said that at the middle school level, she was completing a lot of re-evaluations where students had qualified under the RTI model in elementary school:

So as we're re-qualifying them, sometimes the scores-if it was an initial eligibility, I wouldn't qualify_-based on the cognitive scores or whatever, I wouldn't qualify them. But I've been told that you know, in that case we can simply re-qualify them, if they've qualified before, they can continue to be qualified.

Participant 5, also working at the middle school level, said that she had used the PSW model for three year re-evaluations, and that to her, it was "kind of wishy-washy, just because, it seems you can find, you know, a strength and a weakness, you know, in one area or another in order to make it work for you." She said, "If we want to make someone eligible, we use PSW because you can—you know—kind of put things where you want them, I guess." She also commented on uncertainty surrounding the guidelines using PSW: 
It doesn't seem to be a-a strict number. Even though I've followed the sheet that they gave us, you know, that says where's the strength, where's the weakness, but then you talk to other people sometimes, and they say, well, sometimes an 86 can be a weakness, you know, if their other part of the IQ test was a 105. It's like, well, but I thought it was below 85 that makes it a weakness. So maybe it's education to administrators too.

Participant 5 noted that including state testing results can also indicate a weakness for students because "state testing is so difficult that, you know, kids would always qualify in that area too," particularly those students who experience testing anxiety.

\section{Summary of Data Pertaining to Research Question \#1}

Overall, there appears to be a moderate level of support for the ideas of relativity and acceptability as they are experienced by secondary resource teachers, but less support for the concept of profitability. Table 2 (next page) summarizes the interview data and reports the number of participants whose statements supported each paradigm.

\section{Research Question 2}

The second research question is: What other themes regarding SLD eligibility determination emerge from interviews with secondary resource teachers? Following a second sort of the data cards, several new themes emerged. For the purpose of answering this question, a "theme" was defined as an idea expressed by at least 4 out of the 10 interview participants. This allowed for a more thorough description of the constructs of relativity, acceptability, and profitability, as well as examining some themes that did not fit with the current description. 
Table 2

Summary of Themes from Research Question 1

\begin{tabular}{|c|c|c|}
\hline Question Number & Paradigm & Categories Identified \\
\hline $\begin{array}{l}5 \\
\text { What socio-cultural factors contribute to } \\
\text { an SLD referral }\end{array}$ & Relativity & $\begin{array}{l}\text { Behavioral issues (4) } \\
\text { SES (2) } \\
\text { English language learners (4) } \\
\text { Cultural differences (3) } \\
\text { Higher standards within normative } \\
\text { group (4) }\end{array}$ \\
\hline $\begin{array}{l}10 \\
\text { What pre-referral interventions are used } \\
\text { by teachers before an SLD referral }\end{array}$ & Relativity & $\begin{array}{l}\text { Instructional accommodations (4) } \\
\text { System-wide intervention classes (4) } \\
\text { Time, setting, and scheduling } \\
\text { accommodations (4) } \\
\text { Teachers show a wide range of skill } \\
\text { with pre-referral interventions: (5) }\end{array}$ \\
\hline $\begin{array}{l}\text { 7a } \\
\text { Are classroom-based norms or } \\
\text { standardized testing norms valued more } \\
\text { during SLD eligibility process }\end{array}$ & $\begin{array}{l}\text { Relativity and } \\
\text { Acceptability }\end{array}$ & $\begin{array}{l}\text { Standardized norms valued more (6) } \\
\text { Classroom norms valued more }(2) \\
\text { Depends on individual school site } \\
\text { which is valued more (2) } \\
\text { Using standardized testing as "rule out" } \\
\text { for SLD, but may consider other } \\
\text { options (4) }\end{array}$ \\
\hline $\begin{array}{l}\text { How do teams decide when English } \\
\text { Language Learners should qualify as } \\
\text { SLD }\end{array}$ & $\begin{array}{l}\text { Relativity and } \\
\text { Acceptability }\end{array}$ & $\begin{array}{l}\text { Standardized testing } \\
\text { important to complete in student's } \\
\text { native language (9) } \\
\text { Input from ELD teacher very important } \\
(4) \\
\text { ELPA scores important (3) }\end{array}$ \\
\hline $\begin{array}{l}\text { What differences should teams consider } \\
\text { between struggling students and those } \\
\text { who qualify as SLD }\end{array}$ & Acceptability & $\begin{array}{l}\text { Mentioned PSW model (6) } \\
\text { Not clear on particulars of PSW model } \\
(2) \\
\text { Use state testing as "rule out" for SLD, } \\
\text { but may consider other categories (2) } \\
\text { SLDs should have some areas of high } \\
\text { achievement and some of low } \\
\text { achievement (3) }\end{array}$ \\
\hline $\begin{array}{l}6 \\
\text { What information from standardized } \\
\text { testing was used to help determine SLD }\end{array}$ & Acceptability & $\begin{array}{l}\text { Can see student's strengths and } \\
\text { weaknesses (5) } \\
\text { Norm-based group away from local } \\
\text { school group (4) } \\
\text { Used within district model (3) } \\
\text { Noted weaknesses with standardized } \\
\text { tests (4) }\end{array}$ \\
\hline
\end{tabular}


Table 2 (continued)

\begin{tabular}{|c|c|c|}
\hline Question Number & Paradigm & Categories Identified \\
\hline $\begin{array}{l}\text { 7b } \\
\text { Contradiction between classroom data } \\
\text { and standardized testing and was student } \\
\text { qualified as SLD }\end{array}$ & Profitability & $\begin{array}{l}\text { No impact on standardized testing, not } \\
\text { SLD (5) } \\
\text { No clear academic impact, not SLD (5) } \\
\text { High school students should be } \\
\text { involved (2) } \\
\text { Re-evaluation standards less stringent } \\
\text { than initial SLD standards (2) }\end{array}$ \\
\hline $\begin{array}{c}8 \\
\text { Reflecting on cases where student was } \\
\text { not found eligible as SLD }\end{array}$ & Profitability & $\begin{array}{l}\text { Test scores did not show pattern of } \\
\text { impact (5) } \\
\text { Classroom performance did not show } \\
\text { pattern of impact (4) }\end{array}$ \\
\hline $\begin{array}{c}\text { 9 } \\
\text { Unique services for students who are } \\
\text { eligible for services }\end{array}$ & Profitability & $\begin{array}{l}\text { Accommodations (5) } \\
\text { SDI (8) } \\
\text { Case management (4) }\end{array}$ \\
\hline $\begin{array}{l}12 \\
\text { Team Override for SLD criteria }\end{array}$ & Profitability & $\begin{array}{l}\text { Had participated (6) } \\
\text { Overridden criteria when team felt the } \\
\text { student needed an IEP (4) } \\
\text { Used SLD when medical statement } \\
\text { couldn't be found (3) } \\
\text { Grandfathered students in as SLD when } \\
\text { found eligible in another district (2) } \\
\text { Had used override on a re-evaluation, } \\
\text { but not on an initial SLD eligibility (2) }\end{array}$ \\
\hline
\end{tabular}

\section{Additional Themes for Relativity}

Five themes emerged from the data: (a) higher standards in the school can make it possible that a student performing below average is referred for an SLD evaluation; (b) participants used the standardized academic testing to provide a comparison group for the student beyond the local school; (c) relativity is important as a team considers academic impact, which influences eligibility decisions; (d) teachers show a wide range of skill 
with implementing pre-referral interventions; and (e) support is given through course offerings, both before eligibility and after special education eligibility.

\section{Higher standards in the school can increase the likelihood of an SLD}

referral. Two middle school and two high school teachers discussed that higher standards in the school and state can lead to more SLD referrals. One middle school teacher said that "state testing is so difficult that, you know, kids would always qualify in that area." Another middle school teacher noted that "sometimes they could be referred for testing when, if it were in a different school, with a lower socioeconomic pattern or just lower-performing peers they would not be referred."

\section{Participants used the standardized academic testing to provide a comparison}

group for the student. Three middle school and one high school teacher discussed that the standardized measures provided a norm-based reference. Participant 2 noted that using the standardized, nationally normed measures allowed an examiner to compare that student with a different peer group than that of the local school: "If a student is in a group of high-achievers, then you see that, compared nationally, they really are where they should be."

\section{Relativity is not only important during the referral stage, but also as the} team considers academic impact during the eligibility stage. Two middle school and two high school teachers stated that they would not qualify students as SLD if there was no academic impact; that is, if the student was performing in a similar way when compared to their peers in the classroom. Participant 10 gave an example of two students whose testing in a few areas indicated weaknesses, but classroom participation and test- 
taking abilities in class were not showing academic impact, so the student was not qualified as SLD.

\section{Teachers show a wide range of skills with implementing pre-referral}

interventions. Two middle school and three high school teachers discussed that some teachers were better at implementing pre-referral interventions than others. One middle school teacher commented, 'I've seen it where there's been interventions where-I changed his seat and it didn't get better ... And those are the interventions where you know it's going to be painful, because they just want the kid out of the room but they know it's not really going to happen." A high school teacher said, "I have to say that one of the hardest things we deal with is getting teachers to provide that extra help or accommodations before we ever do the testing."

Support is given through course offerings, both before eligibility and after special education eligibility. One middle school and three high school teachers talked about the importance of system-wide interventions at the secondary level. Both general education and special education students could take smaller math classes with an additional staff member to help students. At the high school level, classes were implemented to support students who have not passed statewide assessments, including students who are already eligible for special education.

\section{Additional Themes Describing the Concept of Acceptability}

I identified five additional themes that further expand the idea of acceptability: (a) teachers used standardized test results as a way to "rule out" SLD as a category of eligibility and consider other options or eligibility categories; (b) some teachers described 
situations where because the team was unable to get a medical statement for ADHD, the student was qualified as SLD instead in order to receive special education services; (c) participants noted difficulties with obtaining assessment materials in languages other than English and Spanish; (d) participants reported that standards for re-evaluations for SLD were less stringent than for initial SLD eligibilities; and (e) the model used for SLD evaluations was very time-consuming.

Standardized test results used as a "rule out" for SLD. Five participants, three at the middle school level and two at the high school level, described using standardized test results to determine that the student did not meet SLD criteria. One middle school teacher cited the SLD eligibility form: "The first question when you get past all the stuff is, has the student met (state) standards in those areas. And if they have, then you really can't go forward anymore." One of the high school teachers said, "I will look at the information, and if they have a history of meeting state standards, it's like, no, there's not LD here, but there's something going on." Two other teachers discussed that after SLD was determined not to be the cause of the student's difficulties, other eligibility categories would be considered.

\section{Lack of medical statement as a reason for qualifying a student as SLD. Five} participants, three middle school teachers and two high school teachers, discussed that sometimes the eligibility team could not obtain a medical statement, which is required to consider the special education category of Other Health Impairment, and so the team would qualify the student as SLD in order to get them services. One high school teacher discussed using team override in situations where there was no medical statement, but the 
team knew that without services "they weren't going to make it in high school." One middle school teacher gave the example of a student who was meeting state benchmarks in math, yet the team qualified him as SLD in math because they were unable to obtain a medical statement for ADHD "because we wanted to get the student some help."

Difficulties discerning an SLD among non-native English speakers. Three middle school teachers and all five high school teachers discussed that it was very difficult to determine if an SLD existed for students who were non-native English speakers. Several participants mentioned that assessment materials were available in Spanish, but two high school teachers discussed that there were no materials available for speakers of other languages, such as Somali or Hungarian. One of these teachers said regarding assessment in the student's native language: "It comes down to gut feeling instead of actual assessment. Because we're not really able to, even though we are legally required to."

\section{Standards for re-evaluation for SLD less stringent than for initial SLD}

evaluations. Three middle school and two high school teachers discussed that it was easier to re-qualify a student who had previously qualified under SLD than it was to qualify them using data from an initial evaluation. One middle school participant described completing re-evaluations for students who had originally qualified under the RTI model:

If it was an initial eligibility, I wouldn't qualify_-based on the cognitive scores or whatever, I wouldn't qualify them. But I've been told that you know, in that case we can simply re-qualify them, if they've qualified before, they can continue to be qualified. 
One high school teacher said, "I've probably grandfathered kids in when we look at a reeval and think, what the heck, wow, but we say okay, he's had services and we'd better not pull them."

Evaluation model for SLD is time-consuming. Three high school teachers and one middle school teacher said that the evaluation model used for SLD eligibility was time-consuming. While one high school teacher described this additional time as a "plus and a minus," another high school teacher discussed that the paperwork requirements also added time to the process:

If you start an eval and you go, we think this might be this, then you have to have another meeting for the parent to sign, you know, to test, and then you have to have a meeting notice, you have to have meeting minutes ... we would do that, but gosh, who has the time to ... you know, it's a lot of work.

\section{Additional Themes Describing the Concept of Profitability}

Five additional themes emerged regarding the idea of profitability: One benefit from eligibility is case management; another benefit is accommodations; a third benefit is study hall support; and a fourth benefit is small group instruction in the area of difficulty identified through the evaluation. Finally, teachers discussed how the team's perception of whether the student needed services would influence their decisions to override SLD district criteria to qualify the student for special education.

Case management as a benefit. Four participants, all working at the high school level, listed case management as a benefit coming from a special education eligibility. Two teachers said that their study hall was only with students on their caseloads so that they were able to help them access IEP accommodations. Another student discussed that 
she had her caseload students for all four years of high school and that the case managers knew them better than anyone else in the school.

Study hall support at the high school level as a benefit. Four high school teachers listed study hall instruction and support as a benefit coming from a special education eligibility. One participant described the study hall as a combination of test preparation and specially designed, direct instruction in the student's area(s) of need. Another described the support as being more general: "They get help, you know."

Middle school teachers list small group instruction as a benefit. Four middle school teachers listed small group instruction as a benefit coming from a special education eligibility. Two teachers discussed that the small group instruction related to the areas of weakness identified through the evaluation and IEP; however, the remaining teacher felt that there was not as much difference between the RTI classes that were taught at the school and the special education resource classes.

Accommodations listed as a benefit. Six teachers, three working at the high school level and three working at the middle school level, listed accommodations as a benefit coming from a special education eligibility. Participant 2, a middle school teacher, said that some parents perceived a benefit from qualifying a child as special education because the student would get more time on tests. A high school participant shared that if a student with SLD was dropped from an IEP because they did not require SDI, they would no longer receive accommodations, and so "I will do anything humanly possible to keep an LD kid on an IEP if they need the accommodations, because I know they don't get them otherwise." 
Team perception that the student needs help leads them to practice team

override. Two middle school and three high school teachers discussed that if the team felt that the student needed support, they would override the SLD district criteria in order to provide services. Two teachers gave instances where this occurred for initial special education evaluations; however, the other three participants discussed that this was more likely to occur with an SLD re-evaluation, where the team believed that continued services were in the best interest of the student. 


\section{CHAPTER 5}

\section{DISCUSSION}

The purpose of this dissertation study was to examine a theory of how schoolbased eligibility teams make decisions regarding SLD eligibility determination, and to see whether teacher descriptions of the process offered support for the theory of competing paradigms. These special education teachers implement district guidelines in the real-life context of middle and high schools, where the needs of students, teachers, and parents intersect with ever-increasing pressure for measurable academic progress. These teachers are also attempting to navigate these decisions in a policy environment that permits both RTI and PSW models, where differences exist in practices between school districts, and where there has been a significant shift away from the traditional IQdiscrepancy model in many districts and states. The first research question was: To what extent do interviews of secondary resource teachers reveal the concepts of relativity, acceptability, and profitability as they reflect on the SLD process? The second research question was: What other themes regarding SLD eligibility determination emerge from interviews with secondary resource teachers?

In this section I summarize results as they relate to the research questions, relate those results to both the theory of competing paradigms and other literature reviewed for this study, advance recommendations for educational leaders, and suggest future research projects. 


\section{Research Question \#1}

\section{Support for the Concept of Relativity}

Interview data showed a moderate degree of support for the concept of relativity. In the current study, the interviewer (question 5) asked participants to identify and discuss those factors that lead teachers to refer a student for a special education evaluation. Four teachers listed behavioral issues, two teachers listed low SES, four teachers cited difficulties with English language acquisition, and three teachers noted that cultural differences were reasons why students were referred. In addition, in response to question 10 , four teachers said that they had seen general education teachers implement interventions and accommodations before referring a student for an SLD evaluation.

These findings support Bocian et al.'s (1999) theory in that socio-cultural factors do influence the referral process at times; however, Bocian et al. discussed that these factors may influence a teacher from refraining to refer a student for special education, and my participants said that these students were more likely to be referred for an evaluation. Some teachers do attempt to remediate a student's low performance in the classroom at first, but if they perceive that gap to be too big, they will refer the student for additional assistance outside their classrooms.

\section{Support for the Concept of Acceptability}

Richey and Graden (1980) found that evaluation teams charged with the task of identifying students as SLD did not appear to use specific criteria when deciding which students met the requirements. I did not find this to be true of the participants in my study, and there appeared to be a moderate level of support for the concept of 
acceptability. Six out of 10 participants said that they used the district's PSW model to determine which students met SLD district criteria; 6 out of 10 participants thought that standardized academic and cognitive results were given more weight than classroom performance when determining SLD eligibility; and when teachers were asked why a specific student did not qualify as SLD (question 8), 5 out of 10 stated that the student did not exhibit a pattern of academic and cognitive strengths and weaknesses. Other than one first-year teacher, who admitted not knowing the criteria and said she had had no training in PSW before beginning her position, teachers did seem to be familiar with the prescribed district model, although two teachers did exhibit some confusion about PSW cut-scores (whether an 87 or an 85 was considered to be a strength on academic and cognitive testing).

\section{Whether Relativity or Acceptability is More Valued During SLD Decision-Making}

Bocian et al. (1999) analyzed the SLD decisions made by elementary school teams to determine whether classroom norms (relativity) or ability-achievement discrepancy (acceptability) were more important. They discovered that when a student's scores on locally normed assessments indicated a need for special education services, but there was no ability-achievement discrepancy, 39\% of those students qualified as SLD. They also discovered that when students demonstrated an ability-achievement discrepancy, but the scores on local norms were within the average range, $45 \%$ of those students qualified as having an SLD. Based on these results, they concluded that they found "no clear-cut pattern suggesting a consistent placement decision favoring one paradigm over the other" (Bocian et al., 1999, p. 9). This study found a similar pattern to 
that of Bocian et al.; there did not seem to be a clear-cut pattern where school staff gave greater weight or consideration to information from one paradigm over another. This finding also contradicted Johnson et al.'s (2006) observation that school staff were more concerned with classroom performance rather than district or state guidelines for acceptability.

In the current study, questions $7 \mathrm{a}$ and $7 \mathrm{~b}$ attempted to gather data about which paradigm was valued more by participants as they considered SLD eligibility. Question 7a asked participants directly whether they thought classroom-based norms or standardized norms were valued more during decision-making. Six out of 10 participants thought that standardized norms were valued more, while only 2 participants thought that classroom norms were more influential, and two teachers thought that it depended upon the individual school site. Question 7b asked participants whether a student would be qualified for services if there was conflicting information between their standardized achievement scores and their classroom performance. Five out of 10 participants said that if there was no impact on standardized testing, the student would not be qualified as SLD; in addition, the other five participants said that if there was no clear academic impact in the classroom, the student would not be considered as SLD. Question 8, which asked participants to consider students who did not qualify as SLD and explain why they did not qualify, showed a similar split in responses. Five participants said that the student's standardized test scores did not show a pattern of impact indicating a disability, while four participants said that the student's classroom performance did not show a pattern of academic impact. Although a majority of participants (six out of ten) said that 
standardized norms were more valued than classroom norms when asked directly, the answers given when participants were asked to reflect on their own cases and practices were almost evenly divided between relativity and acceptability.

The concept of academic impact comes from the Individuals with Disabilities Education Improvement Act of 2004, which states that in order for the student to qualify under any of the 13 disability categories, there must be evidence that the child's impairment "adversely affects educational performance" [(34 CFR 300.7.(b)(i)]. This language is also used in the federal regulations for IDEA in Sec. 300.8 (c)(9)(ii). However, in a 1995 policy letter issued in response to a complaint made by the Learning Disabilities Association of North Carolina, the Office of Special Education and Rehabilitative Services clarified that IDEA does not define either of these concepts explicitly: "Since the measurement of 'educational performance' is different for each child, the Department has not developed a single definition for this term. Similarly, the term 'adversely affects' must be determined on an individual basis" (U.S. Department of Education, Multi-Disciplinary Evaluations section, para. 3) by the student evaluation team. The student's eligibility team has the responsibility to determine the extent of the impact of the disability upon the student's educational performance, which is broader than only academic performance alone and includes behavior as well. In my study, only 5 out of 10 participants mention that not having "academic impact" means not qualifying a student; however, under the law, evidence of negative educational impact of the student's disability is a requirement for all students. 


\section{Support for the Concept of Profitability}

Bocian et al. (1999) defined profitability as the team's decision that the student would benefit from special education as provided at that specific school site. In this study, question $7 \mathrm{~b}, 8,9$, and 12 asked participants about profitability. When participants did not see an academic impact due to a disability, they would make the decision that the student did not qualify for SDI and an IEP, because it would not profit the student to receive that special instruction. Although the responses to questions $7 \mathrm{~b}$ and 8 appear to be support for acceptability, the fact that five participants indicated non-qualifying students would not profit from services indicates that it also relates to profitability. I did not find much support for the concept of profitability as described by Bocian et al. (which was the idea that the eligibility team weighs practical considerations when qualifying students). I did not find any participants that said that they would not qualify students due to having higher caseloads or due to the perceived efficacy of either special education or general education teachers. Because my participants listed different factors as being reasons that students benefit from a special education identification, such as study skill instruction, SDI in an academic skill, classroom accommodations, and case management, my study expanded Bocian et al.'s concept of profitability.

Bocian et al. (1999) did not discuss the concept of team override, but 6 out of 10 participants said that they had used this option when they felt a student would benefit from special education services (meaning that district acceptability criteria was overlooked in the interest of perceived profitability). These responses to questions 9 and 12 are discussed under research question \#2 because they introduce additional themes. 


\section{Research Question \#2}

The second research question is: What other themes regarding SLD eligibility determination emerge from interviews with secondary resource teachers? I identified five themes that further expanded the idea of relativity, five themes that further expanded the concept of acceptability, and five themes that expanded the idea of profitability.

\section{Other Themes Related to Relativity}

Four participants said that higher academic standards led to special education referrals, which was not a factor noted by Bocian et al. (1999). They proposed the theory of competing paradigms in 1999, before the 2002 re-authorization of the Elementary and Secondary Education Act, otherwise known as No Child Left Behind Act of 2001, emphasized higher academic standards and testing. It is doubtful, given the current political climate in schools, whether Bocian et al.'s claim that "the referral decision is not influenced by information from nationally normed scales" (p. 2) is true anymore. The advent of RTI, which also emphasizes curriculum-based measures, also introduces a method of comparing student performance that is norm-based, but generated outside of the local school environment.

As schools adopt even tougher standards through the common core curriculum and tests that are normed over larger populations of students, such as the Smarter Balanced Assessment Consortium, the concept of the teacher as an isolated decisionmaker, reviewing data generated only within the island of their individual classroom, is less pertinent than it was 15 years ago. One of my participants, who had taught for more than 30 years, commented, "With the standards, and what they require kids to do, the bar 
gets higher and higher and-for these kinds of kids the gap gets bigger and more difficult ... School is more difficult .... We need to look at that as well, and what impact it is having on kids."

Responses to question 10, in which participants were asked to list pre-referral interventions, highlighted a second difference between the public schools in the late 1990s and the current time. Although RTI was in its early stages when Bocian et al. (1999) proposed the theory of competing paradigms, they did not mention its use in Southern California, where their study was conducted. In my study, 4 out of 10 participants discussed that system-wide interventions, such as courses in remedial reading, were offered as part of the pre-referral process. At the high school level, placement seemed to be determined by whether students had failed or passed their $8^{\text {th }}$ grade state benchmarks in reading. Two high school teachers mentioned that their jobs were to "push in" to these classes and provide instruction to their caseload students in tandem with general education teachers. However, the classes were also open to students who were not currently eligible for special education. The purpose of these classes seemed to be to raise achievement for both groups of students to meet benchmark levels and pass statewide assessments.

This approach — including both students who are struggling and those who are formally identified as students with disabilities in the same class - is an example of what Fuchs et al. (2010) called "the blurring of special education," a mingling of resources brought about by what they call the NCLB (No Child Left Behind Act of 2001) camp of RTI philosophy. According to these researchers, those within the NCLB group view RTI 
"within the context of standards-driven educational reform" (Fuchs et al., 2010, p. 303) and that "the blurring of professional roles, places, monies and students is the brick and mortar of the new continuum of general education placements and services" (p. 306). This blurring extends the concept of relativity, because teachers are able to access support for struggling students in different ways than were previously available, and small group instruction is not just for students who are eligible for special education services, but also for those who fail to earn passing grades for general education state benchmarks. One positive outcome of this phenomenon may be less "reassignment of responsibility" when a student qualifies for special education services; Mitchell and Poland (1980) noted that once a student qualified, their performance became linked to the efforts of a special education teacher rather than a general education teacher. If the current goal is to have students meet performance benchmarks, regardless of whether a disability exists or not, the standard is the same for all students and both special education and general education are theoretically working towards the same objective.

\section{Other Themes Related to Acceptability}

I identified five additional themes that further expand the idea of acceptability. First, five teachers reported using standardized test results as a way to "rule out" SLD as a category of eligibility and consider other options or eligibility categories. Secondly, five teachers described situations where because the team was unable to get a medical statement for ADHD, which is required to consider the special education category of Other Health Impairment, the student was qualified as SLD instead in order to receive special education services. A third theme was that eight teachers noted difficulties with 
obtaining assessment materials in languages other than English and Spanish and difficulties with qualifying non-native English speakers as SLD. A fourth theme was that four teachers reported that the model used for SLD evaluations was very timeconsuming. A fifth and final theme for this category was that four teachers reported that standards for re-evaluations for SLD were less stringent than for initial SLD eligibilities. When reflecting on the process of re-evaluation, five participants said that standards for SLD re-evaluations appeared to be less stringent than for initial SLD evaluations. One participant discussed that if students had received special education services in the past, "we better not pull them" when the student was re-considered for a legally required threeyear re-evaluation.

Bocian et al. (1999) did not mention re-evaluations in their study, but eligibility teams still consider all three paradigms (relativity, acceptability, and profitability) when determining the need for special education services. The question teams are directed to consider in the participating school district for re-evaluations is, "Does the student still need specially designed instruction?" and the answer to that question may be influenced by the threat of legal action or parental pressure to continue providing "special" instruction whether the student's data meet district criteria or standards for SLD. Interview participants also described being anxious about making the determination that a student did not require special education services anymore because those same special education services might be why the student is doing better academically, and to withdraw them would introduce uncertainty. One high school participant said, "Initials are pretty true to the model, but I think it gets murky when we talk about re-evals.” 


\section{Other Themes Related to Profitability}

My study expanded the concept of profitability beyond just qualifying a student for services. The concept of profitability, especially for older secondary students, seems to be affected by the "blurring" between general education and special education as all students are expected to pass statewide testing in order to graduate from high school. However, this "blurring" of students may lead to delays in accurate identification of those who have learning disabilities, which Fuchs, Fuchs and Stecker described as the purpose of the IDEA/RTI camp. According to one middle school participant in the current study, the RTI classes at her school looked very similar to those classes offered for students who were identified for special education, "and for some cases, we kind of recommended not making the student SLD, because they are going to get more individual support in an RTI class than in our special ed class" due to smaller class sizes. Christenson (1980) reported that in her observational study of special education eligibility teams, teachers discussed who had a caseload opening to serve the student once they qualified for services, meaning that considerations such as caseload sizes and the number of students in a classroom affected decisions about eligibility. In this case, the greater assistance for the student, and better chance of instructional success, may lie on the general education/RTI side of the fence. This may also undermine the concept of profitability as conceived by Bocian et al. (1999) if teachers do not see a benefit by identifying students for services, and they do not need a "label" to receive small group instruction in an area of need, there is less of a reason to refer them for a lengthy evaluation process. 
Question 9 asked teachers to describe the services that are available to students eligible for special education. Five teachers listed accommodations as a benefit for students, including those related to high-stakes testing such as college admission tests. Interestingly enough, accommodations are also tried during the pre-referral process, before students are assessed for services; the difference is that once a student qualifies and receives accommodations as part of an IEP, the school is legally obligated to provide those services. Given that there is a wide range of skill levels among teachers who are implementing classroom accommodations, a formal plan with legal safeguards may be an attractive option for parents and special educators. One teacher also brought up that for students who only qualify as SLD, they will no longer receive accommodations if they do not re-qualify at a three year re-evaluation. (They are not eligible under a district 504 plan because SLD is not seen as a medical condition.) Accommodations may be an incentive for teachers to keep students on an IEP after they no longer need SDI because they may still need accommodations such as extra time on assessments.

Another benefit listed by four high school teachers, but no middle school teachers, is case management for students who are eligible for services. The benefit of this service may be due to the fact that many students with disabilities struggle with executive functioning and that as school demands increase, so do demands on organizational skills such as time management and prioritizing commitments. The perceived advantage of case management may also be due to increased pressure for students to meet graduation requirements, which includes passing statewide assessments. 
Both middle and high school teachers listed small group instruction as a benefit for students receiving special education services, but there appeared to be a difference in the type of small group instruction. The emphasis for high school students seemed to be on passing general education classes and receiving help with requesting and coordinating accommodations; while all students take study hall, students who are eligible take it with their case managers in order to receive extra support and help with study skills. The middle school teachers listed small group instruction as a benefit but did not specifically discuss the nature of the instruction, rather than saying it was linked to the area in which the student qualified for services. It may be that due to the increased influence of RTI in the elementary and middle schools, there is more of an emphasis on remediation and early intervention than at the high school level.

A final idea linked to the concept of profitability is team override, which was explored in question 12. If team members perceive that a student needs "help," they may override district SLD criteria in order for the student to receive the benefits of special education services. Six out of 10 participants said that they had overridden district criteria to qualify a student as SLD, and 5 out of 10 participants said that it occurred when the team could not obtain a medical statement for the student and was not able to consider the category of Other Health Impairment. Four participants also said that their decision to override SLD criteria was because the team knew the student needed services and that they would not be successful in school without assistance. It may be that there is more of an element of "competing eligibilities" rather than "competing paradigms" as teams make decisions; they may be trying to put together pieces of the data they have and assemble 
them in a package that provides services, regardless of disability category. Bocian et al. (1999) focused exclusively on SLD, but in the real-life context of schools, teams may consider at least two eligibility categories (or more) during the evaluation stage, and may use information from either statewide testing (passing scores) or standardized academic or cognitive testing (no pattern of strengths and weaknesses) to rule out SLD according to this study.

\section{Additional Observation}

I also asked teachers to list specific interventions that were tried by teachers before a student was referred for special education (question 10). Five out of 10 teachers reported that there was a wide range of skill abilities among teachers as far as implementing pre-referral accommodations and strategies. This also means that teachers who are more skilled in developing and delivering accommodations and simple behavior plans may not move as quickly to refer a student for special education if they feel their own efforts are able to affect positive change. Teachers who have less training and are less skilled in these techniques will tend to refer challenging students at a higher rate than those who have a bigger "bag of tricks" to rely upon during their career. Bocian et al. (1999) did not refer to individual teacher skills in relation to relativity, but did mention "class size, past responsiveness of the child, and the resources available in the class" (p. 2) as factors that influence the teacher's likelihood to refer specific students for an evaluation. However, they did not mention the self-efficacy and experience level of the particular teacher making the referral. University teacher preparation programs should add specific coursework in how to deliver accommodations and modifications within the 
general education classroom in order to boost teachers' sense of self-efficacy and in order to reduce special education referrals.

\section{Possible Paradigm Shift?}

Overall, based on the results from this study, there seems to be a moderate level of support for the concepts of relativity and acceptability as they are perceived by resource teachers, and somewhat less support for the concept of profitability (research question 1). However, this may be because Bocian et al. (1999) operationalized profitability as "the actual school decision as placed or non-placed" (p. 6) into special education. The questions related to profitability that I asked participants for this study had more to do with what they perceived as the benefits of special education, which would influence placement decisions. The study also revealed some additional themes that could be added to expand or further develop the concept of profitability (research question 2). However, the concepts of relativity, acceptability, and profitability are not "pure" in that they do not map directly and discretely upon the three phases of the eligibility process itself (referral, evaluation, and eligibility determination) as proposed by Bocian et al. Instead, the concepts appear throughout the special education identification process.

One example of this conceptual overlap occurs between the categories of relativity (referral stage) and profitability (eligibility determination stage). Teams can and do consider relativity (local norms) as they determine whether a student should be referred for an initial SLD evaluation, as suggested by Bocian et al. (1999). However, teams also consider local norms when determining eligibility - they do not only consider 
whether the student will profit from special education. If a student does not demonstrate academic impact in the classroom, they are not found eligible for special education.

The concept of academic impact also seems to extend to how special education teachers regard statewide assessment scores. Five teachers reported considering whether a student had passed or failed state benchmark testing (a legal requirement for students who are identified as SLD) during the referral process as a way to "rule out" SLD before the acceptability phase (formal standardized academic and cognitive testing) was even initiated. Most teachers mentioned that they would not qualify or consider a student for the category of SLD if they demonstrated a history of passing these benchmark tests, and one teacher mentioned that the eligibility determination paperwork requires teams to consider "has the student met (state) standards in these areas ... And if they have, you really can’t go forward anymore.” Although state testing results do not represent local norms in Bocian et al.'s theory, they do provide an indication that a student is performing within the average range when compared to state standards, and that is similar to the concept of relativity; there is no gap between that child and their peers that needs to be closed through either interventions or special education.

In another twist, four participants reported using the national norms that resulted from standardized academic testing during the assessment phase to provide a norm-based reference group outside of the local school context. One teacher described this as "solving the problem" caused by having an average-performing student in a highachieving group of students; when the student was compared with their peers over a larger sample, their performance was within the average range, rather than limiting the 
comparison to the group of "high fliers" attending that particular school. In that scenario, information classified by Bocian et al. as belonging to the concept of acceptability was used to counterbalance information belonging to the concept of relativity. If the concepts flowed in a linear pattern throughout the special education process, as suggested by Bocian et al., this type of transfer would not occur.

A final example of overlap between concepts was revealed when participants discussed the difficulties of assessing English language learners using testing materials in their native language; teachers stated that it was difficult to find any materials other than those developed in English or Spanish. The assessment phase (acceptability) is influenced by socio-cultural and contextual factors, although Bocian et al. (1999) claimed that "the testing step is devoid of such factors" (p. 2). In addition, these teachers needed to use their professional judgment in order to ascertain whether the student's English skills were advanced enough to gain an accurate academic assessment if the student was assessed using English; professional judgment influenced the supposedly neutral and objective testing decisions and results. (If a student whose native language is not English is assessed before their academic language skills are strong enough, low scores could mistakenly indicate a disability rather than issues with ongoing second language acquisition.) Bocian et al. discussed that teachers may hold off on referring students due to concerns with language acquisition; in contrast, teachers in this study reported that second language learners appeared to be referred at higher rates than their native Englishspeaking classmates and that, once referred, determination whether a disability existed 
was particularly challenging. In the words of one experienced participant, "I think you have to just not speak English, and you're in."

Kavale, Forness, MacMillan, and Gresham (1998) argued that school-based eligibility teams placed more importance on "what a child 'needs' rather than 'what kind of child they are' .... With the prevailing attitude emphasizing service, science, defined as an understanding of the phenomenon question, becomes secondary" (p. 309). Bocian et al.'s theory of competing paradigms is a good starting point for discussions on how the public schools go about identifying students, but the theory itself needs refinement and expansion in order to embrace the wider phenomenon of school-based SLD identification. The difficulty is not that school-based teams do not care about legal definitions or scientific constructs of what constitutes a learning disability; it is that the legal question they are supposed to answer is not only whether or not a child has a disability, but also whether they need special education services as a result of that disability.

Furthermore, the decision whether a public school student qualifies as SLD depends upon the type and quality of the data available to the team at the time of the eligibility determination. Parents do not follow through with producing medical statements, students move in from districts with active SLD eligibilities determined under different service and identification models, and snow days close the school and interfere with data-gathering and assessment. Bocian et al. (1999) are correct when they stated that the schools are not in the business of providing "pristine" samples for the research community; they are attempting to find and serve those students who need the help. 
Comparing assessment profiles of research-identified SLD students with those of schoolbased SLD students is an interesting exercise, but without addressing other elements within the school environment, it will not lead to better SLD identification practices by school-based teams.

\section{Policy Recommendations}

The NRCLD (2007) noted that

any proposed identification tool, process, or model will likely fall short of the goal of improved SLD identification if the problem is only or primarily viewed as a problem requiring better tools .... the issues involve the decisions regarding the provision of services to students. (p. 10)

They suggested that improvement in school-based SLD identification could only be achieved by adjusting the definition of IDEA held by stakeholders, as well as making changes to the way evaluation team members viewed their school cultures, roles and values during the SLD determination process. However, because what goes on in schools is influenced by legislation, there are also policy changes can positively influence the actions of student evaluation teams.

\section{IDEA Definition}

The NRCLD (2007) stated that how schools interpret the 2004 legal definition of SLD, which also involves whether or not the school and district in question implement an RTI or PSW approach in assessing students, is an important element of SLD identification. Is the student's learning difficulty seen as something that can be remediated with small group instruction, something that is intrinsic to the child, or both? In the district under study for this investigation, special education administrators announced in November 2014 (after this study was completed) that the district would 
only use PSW for identification of SLD at all levels; RTI would be used only in the prereferral process. This may be a good change for this particular district and may clear up confusion among practitioners; however, there continues to be confusion throughout the state when each district chooses their own SLD identification model, and when students arrive in one district with active SLD eligibilities. In this study, participants also expressed concern when students were identified under one SLD model and then reevaluated under another. Policymakers may want to consider making a statewide decision on which eligibility model to implement, or adopt one that could be implemented nationally to make decision-making more consistent.

In June 2015, the Oregon Senate passed Senate Bill 612, which requires every K-5 school to train a minimum of one teacher to identify and provide remedial instruction for students with dyslexia, and that the Oregon Department of Education will have a dyslexia specialist on staff to oversee the implementation of this law throughout the state's school districts. Oregon House Bill 2412 further states that this training needs to be consistent with the recommendation of organizations that focus on preparing teachers for students with dyslexia. While this is a positive change and demonstrates the spirit of RTI by identifying students who need reading instruction early in their education, as well as expanding research-based instructional practices, it does not change the fact that every district chooses their own SLD identification model to use when qualifying students for special education. Practices for students with dyslexia may become more standardized across districts based on this new legislation, but unless there is a statewide or national 
format for a single SLD evaluation model, inconsistencies between districts will continue to be a challenge for practitioners in the schools.

\section{School Culture}

The NRCLD (2007) explained that school culture affects whether innovations were either encouraged or suppressed within the local school. In this study, most participants seemed to support early intervention as a philosophy and liked the idea that students could receive help without a special education eligibility. It may be that as general education implements interventions to improve student achievement, such as the co-taught remedial classes mentioned by participants in this study, there is less a sense that those are "my students" before special education identification and "your students" after special education identification and placement. Participants reported that there was a wide range of skill levels among teachers attempting to implement pre-referral accommodations, and that once a student became eligible, teachers did not always use the information from the testing to adjust or refine their classroom instruction and accommodations.

New legislation has established a new organization that might provide more opportunities for teachers to learn the art of curriculum accommodation. Oregon Senate Bill 612, as well as establishing training programs for teachers that focus on effective instruction for students with dyslexia, also established the Network of Quality Teaching and Learning, which is supposed to promote a culture of "collaboration and collective responsibility." The legislature will allocate funds to higher education in order to better strengthen teacher education programs. As part of these programs, teacher pre-service 
programs and professional development opportunities and courses should include instruction on how teachers can provide accommodations and modifications for students with disabilities in their least restrictive environment. University professors, administrators, and special education teachers should collaborate in order to provide good instruction to general education teachers so that they have the knowledge and the skills they need. Within the elementary schools, the new dyslexia specialists can help educators understand how dyslexia and other learning disabilities affect every aspect of a child's schooling and how to accommodate those needs; however, because Senate Bill 612 does not provide for dyslexia specialists at the middle or high school level, this responsibility may need to be addressed by other district or university personnel.

\section{Roles and Values}

The NRCLD (2007) said that to affect changes in SLD identification, changes needed to be made in how individual educators viewed their roles during the SLD determination process and the values they hold during decision-making. One participant in this study, with more than 20 years of experience, discussed that sometimes her colleagues said that the student needed "help," and she would argue that special education is only for students with disabilities, not just those who need help.

Honest and open discussions need to happen among special education teachers and other evaluation team members about the purpose of special education and their roles as gatekeepers to services. Do team members see themselves as enforcers of district SLD guidelines, or do they see themselves as being caring practitioners able to bend the criteria in order to provide perceived benefits to students? As described by one first year 
teacher in this study, "If the student needs it, make it fit." Do team members hold a bias that special education is beneficial for all students? One participant in this study said, "I think we really try to work to find kids eligible." Six out of 10 special education teachers interviewed for this study had used team override when student data did not meet SLD district guidelines as a way to provide special education services. If special education is perceived as the only way struggling students can get help, it becomes the automatic answer to every question. Both building and district leaders should work to develop ways to increase capacity for helping students (i.e., intervention classes, homework club, a student study team that attempts to help individual teachers before a student is referred). Policy-makers could work to fund these attempts so that special education dollars are spent on the students who truly have disabilities and not on those whose needs could be met within a more expansive, enriched general education curriculum.

Once teams have discussed these issues honestly and openly and identified their underlying assumptions about their role in the process, SLD identification can and should improve. These discussions could be led and facilitated by an administrator knowledgeable about SLD identification models and practices. There could also be education for the whole staff about SLD identification processes. At the time of data collection for this study, not all resource teachers had received formal training in the PSW model; beginning in spring 2015, the district under study is now training all resource staff in this model. The district also has learning teams, where staff members meet twice a month and attempt to work towards educational reforms at a local level. This may provide a good avenue for resource teachers and other evaluation team 
members to share case studies of SLD determination and talk about their decision-making process in an attempt to examine past practice and reform current practice.

\section{Limitations to Study}

There are several limitations to this study. First of all, the sample size was small (10 participants), thereby limiting generalization. The fact that participation was voluntary (self-selection) may have meant that those teachers who sent back the informed consent may have been more interested in the topic of SLD identification than the average teacher. Because of this, my participants may have had more professional experiences to discuss or have been more likely to reflect on the SLD eligibility process than the average resource teacher. There were only six schools (three middle and three high schools) represented by these 10 teachers, and so their observations are limited to events occurring at those particular schools. Two of the participants had worked directly with the researcher before, and one other participant had worked in the same school concurrently with the researcher, but not in a similar position. The fact that the researcher was known as a district employee and peer may have influenced the comfort level of the participants as they spoke about their experiences.

Another limitation is that this study was restricted to reflections given by participants who regularly determined SLD eligibility. Due to privacy laws, I was not permitted to review actual SLD paperwork or observe actual eligibility meetings, which would have revealed how closely participants were adhering to district SLD guidelines. When discussing their experiences, participants may have forgotten information related to particular cases. 
The last limitation is that during this study, the participating school district used two different models - PSW and RTI - to determine SLD eligibility, and at the time of the interviews, not all participants had received thorough training. Since that time, the district has adopted only PSW as the model of choice and all teachers have received this information as part of an annual mandated training in the spring of 2015. Because the interviews were conducted at a point in time when both eligibility models were in use (although RTI was primarily being used in elementary schools), and because some teachers had not received training, all participants did not have the same level of background knowledge while answering questions.

\section{Future Research}

Future research should address the theory of competing paradigms. The study, using the same interview questions, could be repeated with different participants in a different school district to see if teams favor one paradigm over another, or whether their answers support the theory, or whether additional themes emerge. The study could be repeated in a few years within the same school district to see whether the PSW model, which has more of an emphasis on acceptability due to cognitive and academic scores, led to changes in participant responses. The study could also be repeated in a district that practices only the RTI model; findings could be compared to the current study to see if the model used in a particular district influences participant responses and how they view the SLD identification process. In addition, if a survey was used to gather information about whether teachers noted evidence of the three paradigms, it would increase generalizability by increasing the sample size of participants. 
Further studies should also focus on attempting changes in one part of the NRCLD framework (IDEA definitions, school culture, values, and roles) and conducting follow-up interviews to see whether district resource teachers noted better SLD identification practices. By encouraging open dialogue about the roles and values of team members, educational leaders may be able to make the SLD identification process less "haphazard and capricious" (Shinn, 2007, p. 603) and more of a unification between scientific application of knowledge about learning disabilities and compassion for struggling students. In a better system, SLD identification would not be either "science" or "service" — it would be both. 


\section{REFERENCES}

Algozzine, B., \& Ysseldyke, J. (1983). Learning disabilities: The oversophistication of a concept. Exceptional Children, 50(3), 242-246.

Barnes, A., \& Harlacher, J. (2008). Clearing the confusion: Response to intervention as a set of principles. Education and Treatment of Children, 31(3), 417-431.

Bateman, B. (2005). The play's the thing. Learning Disability Quarterly, 28(2), 93-95.

Bender, W., \& Shores, C. (2007). Response to intervention: A practical guide for every teacher. Thousand Oaks, CA: Corwin.

Berninger, V., \& Holdnack, J. (2008). Nature-nurture perspectives in diagnosing and treating learning disabilities: Responses to questions begging answers that see the forest and the trees. In E. Fletcher Jantzen \& C. Reynolds (Eds.), Neuropsychological perspectives on learning disabilities in the era of RTI: Recommendations for diagnosis and intervention (pp. 66-81). Hoboken, NJ: John Wiley \& Sons.

Bocian, K., Beebe, M., MacMillan, D., \& Gresham, F. (1999). Competing paradigms in learning disabilities classification by schools and the variations in the meaning of discrepant achievement. Learning Disabilities Research and Practice, 14(1), $1-14$.

Burns, M. (2008). Response to intervention at the secondary level. Principal Leadership (Middle School Edition), 8(7), 12-15.

Canter, A., Klotz, M., \& Cowan, K. (2008). Response to intervention: The future for secondary schools. Principal Leadership, 8(6), 12-15.

Christenson, S. (1980). Decision-making in a suburban school: Atypical examples of the process. In J. Ysseldyke \& M. Thurlow (Eds.), The special education assessment and decision making process: Seven case studies (pp. 69-99). Minneapolis, MN: Minnesota University, Institute for Research on Learning Disabilities.

Creswell, J. (2008). Educational research: Planning, conducting and evaluating quantitative and qualitative research. Upper Saddle River, NJ: Pearson Educational Group.

Deno, S. (2006). Developments in curriculum-based measurement. In B. Cook \& B. Schirmer, (Eds.), What is special about special education? Examining the role of research-based practices (pp. 100-112). Austin, TX: Pro-Ed. 
Education for All Handicapped Children Act of 1975 (1975). 20 U.S.C. 1401 et. seq. Retrieved from www.gpo.gov

Epps, S, Ysseldyke, J., \& McGue, M. (1984). "I know one when I see one: Differentiating LD and non-LD students. Learning Disability Quarterly, 7(1), 89-101.

Ferri, B., Gallagher, D., \& Connor, D. (2011). Pluralizing methodologies in the field of LD: From "what works" to "what matters." Learning Disability Quarterly, 34(3), 222-231.

Flanagan, D., Alfonso, V., Mascolo, J., \& Sotelo-Dynega, M. (2012). Use of ability tests in the identification of specific learning disabilities within the context of an operational definition. In D. Flanagan \& P. Harrison (Eds.), Contemporary intellectual assessment: Theories, tests and issues ( $3^{\text {rd }}$ ed.; pp. 643-669). New York, NY: Guilford.

Flanagan, D., Fiorello, C., \& Ortiz, S. (2010). Enhancing practice through application of Cattell-Horn-Carroll theory and research: A "third method" approach to specific learning disability identification. Psychology in the Schools, 47(7), 739-760.

Flanagan, D., Ortiz, S., Alfonso, V, \& Dynda, A. (2006). Integration of response to intervention and norm-referenced tests in learning disability identification: Learning from the Tower of Babel. Psychology in the Schools, 43(7), 807-825.

Fletcher, J., Morris, R., \& Lyon, G. R. (2003). Learning disabilities: An integrative perspective. In H. Lee Swanson, K. Harris, \& S. Graham (Eds.), Handbook of Learning Disabilities (pp. 30-56). New York, NY: Guilford.

Fuchs, L. (2003). Assessing intervention responsiveness: Conceptual and technical issues. Learning Disabilities Research and Practice, 18(3), 172-186.

Fuchs, D., Fuchs, L., \& Stecker, P. (2010). The "blurring" of special education in a new continuum of general education placement and services. Exceptional Children, 76(3), 301-329.

Glaser, B., \& Strauss, A. (1967). The discovery of grounded theory: Strategies for qualitative research. Chicago, IL: Aldine.

Glover, T. (2010). Key RTI service delivery programs: Considerations for researchinformed practice. In T. Glover \& S. Vaughn (Eds.), The promise of response to intervention: Evaluating current science and practice (pp. 8-22). New York, NY: Guilford. 
Gresham, F., MacMillan, D., \& Bocian, K. (1998). Agreement between school study team decisions and authoritative definitions in classification of students at-risk for mild disabilities. School Psychology Quarterly, 13(3), 181-191.

Hallahan, D., Lloyd, J., Kauffman, J., Weiss, M., \& Martinez, E. (2005). Learning disabilities: Foundations, characteristics, and effective teaching $\left(3^{\mathrm{rd}} \mathrm{ed}\right.$.). Boston, MA: Pearson Education.

Hughes, C., \& Dexter, D. (2013). The use of RTI to identify students with learning disabilities: A review of the research. Retrieved on January 27, 2013, from www.rtinetwork.org/learn/research/use-rti-identify-students-with-learningdisabilities-research-review

Ikeda, M., Rahn-Blakeslee, A., Niebling, B., Gustafson, J., Allison, R., \& Stumme, J. (2009). The Heartland area educational agency 11 problem solving approach: An overview and lessons learned. In S. Jimerson, M. Burns, \& A. VanDerHeyden (Eds.), Handbook of response to intervention: The science and practice of intervention (pp. 255-268). New York, NY: Springer.

Individuals with Disabilities Education Improvement Act of 2004, H.R. 1350, S. 614 (2004). Retrieved from http://thomas.loc.gov.cgi-bin

Individuals with Disabilities Education Improvement Act of 2004, Final Regulation, 34 Fed. Reg. 300.309 (2006). Retrieved from http://idea.ed.gov

Jenkins, J., Hudson, R., \& Johnson, E. (2007). Screening for at-risk readers in a response to intervention framework. School Psychology Review, 36(4), 582-600. Retrieved from http://web.b.ebscohost.com.proxy.lib.pdx.edu/ehost/pdfviewfinder?sid= 0e74463-5cf3-47ed-98c9-7d708e5e25505\%40sessionmgr11\&hid+ 129

Johnson, E., Mellard, D., \& Byrd, S. (2006). Challenges with SLD identification: What is the SLD problem? Teaching Exceptional Children Plus, 3(1), Article 3.

Johnson, E., \& Smith, L. (2008). Implementation of response to intervention and middle school: Challenges and benefits. Teaching Exceptional Children, 40(3), 46-52. Retrieved from http://tcx.sagepub.com/proxy/lib.pdx.edu/content/40/3/46.full.pdf

Kavale, K. (2001, August 27-28). Discrepancy models in the identification of learning disability: Executive summary. Paper presented at the Learning Disabilities Summit: Building a foundation for the future, Washington, DC.

Kavale, K., Forness, S., MacMillan, D., \& Gresham, F. (1998). The politics of learning disabilities: A rejoinder. Learning Disability Quarterly, 21(4), 306-317. 
Kavale, K., Kauffman, J., Bachmeier, R., \& LeFever, G. (2008). Response to intervention: Separating the rhetoric or self-congratulation from the reality of specific learning disability identification. Learning Disability Quarterly, 31(3), $135-150$.

Kavale, K., Spaulding, L., \& Beam, A. (2009). A time to define: Making the specific learning disability definition prescribe specific learning disability. Learning Disability Quarterly, 32, 39-48.

Kovaleski, J., \& Black, L. (2010). Multi-tier service delivery: Current status and future directions. In T. Glover \& S. Vaughn, Eds., The promise of response to intervention: Evaluating current science and practice (pp. 23-56). New York, NY: Guilford.

Kowalski, T. (2009). Evidence and decision-making. In T. Kowalski \& T. Lasley III (Eds.), Handbook of data-based decision making in education (pp. 1-17). New York, NY: Routledge.

Kvale, S., \& Brinkmann, S. (2009). InterViews: learning the craft of qualitative research interviewing. Thousand Oaks, CA: Sage.

Lee, T. (1999). Using qualitative methods in organizational research. Thousand Oaks, CA: Sage.

Lezotte, L. (2005). More effective schools: Professional learning communities in action. In R. DuFour, R. Eaker, \& R. DuFour (Eds.), On common ground: The power of professional learning communities (pp. 177-191). Bloomington, IN: Solution.

Lincoln, Y., \& Guba, E. (1985). Naturalistic inquiry. Newbury Park, CA: Sage.

MacMillan, D., Gresham, F., \& Bocian, K. (1998). Discrepancy between definitions of learning disabilities and school practices: An empirical investigation. Journal of Learning Disabilities, 31(4), 314-326.

MacMillan, D., \& Siperstein, G. (2001, August 27-28). Learning disabilities as operationalized by schools. Executive summary. Paper presented at the Learning Disabilities Summit: Building a Foundation for the Future, Washington, DC. Retrieved from http://www.air.org./ldsummit/

Marshall, C., \& Rossman, G. (1995). Designing qualitative research. Thousand Oaks, CA: Sage.

Maykut, P., \& Moorehouse, R. (1994). Beginning qualitative research: A philosophic and practical guide. London, England: Falmer. 
McKenzie, R. (2009). Obscuring vital distinctions: The oversimplification of learning disabilities within RTI. Learning Disability Quarterly, 32(4), 203-213.

Mellard, D., Deshler, D., \& Barth, A. (2004). LD identification: It's not simply a matter of building a better mousetrap. Learning Disability Quarterly, 27, 229-242.

Merrell, K., \& Buchanan, R. (2006). Intervention selection in school-based practice: Using public health models to enhance systems capacity of schools. School Psychology Review, 35(2), 167-180.

Miles, M., \& Huberman, A. (1994). Qualitative data analysis: An expanded sourcebook ( $2^{\text {nd }}$ ed.). Thousand Oaks, CA: Sage.

Mirkin, P. (1980). Conclusions. In J. Ysseldyke \& M. Thurlow (Eds.), The special education assessment and decision making process: Seven case studies (pp. 100113). Minneapolis, MN: Minnesota University, Institute for Research on Learning Disabilities.

Mitchell, J., \& Poland, S. (1980). Decision making in an urban school: Two examples reflecting degrees of complexity in the process. In J. Ysseldyke \& M. Thurlow (Eds.), The special education assessment and decision making process: Seven case studies (pp. 20-50). Minneapolis, MN: Minnesota University, Institute for Research on Learning Disabilities.

National Research Center for Learning Disabilities. (2007). SLD identification overview: General information and tools to get started [Brochure]. Lawrence, KS: Author. Retrieved January 27, 2013, from www.nrcld.org

No Child Left Behind Act of 2001, 20 U.S.C. S. 6319 (2002).

Olson, D. (2003). Psychological theory and educational reform: How school remakes mind and society. New York, NY: Cambridge University Press.

Oregon Senate Bill $612,78^{\text {th }}$ Oregon Legislative Assembly—2015 regular session (2015). Downloaded from www.ois.leg.state.or.us./us/112/OISRI/Downloads/ MeasureDocument/SB612

Oregon House Bill 2412, $78^{\text {th }}$ Oregon Legislative Assembly-2015 regular session (2015). Downloaded from www.ois.leg.state.or.us/liz/2015R1/Measures/ Overview/HB2412

O’Shaughnessy, T., Lane, K. Gresham, F., \& Beebe-Frankenberger, M. (2003). Children placed at risk for learning and behavioral difficulties: Implementing a systemwide system for early identification and intervention. Remedial and Special Education, 24(1), 27-35. Retrieved from http://rse.sagepub.com.proxy.lib.pdx. edu/content/24/1/27.full.pdf + html 
Peterson, K. H., \& Shinn, M. (2002). Severe discrepancy models: Which best explains school identification practices for learning disabilities? School Psychology Review, 31(4), 459-476.

Raths, J., Kotch, S., \& Carrino-Gorowara, C. (2009). Research on teachers using data to make decisions. In T. Kowalski \& T. Lashley III (Eds.), Handbook of data-based decision making in education (pp. 207-221). New York, NY: Routledge.

Reschly, D. (2005). Learning disabilities identification: Primary intervention, secondary intervention, and then what? Journal of Learning Disabilities, 38(6), 510-515.

Reschly, D., \& Hosp, J. (2004). State SLD identification policies and practices. Learning Disability Quarterly, 27, 197-213.

Reschly, D., \& Ysseldyke, J. (2002). Paradigm shift: The past is not the future. In A. Thomas \& J. Grimes (Eds.), Best practices in school psychology IV (pp. 3-20). Bethesda, MD: National Association of School Psychologists.

Reynolds, C., \& Shaywitz, S. (2009). Response to intervention: Ready or not? Or, from wait-to-fail to watch-them-fail. School Psychology Quarterly, 24(2), 130-145.

Richey, L., \& Graden, J. (1980). The special education team process: To what extent is it data based? In J. Ysseldyke, B. Algozzine, \& M. Thurlow (Eds.), A naturalistic investigation of special education team meetings (pp. 46-53). Minneapolis, MN: Minnesota University, Minneapolis Institute for Research on Learning

Rostollon, D. (1980). Domains of data discussed at special education team meetings. In J. Ysseldyke, B. Algozzine, \& M. Thurlow (Eds.), A naturalistic investigation of special education team meetings (pp. 35-43). Minneapolis, MN: Minnesota University, Minneapolis Institute for Research on Learning Disabilities.

Rumrill, P., Cook, B., \& Wiley, A. (2011). Quantitative designs. In P. Rumrill, B., Cook, \& A. Wiley (Eds.), Research in special education: Designs, methods, and applications ( $2^{\text {nd }}$ ed.; pp. 118-152). Springfield, IL: Charles C. Thomas.

Samuels, C. (2009, January 28). High schools try out RTI. Education Week, 28(19), 20-22.

Schneider, J., \& McGrew, K. (2012). The Cattell-Horn-Carroll model of intelligence. In D. Flanagan \& P. Harrison (Eds.), Contemporary intellectual assessment: Theories, tests and issues ( $3^{\text {rd }}$ ed.; pp. 99-144). New York, NY: Guilford.

Scruggs, T., \& Mastropieri, M. (2002). On babies and bathwater: Addressing the problems of identification of learning disabilities. Learning Disabilities Quarterly, 25(3), 155-168. 
Shinn, M. (2007). Identifying students at risk, monitoring performance, and determining eligibility within response to intervention: Research on educational need and benefit from academic intervention. School Psychology Review, 36(4), 601-617.

Stewart, R., Benner, G., Martella, R., \& Marchand-Martella, N. (2007). Three-tier models of reading and behavior: A research review. Journal of Positive Behavior Interventions, 9, 239-253. Retrieved from http://pbi.sagepub.com.proxy.lib.pdx. edu/ content/9/4/239. short

Sugai, G., \& Horner, R. (2008). What we know and need to know about preventing problem behavior in schools. Exceptionality, 16, 67-77.

U.S. Department of Education, Office of Special Education Programs. (1995). Letter to Lillie/Felton. Retrieved September 17, 2015, from Rebecca.Walawender@ed.gov

Vaughn, S., \& Fuchs, L. (2006). A response to “competing views': A dialogue on response to intervention: Why response to intervention is necessary but not sufficient for identifying students with learning disabilities. Assessment for Effective Intervention, 32(1), 58-61.

Ysseldyke, J., \& Algozzine, B. (1982). Bias among professionals who erroneously declare students eligible for special services. Journal of Experimental Education, 50(4), 223-228.

Ysseldyke, J., \& Algozzine, B. (1983). LD or not LD: That's not the question! Journal of Learning Disabilities, 16(1), 29-31.

Ysseldyke, J., Algozzine, B., \& Epps, S. (1982). A logical and empirical analysis of current practices in classifying students as handicapped. Minneapolis, MN: University of Minnesota, Institute for Research on Learning Disabilities.

Ysseldyke, J., Algozzine, B., Shinn, M., \& McGue, M. (1982). Similarities and differences between low achievers and student classified learning disabled. The Journal of Special Education, 16, 73-85.

Ysseldyke, J., \& Thurlow, M. (1980). The special education assessment and decisionmaking process: Seven case studies. Minneapolis, MN: University of Minnesota, Minneapolis Institute for Research on Learning Disabilities. (ERIC Document Reproduction Service No. ED203589) 
APPENDIX A

LIST OF INTERVIEW QUESTIONS FROM PILOT STUDY 
List of Interview Questions from Pilot Study

1. How long have you been teaching special education?

2. Can you tell me about your university preparation for assessing students with SLD?

3. How long have you been teaching in the district?

4. What differences should eligibility teams consider when distinguishing between students with SLD and other students who struggle with academic skills?

5. Researchers have discussed that sometimes students may have standardized cognitive and academic testing that shows a need for special education services, but a review of their performance in relation to grade level peers does not show a need for service. Alternatively, sometimes a student is struggling in the classroom, yet they do not meet district criteria for SLD given their performance on standardized cognitive and academic tests.

a. Do you think local norms (e.g., proficiency data, curriculum-based measures) or standardized test norms are valued more as part of decisionmaking, and why?

b. During the 2012-13 school year, did your team encounter evaluations where the data yielded "competing recommendations" for eligibility (meaning that either classroom performance was good, but standardized testing was not, or vice versa?) If so, how did your team resolve this contradiction and was that particular student (not using names) qualified as SLD?

6. Without using the names of particular students, think about any cases where the team did not qualify the student as SLD. What were the reasons for not qualifying them?

7. In your school, what were the resources available for struggling students during the 2012-13 school year, and how did students receive these supports? (e.g., identification for an intervention math or reading class, tutoring programs, homework club)

8. Have you ever participated on a team that engaged in "team override," meaning that the student's scores did not support SLD given the district model, but that the team qualified them as SLD anyway? What were the reason the team gave for qualifying that child? 
9. Most of what we know about SLD identification comes from research with elementary age students. What are your thoughts about the process of identifying students at the secondary level?

10. If you started participating on student evaluation teams before the PSW and RTI models were implemented, what do you think about the new processes?

a. (Follow up): Do teachers, parents or students obtain a benefit through the model used to determine eligibility?

b. (Follow up): What are the difficulties with implementation of these models? 
APPENDIX B

FINAL INTERVIEW QUESTIONS FOR STUDY 
Final Interview Questions for Study

1. How long have you been teaching special education?

2. Can you tell me about your preparation for assessing students with SLD both a) university preparation and $\mathrm{b}$ ) district in-service preparation?

3. How long have you been teaching in the district?

4. What differences should eligibility teams consider when distinguishing between students with SLD and other students who struggle with academic skills and do not qualify for special education? (addresses participants' understanding of acceptability)

5. Researchers have noted that the decision to refer a student for testing for a specific learning disability can be "tempered by socio-cultural and contextual factors." Do you agree with that observation and, if so, what in your experience are some of the "socio-cultural and contextual factors," other than the learning problem itself, that can influence a teacher to refer a student for testing? (assesses understanding of relativity)

6. Standardized academic tests are frequently given as part of the evaluation or reevaluation for SLD. What information do you get from these tests that helps you to identify learning disabilities? (addresses acceptability)

7. Sometimes standardized cognitive and academic testing shows a need for special education services, but a review of performance in relation to grade level peers does not show a need for service. Alternatively, sometimes a student is struggling in the classroom, yet they do not meet district criteria for SLD given their performance on standardized cognitive and academic tests.

a. Do you think local norms (e.g., proficiency data, curriculum-based measures) or standardized norms are valued more as part of decisionmaking, and why? (addresses participants' understanding of relativity and acceptability)

b. Has your team encountered evaluations where the data yielded "competing recommendations" for eligibility (meaning that either classroom performance was good, but standardized testing was not, or vice versa?) If so, how did your team resolve this contradiction and was that particular student (not using names) qualified as SLD? (addresses participants' understanding of profitability) 
8. Without using the names of particular students, think about any cases where the team did not qualify the student as SLD. What were the reasons for not qualifying them? (addresses participants' understanding of profitability)

9. What unique services does a student get when they are identified for special education as opposed to students who struggle but do not qualify for special education services? (addresses profitability)

10. What sorts of interventions do you see teachers trying before a student is referred for an initial SLD evaluation? (addresses relativity)

11. How do teams make the decision that a student has a specific learning disability when the students' native language is not English? (addresses relativity and acceptability)

12. Have you ever participated on a team that engaged in "team override," meaning that the student's scores did not support SLD given the district model, but that the team qualified them as SLD anyway? What were the reason the team gave for qualifying that child? (addresses participants' understanding of profitability)

13. If you started participating on student evaluation teams before the PSW and RTI models were implemented, what do you think about the new processes? (addresses participants' understanding of policy)

a. (Follow up): Do teachers, parents or students obtain a benefit through the model used to determine eligibility?

b. (Follow up): What are the difficulties with implementation of these models? 


\section{APPENDIX C}

SAMPLE TRANSCRIPT 
Transcript \#2/Participant \#2

File C-4

Tuesday, July 8, 2014

HB: Let's see . . okay. Participant number two. Uh, July 8, 2014. Um . . . how long have you been teaching special education?

\#2: Well, I have a-my career has some starts and stops. So I started teaching in, 1982, I think it was. But I haven't taught every year since then.

HB: Okay. So, overall, how many years would you say, like, if you added it up?

\#2: I probably have over 15 years, but then I worked many years in half-time positions, so how do you want to count that?

HB: Okay. Can you tell me about your preparation for assessing students with SLD, both university preparation and district in-service preparation?

\#2: Well . . . that's a long time since (laughs) I was in university, um, preparing to teach special education. Of course, you take a class, a methods class of how to, um, administer tests and you know, that consisted of practicing giving the tests and, uh, taking very specific courses that teach you very specific tests, like the Woodcock Johnson, and, I gave some-I gave IQ tests, I remember I did the Stanford-Binet, and the WISC. I wasn't specifically, you know, training for that. That was just included. And then the other, uh, tests that test academic achievement. Because they-in the old days it was, uh, IQ and achievement levels. So is your IQ - is your academic achievement commensurate with your tested ability.

HB: Okay.

\#2: And that model (name of district) used for years and years and years, and they've just changed it within the past—what?-five years?

HB: So would you say then that most of your university preparation was in test administration?

\#2: For-you mean for-determining whether someone has a, uh, learning disability?

HB: Right.

\#2: Um . . y yeah. I'd say so. And it wasn't just - it was a variety of tests, and working, um, with a team. There's always been a team.

HB: Okay. 
\#2: I think in fact, I developed the first child study team in (names a different district) Elementary district, working with a psychologist and, um, an SLP and, I mean, so it's always a team decision. Teachers kind of came to the team with concerns and then we decided to administer district tests, and what tests to administer and then contacting the parents and...

HB: Okay. What would you say about your district in-service preparation, as far as assessing students with SLD?

\#2: Um, you mean when I first started, or now?

HB: Um ... maybe all the way through.

\#2: Okay. Well, when I first started my first job, I had a-uh, the administrator who was in charge of special education in the (names a different district) Elementary District worked closely with me and, um, you know-had-we had meetings. I think we had monthly meetings and as a group, all the resource teachers and talked about different issues. And then of course you had the guidance of working with a psychologist and a speech language pathologist and, you know, it's different things became, uh, I want to say popular, but that's not right . . . became more, well, recognized, and as a tool to use to identify kids, um, oh, we used the Slingerland, we used the BADS, the BILL, oral digit span, have you ever used that?

HB: Uh-uh.

\#2: Where the kids say numbers backwards to you, I think I still use it sometimes. And then reading inventories and things, observations.

HB: Okay.

\#2: Um . . . and then I remember, years ago, for the SLP's pragmatics became a big thing. So we started looking at pragmatics. And you know, we didn't really - um . . . say, this kid is - we think this student who is having learning problems is learning disabled. We just looked at them as a team of - and investigated certain things. Does that make-it wasn't that we decided, oh, we're going to test and see if this kid is learning disabled, so we're going to look at a lot of different things.

HB: Okay. And then you went from there?

\#2: Right.

HB: Okay. Um, what about current district in-service preparation?

\#2: Um ... I-I think that we've had some in-service on this. We don't really meet regularly. And the in-services we do have seem to be more with filling paperwork out correctly, or making - making the paperwork all tie up together. And I don't think we 
have a lot of problems or a lot of in-service on how to fill out the eligibility paperwork, it's more, uh, carrying out the program.

HB: Okay.

\#2: Isn't it? Because every year we have the one in-service- the SPR\&I-

HB: Okay. So what you're saying is more of it is compliance things?

\#2: Yes. And that's the only mandatory in-service we have, isn't it? Yeah.

HB: Okay.

\#2: And then, in the fall, we have a meeting, usually, and we talk about filling in paperwork. And - it's more being in compliance, like you said.

HB: Okay.

\#2: But we have had some in-service on looking at a model of strengths and weaknesses. And we do have some handouts on that. And, um, I've worked with different psychologists trying to interpret what we're supposed to do, how we're supposed to determine that. Um, and I've talked endlessly with other resource teachers about how to do that.

HB: Okay. So it sounds like some of it is - has been - in school, like, more in the actual school building rather than at the district level?

\#2: Right. I don't see that we get a lot of — but perhaps the - perhaps what they've done and actually, I think this is what they've done - they've trained the psychologists, the school psychs, and then the information is supposed to filter down to us through the school psychs.

HB: Okay.

\#2: But I'm not—but like I said, the psychs have shared lots of ideas about it, and paperwork, and are very willing to discuss it, that I've seen. The psychologists I've worked with have been.

HB: Okay. How long have you been teaching in the district?

\#2: Well, um . . . I've been teaching six years since I came back from staying home with my kids for ten. And before that, let's see, I did a part-time year as work experience, I did about three or four part-time years at (name) High School, oh, and then a full-time year at (name of school). So, six years, then six years that I've been back. And then five years at the other school. 
HB: Okay.

\#2: And then three years where I took temporary jobs while my kids were little, so . .

HB: So if we counted the full time years, we would say twelve, and then probably-so what you said, about fifteen years.

\#2: Yeah.

HB: And it's all been in (name of district under study)?

\#2: Um, no. I worked in (names a different district).

HB: Okay.

\#2: For-for one year, a half time job, and then I worked in (names a different district) for probably seven years.

$\mathrm{HB}: \mathrm{Oh}-\mathrm{as}$ part of that?

\#2: Yes.

HB: So (names current district) might be six years?

\#2: For (names district under study) it's been twelve.

HB: Okay.

\#2: Close to twelve.

HB: Okay.

\#2: Anyway, I'm on the top end of the pay scale (laughs). However they've figured it out.

HB: All right, you know?

\#2: Bless them.

HB: So here comes another question.

\#2: Sorry, this is ...

HB: You're fine. What differences should eligibility teams consider when distinguishing between students with SLD and other students who struggle with academic skills but do not qualify for special education?

\#2: So what differences should they ... 
HB: What differences should eligibility teams consider when distinguishing between students with SLD and other students who struggle with academic skills and do not qualify for special education?

\#2: Well, I think ... what the eligibility teams are trying to do at this point is to, uh, look at IQ scores across different areas, like perceptual speed, and um, I'm trying to think of some others .... oh, visual skills, oral skills, they divide things up, I can't remember exactly what all the categories are. And so you're looking for a pattern of one area being - two areas being strong, and some other areas being weak. I think it's at least two areas have to be strong.

HB: Okay.

\#2: And I think a strength is, like, 87 , standard score and above. So it doesn't have to be a very big strength.

HB: Okay.

\#2: I think.

HB: Okay.

\#2: Actually, I think maybe 88 is what it is.

HB: Okay.

\#2: And, um, and then the - the difference would be is that students who are not learning disabled would be kids who had flat scores.

HB: Okay.

\#2: Well, maybe - maybe they would even have pretty high scores.

HB: Okay.

\#2: And were flat across the board. So it wasn't—it's not a learning disability that's keeping them from learning.

HB: Okay.

\#2: So it could be something else. It could be attention deficit, or it could be an emotional problem. Or it could be they don't attend school, you know?

HB: So would you say basically the difference is the IQ scores and the pattern of strengths and weaknesses? Would that be - sort of what distinguishes between- 
\#2: Those IQ scores, those weaknesses in IQ score have to correspond to weaknesses in specific academic achievement areas.

HB: Okay.

\#2: So the psychologist, um, gives the IQ score and you have the different areas and if they_-if a student has a weakness in one area the psychologist can say, um, well, a weakness in this area on the IQ score corresponds with a weakness this student has in math, or a weakness the student has in reading. So what's happened is because the brain shows a weakness in that area, that's why they can't learn how to do math.

HB: Okay. Um ...

\#2: Okay. (laughs)

HB: So researchers have noted that that the decision to refer a student for testing for specific learning disability can be "tempered by socio-cultural and contextual factors." Do you agree with that observation, and if so, what in your experience are some of the socio-cultural and contextual factors, other than the learning problem itself, that can influence a teacher to refer a student for testing?

\#2: I think that - that, uh, one factor is how high-achieving the group is, the school is. So if a student, um, stands out as being below the norm of the kids in the school, they might be right on average nationally. I noticed this at (names school of employment).

HB: Okay.

\#2: Because most of the kids - many of the kids are real high-fliers. And so I think kids with, um, who don't really have-who might not be referred at another school in the district - maybe wouldn't be referred at (names another district school) or wouldn't be referred at (names a second different school in the district).

HB: Okay.

\#2: That's one thing. I think another factor is - another factor is I think the kids who are, uh, bilingual get referred more often. And I think that cultural differences sometimes cause teachers to - to think that a student has a learning problem.

HB: Okay.

\#2: And another thing I see — and I'm not sure this fits into this category or not-is parents see an advantage in, um, a student being found eligible for special education because they get more time on tests and they get - other accommodations, so they request that their child be tested. But that's not necessarily for SLD.

HB: Okay. 
\#2: I think that works more for attention deficit.

HB: So it basically sounds like what you're saying is there's three reasons. What you're seeing-

\#2: Well, three that I can think of.

HB: And one might be how the student performs compared to their peers ....

\#2: Right.

HB: One is bilingualism, and one is parents that see an advantage.

\#2: And it's not just being bilingual. It's also cultural differences.

HB: Okay.

\#2: So we had a student at (names school of employment) who moved here from the Marshall Islands.

HB: Okay.

\#2: And, um, he had not been in school at all. So he came as a seventh grader. He had not been in school at all.

HB: Okay.

\#2: And there were several teachers at the school who were convinced that he was retarded.

HB: Okay.

\#2: And it was really - they gave him a nonverbal IQ test, and he was way above average in many ways. But it's just such a different that doesn't value - the vice principal would say, okay, it's time to get on your bus now, the bus is gonna leave. And he'd just run off and play. And she'd say, oh, he just doesn't - he knows, he's just retarded. I mean, and I say, well, on the Marshall Islands it's really not all that important to run for your bus.

HB: Right.

\#2: You wait for that door to close, and the brakes - and then you go running. I mean, that's a cultural difference. Anyway, we did not find him eligible for special education.

HB: Okay. Okay. So standardized academic tests are frequently given as part of the evaluation or re-evaluation for SLD.

\#2: Hmm-hmm. 
HB: What information do you get from these tests that help you to identify learning disabilities?

\#2: Well, I think you get-you solve some of the problems that we were just talking about. Uh, if a student is in a-with a group that, um, you know, high-achievers, then you see that compared nationally, compared with-compared nationally that they really are where they should be. Or they're not really behind - they're not really so far behind in their academic achievement that they are-um-considered disabled. They might have a weakness but they don't have a disability. Um, the other thing that you can find out islet's say that it's a - a cultural difference or a bilingual kid-you can see by using an achievement test that has been, used for other kids with the same cultural background you can see, oh, this student really is where he should be. He's not really disabled. Or, oh, wow, this kid does have a disability. He scores in a way that would suggest that he has a learning problem.

HB: Okay. So what we're saying is basically it clarifies if they're performing in the average range or not.

\#2: Right. Right.

HB: Okay.

\#2: I think it's a really good piece of information. I mean, certainly-you have alsowell, okay, you're talking about all standardized tests. Because you can use the state reading and math tests. You can use - and that's less valid than the individual achievement test. Because when you give an individual achievement test you have, uh, also taken away a lot of distractions. You've-you get a one on one testing situation, and uh, a student is you know-(unintelligible) can't fade into the woodwork and not participate. They have to respond. It's easier to keep someone's attention if they're in a small room with one person than in a large room with distractions and-so it gives you a more accurate picture, uh, of where the student is academically and also in comparison with lots of other people instead of the high-flying group they're with or the low-flying group they're with.

HB: Okay. So here's the next one.

\#2: Okay. Sorry. (laughs)

HB: No, you're fine.

\#2: Am I going on too much?

HB: No. You are fine.

\#2: All right. 
HB: Sometimes standardized cognitive and academic testing shows a need for special education services, but a review of performance in relation to grade level peers does not show a need for service. So, alternatively, sometimes a student is struggling in the classroom, yet they don't meet district criteria for SLD given their performance on standardized cognitive and academic tests. So - given that - do you think local norms, such as proficiency-based data, curriculum-based measures - or standardized norms are valued more as part of decision-making, and why?

\#2: Oh. Well. That's a really good ... question. I think that-you know, it's - there is a question of, is it that the student can't do it or the student won't do it, or are there other things that are happening in the student's life that interfere with them learning, not necessarily a learning disability, or - I mean — a specific learning disability, or asomething like attention deficit. It might not be any of those things. It might be things happening at home, or - or education isn't valued by - there could be lots of reasons why they don't want to write a perfect term paper.

HB: Okay.

\#2: Or they don't buy into the class. So, so if you have a standardized test, and it shows that the student is right on average in reading and math, but not participating in class, then you can say, well, does the student have emotional problems, or does the student have, um, attention-deficit problems. Are there any other things we need to look at?

HB: Okay. Okay. So let me see if I've got this right. So what you're saying is you think standardized testing is probably valued more as part of the decision-making for SLD?

\#2: Um . . . so . . . yes, I do. But it's not the only thing. I mean, we use a variety of things. We use work samples. We use observations for uh, classroom participation. We use, um, standardized tests. We look at health records. We look at, uh, attendance. We look at behavior. We look at all kinds of things.

HB: Okay.

\#2: So it's just one part of the puzzle.

HB: Okay. So ... has your team encountered evaluations where the data yielded competing recommendations for eligibility? What that means is that either the classroom performance was good, but standardized testing was not good, or vice versa?

\#2: Have I seen that?

HB: Yeah.

\#2: Um ... I have. Uh, well, I have students who are actually in my resource classes, who are - have attention deficit, let's say—who, um, on a standardized test, perform very well. They have passed the state standard reading and math, excel-exceeded in math. 
And they read like crazy. But they just can't put pencil to paper and write that little book report or whatever, you know, the gab log. I don't know, do you guys have gab logs?

HB: Okay.

\#2: Um . . . so, uh-

HB: So, in specific — since you've seen this — um, how did your team resolve that contradiction, and was that particular student, not using names, qualified as SLD?

\#2: Um, well, they weren't qualified - those are both attention deficit that I'm thinking of.

HB: Okay.

\#2: And, uh, most of the students who are like that - who have been found are attention deficit. And I did have a student this year whose-his parents wanted him to be, um, evaluated. But his grades - he'd never had a bad grade. He passed or exceeded the state standards in reading, and writing, and math. And the - you know - the - and we said we can look and see if he-we can probably find him attention deficit, because you say that you have - you say that he's been diagnosed as that — but we don't see any educational impact.

HB: Okay.

\#2: But that's not what you're asking. You're asking the opposite, aren't you?

HB: That is sort of what I'm asking. Have you seen that pattern and on a referral, you know, for a new referral for an evaluation, and did you qualify that student as SLD?

\#2: Um-

HB: Let's say_classroom performance is strong, standardized test scores are not.

\#2: Well, yeah, but this was-uh-

HB: It sounds like you're saying yes. But that it's more for attention deficit and not SLD.

\#2: I think that for SLD kids, uh, I think they pretty much have to do poorly on some academic measure.

HB: Okay.

\#2: Um, and part of that can be work samples from the classroom.

HB: Okay. 
\#2: But I think it's—it's gotta make—it's gotta have—it has to be a fuller picture.

HB: Okay.

\#2: I'm not sure. Let me see what the question says. Okay. Where the data yielded competing —yes, I think that - another way that we've resolved this is to given the student more time. Look at the student again.

HB: So you're saying sort of that you would meet and then make the student not eligible, but then give them more time after the evaluation, and then look at them again?

\#2: You see, I'm thinking of . . . before. Okay. I just thought of something else. I think if a student has already been found eligible that the - the, um, criteria for being re-eligible is not as strong as the first time. That if they still show a weakness then you continue toyou continue to give them service in math.

HB: Okay.

\#2: Um ... if it's an initial evaluation, on the secondary level, and the student is, you know, passed the Oregon state standardized tests for years in math, it's not likely that that student has a disability in math.

HB: Okay.

\#2: You see what I'm saying? Um, and ...

HB: You're saying that the standards might be tougher for initials?

\#2: I think so. I think they are.

HB: Okay.

\#2: Um. Yeah.

HB: So without using the names of particular students, think about any cases where the team did not qualify the student as SLD. What were the reasons for not qualifying them?

\#2: I think that—um—a really flat profile.

HB: Okay.

\#2: So consistently scoring an 80 standard score on the different parts of the IQ test.

HB: Okay.

\#2: But I think I-I would also say that oftentimes what happens is people come in, and um, call the student attention deficit after that, just to get them served. 
HB: Okay.

\#2: But I've never done that.

HB: Okay. But as far as not qualifying for SLD, it sounds like it's because of the flat profile.

\#2: Yes.

HB: That's mostly what you've seen. Okay.

\#2: I think that we really work to try and find kids eligible. We want to stay within the law, we try and stay within the rules, but we really-if a student is struggling, we really try to find them a way to give them the help they need.

HB: Okay.

\#2: Does that...I mean, as much as we can, working within the guidelines that we have. We have to fill in the paperwork, we have to answer the questions honestly. And I think that for the most part, I think that everybody tries to be as fair and appropriate as they possibly can.

HB: Okay.

\#2: - staying within the confines of the - the federal law and the state law.

HB: Okay. So what unique services does a student get when they are identified for special education, as opposed to students who struggle, but do not qualify for special education services?

\#2: Um...they, um, well, I mean, they have a written plan that corresponds to how they were identified. So if someone is eligible for, for reading, has a-a-disability in reading comprehension, that student gets a-small group instruction in reading comprehension.

HB: Okay. What sorts of intervention do you see teachers trying before a student is referred for an initial SLD evaluation?

\#2: Um . . . I-I think I see a-I see lots of different interventions that teachers use on, um, almost a classroom-wide basis. They break the classes into smaller groups and give a problem for that small group to solve. You know, each group gets their own, and go around and talk with the groups individually. I've seen that technique used in humanities classes, in math classes. Um, I think they use, uh, peer tutors a lot. I think they use, um, seating the student - preferential seating, or seating the student close to the teacher. Um, I think I've seen them use pretty simple behavior programs. The vice principal uses a card, you know, a behavior card where each teacher signs and says how the student did during 
the day and they turn it over to the vice principal. And I've seen kids who are resource students and kids who are regular ed students both do that.

HB: Okay. So it sounds like, um, so small group structure is one intervention\#2: Yeah.

HB: - preferential seating, behavior programs, and behavior cards.

\#2: Yes, and also general instructions.

HB: Okay.

\#2: Making sure he has that student's attention, writing instruction on the board-this is sort of for the whole class, directing that student's attention, making sure that the student is tuned in when you're giving directions-

HB: Okay. So we'll add written directions, directing students' attention, and getting student's attention.

\#2: Yeah.

HB: Okay. Um, how do teams make the decision that the student has a specific learning disability when the student's native language is not English?

\#2: Well, that makes it really tough. We have interpreters available. We have a-a psychologist who can test in Spanish, and many of the students who are referred to us who speak another language speak Spanish. So we can have a student tested in Spanish. Um, um, let's see ... oh, there are, yeah, did I say the non-verbal tests available?

HB: Okay.

\#2: There's a test of nonverbal intelligence that they use.

HB: So it basically sounds like that the differences are, that the psychologist can test in Spanish, and there are nonverbal tests of intelligence that are available.

\#2: Mmm-hmm.

HB: Okay. Anything else you can think of?

\#2: Okay. Yeah, I think they also-I think rely heavily on what the English as a second language teacher says, how the student looks compared to his peers.

HB: Okay. So that would be more like you talked about before, how they look compared to their group, the norm group that they have. 
\#2: That's pretty much — that's pretty much how we decide if kids are learning disabled or not. We just look at everybody compared to everybody else. That's the only way we can.

HB: Um . . . so . . last question.

\#2: Okay. Woo-hoo!

HB: Yeah. Have you ever participated on a team that engaged in team override, meaning that the student's scores did not support SLD given the district model, but that the team qualified them as SLD anyway?

\#2: I haven't, but I've certainly seen paperwork on kids who have been.

HB: Okay.

\#2: And you know what? I-I think it's more the kids who are attention deficit that this happens with.

HB: Okay. So it sounds like you haven't participated, but you've seen paperwork that looks like that, that the team may have decided-

\#2: Right.

HB: - and it seems like it's happening more with the attention-deficit kids, kids with attention issues. If you started participating on student evaluation teams before PSW and RTI models were implemented-

\#2: Yes-

HB: What do you think about the new processes?

\#2: Um, uh, I think that the - it would be nice if the RTI team, uh, the RTI teams I've worked with have not been a very efficient gatherer of data and information. Or there seems to be a lot of difficulty. It seems like they try to gather a lot of data, but it never seems to get passed on. Or it's not - they'll say, 'oh, yeah, we looked at the cum file', but there are no notes on the cum file. In second grade, didn't turn in one assignment (laughs). They didn't note - they said, we looked at that, but they don't — there's nothere are no notes on it, or-

HB: Uh-

\#2: It would be nice if they had a form to fill out on it. Attendance-no problems here, or .... they'll just leave it blank, or they just won't say anything about attendance.

HB: Hm-mm. 
\#2: I think there's great difficulty getting the information they gather passed on to the resource team.

HB: So it sounds like communication, possibly between RTI and the ...

\#2: Yes. But it's not-it seems to be friendly, and they invite the resource teachers to those meetings, but what happens is - the hard data that resource teachers need in order to complete an eligibility on a student doesn't seem to get passed on.

HB: Okay.

\#2: I think it's a great idea. I think it's a great way to, um, help teachers figure out ways to work with kids who are having troubles within their classes.

HB: Okay. Do you mean as far as RTI?

\#2: Yes. And as far as the pattern of strengths and weaknesses-um, well, I see a lot of similarities between the pattern of strengths and weaknesses and the-the-comparison between ability and achievement. There are certainly differences. But to me, it - it is completely appropriate.

HB: Okay. So it's basically_you're saying it's similar to how we did things with ability and achievement?

\#2: Yes. Because it - I mean, it is. It's comparing ability and achievement. It's not exactly the same, and it's a more complex, more interesting process, I think. But I didn't find it jarring to change.

HB: Okay. Okay. And then it sounded like RTI was more to help teachers referring-to help teachers with the kids who are struggling.

\#2: Yeah.

HB: Okay. So ... let's see ... do teachers, parents or students obtain a benefit from the model used to determine eligibility?

\#2: I think they do. I think that resource teachers, psychologists do a really good job of gathering information about a student. I think that - they have, uh, - I think it's really great that it's a team process, and it's not just one person. I think that, um, you know, having input from parents, from regular ed teachers - I think that it's a very solid process. And I think that all the professionals involved do a really good job of gathering and interpreting information and if they don't find the student - well, if they do find the student eligible, finding ways to, um, help that student develop coping strategies, or develop their skills, or whatever is appropriate. I think people do a really good job. Um, I think that, uh, when you evaluate a student, it's a very comprehensive process. We take 
hours, we take days. I mean, days of actual paperwork, of actually gathering data and analyzing it and writing it down and looking at it, and trying to figure it out.

HB: Okay. So would you say then the benefit is the information that's provided to the parents and then the services that are provided to the student?

\#2: Well, I think that — the information that is gathered is absolutely necessary for figuring out the education plan. I think that, um, that it gives - it's valuable for the parent to know, that yeah, not getting to school on time is harmful (laughs). I mean, it - this is not-I've heard parent after parent say, 'is it that many days?' and it, uh, when I say to someone, your child's good at this, and does this well, and that well, and it's math, the math is the problem. And so anything you can do to help them with math - that's valuable information, I think.

HB: Okay. Okay. And what are the difficulties with implementation of these models?

\#2: Well, I think you're limited by time. You are limited by sometimes the size of your groups get unmanageable. Sometimes the kids have behavior problems and it's sometimes hard to get, um, back-up for behavior difficulties. I think that the implementation - okay, here's one really difficult thing. When you have a group of 8 kids who have difficulties completing classroom assignments, they can't put a pencil to a piece of paper, and you don't have word processors for them. You don't have any way for them to write except pencil and paper.

HB: Okay. So possibly would that fall under assistive technology? Like labs . . .

\#2: Technology is one thing. There are other problems. Like when you have a bilingual student who - at (names school) the schedule is such so that a student cannot do bilingual education-I mean the ELD, the ESL - the student can't do resource and ESL at the same time because the class of $7^{\text {th }}$ graders can only come during the $7^{\text {th }}$ grade time and you're either in ESL or you're in um, resource.

HB: Okay. So basically-I'm going to read these back. So the size of instructional groups, behavioral difficulties, difficulty accessing technology, and possibly difficulties with scheduling.

\#2: Right.

HB: To coordinate services. Okay. Well, I think that's it.

\#2: Okay.

HB: Thank you very much. 
APPENDIX D

SAMPLE CASE STUDY 
Case Study 2

Based on Transcript \#2

October 14, 2014

Bocian, Beebe, MacMillan, and Gresham (1999) proposed the theory of competing paradigms as an explanation of why researchers and public school staff classify different students as having specific learning disabilities (SLD). In their theory, relativity is the idea that a student needs to be behind their peers according to local norms; the teacher makes the decision to refer for special education evaluation in part due to the sense that they are unable to help the student "catch up" without additional services. Acceptability is defined as the statistical and conceptual standardized model adopted by the school district for use during SLD evaluation; the team must determine whether the child's standardized testing data conform with the requirements of that model. Profitability is defined as team judgment; it is the collective decision of the student evaluation team that that particular student will benefit from special education services as they are practiced or available at that specific school site and results in a decision to identify the student as SLD. The purpose of the current research study is to explore the following research questions: 1) To what extent do interviews of secondary resource teachers reveal the concepts of relativity, acceptability, and profitability as they reflect on the SLD process? 2) What other themes regarding SLD eligibility determination emerge from interviews with secondary resource teachers? The setting is a large suburban district in the Pacific Northwest that is in its sixth year of using the Patterns of Strengths and Weaknesses SLD identification model.

Participants were 10 secondary resource teachers interviewed during the summer of 2014. Member checks were both informal and formal. As participants responded to interview questions, the inquirer summarized their responses and asked for agreement or disagreement. After the interviews were completed, the inquirer sent short reports to respondents, asking for feedback regarding facts in their interviews as well as interpretations made by the inquirer.

\section{Participant 2}

Participant 2 has taught for over 15 years, 12 of which have been in the current district under study. Although she has been teaching since 1982, her career has had some "starts and stops," and she has taught for several years in half-time positions. Reflecting back on her professional university preparation, she recalled that most of it was in test administration, and that she had taken a course that addressed both standardized academic and cognitive assessment. She recalled that when she started her first job, the district administrator in charge of special education arranged monthly meetings with resource teachers and they met as a group to discuss different issues. She described the evaluation process as one where a team of professionals, which included a speech language pathologist and school psychologist "investigated certain things... it wasn't that 
we decided we're going to test and see if this kid is learning disabled." When asked to describe her current district's practices towards SLD in-service training, she commented that "the in-services we do have seem to be more with filling paperwork out correctly" and that the only mandated training throughout the school year is more around issues of compliance with regulations and paperwork. She said there had been some in-service and handouts on the SLD model of strengths and weaknesses and that she had "talked endlessly with other resource teachers about how to do that." She also described that she has worked with different school psychologists "trying to interpret what we are supposed to do, how we are supposed to determine" whether a student qualifies as SLD or not, and that "I think this is what they've done - they've trained the school psychs and then the information is supposed to filter down to us through the school psychs." She felt that because of this approach, there was more learning about the SLD model in the actual school building itself rather than at district in-services.

\section{Acceptability (Questions 4, 6, 7a, 11)}

Question 4 asked participants what differences should be considered by eligibility teams when distinguishing between students with SLD and other students who struggle academically, but do not qualify for special education services. Participant 2 described the patterns of strengths and weaknesses SLD model currently in use within the cooperating district. She stated that "what eligibility teams are trying to do at this point is to look at IQ scores across different areas" and that they were looking for at least two cognitive areas to be in the average range. She said a strong score would be an 87 or above, "so it doesn't have to be a very big strength," but then added that she thought an 88 may also be the cut-off for a strong score. The difference between students who qualified as SLD and students who did not would be that the students who did not qualify could have scores that were fairly high, but that did not show a pattern of strengths and weaknesses and would appear to be "flat." She described that the "weaknesses in IQ scores have to correspond to weaknesses in specific academic achievement areas" and gave the example of "because the brain shows a weakness in that area, that's why they can't learn how to do math."

Question 6 asked participants how information from standardized academic tests helped them determine whether a student has a specific learning disability. Participant 2 felt that it was helpful to have the student's performance compared to a national norm, because if they were among a group of high achievers at their local neighborhood school, they may appear to be behind academically, when actually "they really are where they should be" and "that they're really not so far behind in their academic achievement that they are considered disabled." She also thought that for students of different cultural backgrounds it would be helpful to use a test normed on students with that cultural background in order to rule out a disability.

Question 7a asked participants whether they felt that local norms, such as classroom achievement data, or national norms, such as individual standardized academic testing data, were valued more during the SLD decision-making process. Participant 2 
felt that standardized testing was valued more, but that it was "just one part of the puzzle," and that work samples, classroom observations, standardized tests, health records, and attendance records all provided information as well.

Question 11 asked participants how teams made the decision that a student had a specific learning disability when their native language was not English. Participant 2 explained that there was a school psychologist could administer tests in Spanish and that they would also use tests of nonverbal intelligence. She stated that the team would also rely greatly on input from the English as a second language teacher as to whether the student was progressing at the same rate as his peers.

\section{Relativity (Questions 5 and 10)}

Question 5 asked about socio-cultural and contextual factors that may influence a teacher to refer a student for an evaluation for specific learning disability. Participant 2 thought that one factor was "how high-achieving the group is, the school is. So if a student stands out as being below the norms of the kids in the school, they might be right on average nationally," but because they are in a high-achieving building, they would be more likely to be referred than if they were at a school with more low-achieving students. Participant 2 noted that in her experience, bilingualism and cultural differences also contributed to whether teachers referred certain students. She also described parents who "see an advantage in a student being found eligible for special education because they get more time on tests and they get other accommodations, so they request that their child be tested." However, she felt that this happened more with students who were referred for attention issues rather than specific learning disabilities.

Question 10 asked participants what sorts of interventions did they see teachers attempting with students before referring them for an initial SLD evaluation. Participant 2 described seeing teachers use differentiated, small group instruction, peer tutoring, preferential seating, general classroom instructions, and simple behavior plans. She said she had also seen teachers provide written directions, prompts to gain student attention, and directing students' attention. She stated that these interventions tended to be used within the whole class, rather than just with individual students.

\section{Profitability (Questions 7b, 8, 9, and 12)}

Question 7b asked participants whether they had encountered evaluations where standardized and informal data gathered during the assessment process yielded "competing recommendations for eligibility," and how teams resolved those cases. Participant 2 said that she had seen that pattern in referrals, where students met or exceeded on state benchmark testing, but that in her experience, these students would qualify under the category of Other Health Impaired if there was a medical diagnosis, and not SLD. She said that "for SLD kids, I think they pretty much have to do poorly on some academic measure," and that it could be classroom work samples. She also said that at times, the team could resolve this issue by "giving the student more time" and 
considering them for special education services at a later point in their schooling. She also discussed that with re-evaluations, "the criteria is not as strong" as for initial referrals, and that if the student still showed a weakness they could continue to serve them for services.

Question 8 asked participants to think about cases where the student did not qualify as SLD and to explain why those students did not qualify. Participant 2 said that a student with a "flat profile" for cognitive abilities would not qualify as SLD, but that "oftentimes what happens is people come in, and call the student attention deficit after that, just to get them served." She explained that "I think we really work to find kids eligible. We want to stay within the law, we try and stay within the rules, but we reallyif a student is struggling, we really try to find a way to give them the help they need."

Question 9 asked participants what unique services students received once they were eligible for special education compared to other struggling students within their school buildings. Participant 2 said that the students received a "a written plan that corresponds to how they were identified," providing an example that if a student becomes eligible in the area of reading comprehension, this would be addressed with reading comprehension goals on their IEP.

Question 12 asked participants if they had ever served on a team that practiced "team override," meaning that although the student's scores did not meet district criteria for SLD, they were qualified under that category anyway. Participant 2 said she had not served on such a team herself, "but I've certainly seen paperwork on kids" who had been qualified that way, and that she thought it happened more with students with attention difficulties than with SLD.

\section{General Reflection on Policy}

Question 13 asked participants if they had worked on student evaluation teams before the introduction of response to intervention (RTI) and PSW models, and if so, what their opinion was on the new processes for SLD identification. Participant 2 stated she had worked on teams before the new models currently being implemented. She said that with RTI, it seemed as though "the teams I've worked with were not a very efficient gatherer of information," and that "there's great difficulty getting the information they gather passed on to the resource team," where it is needed to complete an eligibility. She liked the concept of RTI and thought it was "a great way to help teachers figure out ways to work with kids who are having troubles within their classes." She did not find it a difficult transition to using a PSW model for SLD identification because it was similar to how staff used to use the scores from ability and achievement testing, and although "it's not exactly the same, and it's a more complex, more interesting process," it felt appropriate to her because it compared ability and achievement.

Question 13a asked participants whether teachers, parents, or students obtained a benefit through the model used to determine SLD eligibility. Participant 2 said she felt 
they did, and that "it's a very solid process" and that the information gathered during an evaluation is essential to determining a successful educational plan. She also said that the information shared with parents, whether it be about something like attendance history or a weakness in math skills, can help the parent know how to better help their student.

Question 13b asked participants to list difficulties with the models used to determine SLD eligibility. Participant 2 listed time limitations, but focused more on the implementation of special education services once students were found eligible rather than on the eligibility process. She said that scheduling constraints, size of instructional groups, lack of technology for struggling writers, and behavioral challenges were all difficulties involved with service model delivery. 
APPENDIX E

DIRECTIONS FOR AUDIT TRAIL 


\section{Directions for Audit Trail}

The goal of this audit trail is confirmability, or the idea that findings developed from the data can be confirmed (you will read the results section and check if my cards with the interview quotes match what you are reading!)

1) Please read the Bocian article and get a sense for each of the three paradigms: Relativity, acceptability, and profitability. Please also read the Method section that I wrote (pages 12,13 , and 25), which describe the concepts of confirmability and reliability and the job of the auditor.

2) Please read the Results section (part 1, pages 1-62). The section is organized by concepts (relativity, then acceptability, and then profitability and a question on policy). For each concept, there were at least two interview questions, and there will be at least one large manila envelope with the data cards I used for each question. On the outside of the envelope, there will be the interview question number and the theory that is related to that interview question. For some questions, I also took notes on the way I sorted the cards into categories. In the Results section, I put the card information next to the statement that is supported by that card. (The cards are labeled like this: Participant number, interview question, and statement number). In most of the envelopes, there is also a pile of "miscellaneous" cards that did not get sorted into a category (those you can just ignore!)

3) To establish confirmability, you will go through and put a red check mark on all of the cards that appear in the Results section, listing any concerns or discrepancies on a separate sheet of paper. As you go, you can also make a small check mark on the Results section copy itself, to make sure that all the cards I listed were included in the set of cards you are checking. If I made a mistake labeling a card, you would note that, or if I used an incorrect number in the results section, you would note that too. There should be an index card with the "rule" grouping each set of cards together, and when you finish looking and marking the cards for that section, please clip them back in the same order that they were in before. (I have to re-sort them before I can analyze and answer question \#2).

4) After you are done with both parts of the audit (for research question 1 and then research question 2), you will write a letter of attestation. Lincoln and Guba (1985) have a description of this process on pages 320-327. I am also including a sample auditor letter from a different dissertation as a model for what to write. You would say that you had done the audit and that the statements in the Results section are supported by the cards. If you want, you can also say whether you think the statements in the interview support the three paradigms (relativity, acceptability, and profitability). We may be identifying more themes that were not included in Bocian's original theory, but we won't have those results yet for you to look at until I get the cards back from the first audit. 


\section{APPENDIX F}

LETTER OF ATTESTATION 


\section{象 Portland State}

Donna Barrow, Doctoral Student

Faculty, Infant Toddler Mental Health

Instructor, Department of Psychology

Portland State University

P.O. Box 751

Portland, Oregon 97207

503-756-7006

September 21, 2015

Dear Ms. Bartos,

It is my pleasure to provide this auditor's letter of attestation to include in your doctoral dissertation. The audit was conducted using the criteria set forth in Guba and Lincoln's Naturalistic Inquiry (1985). I reviewed your data and found the following:

- Validating the data was easily accomplished. The audit trail was clear, systematized, complete and comprehensible. The notation system allowed easy cross-reference of data, themes, definitions and relationships.

- The credibility of your study was confirmed through implementation of member checking following each interview.

- The process of inquiry attested to the dependability of your research. (e.g., interview protocols and sampling methods). Your methodological decisions were purposeful and relevant.

- The confirmability of the inquiry was supported by (a) the data reduction and analysis, evident in the condensed notes found within the data system, and (b) the data reconstruction and synthesis including the categorical structure (i.e., themes, definitions and relationships); findings and conclusions; and final report (e.g., connection to the literature, integrated concepts, relationships and interpretations). There was no evidence of bias in the study.

Your study was conducted in a professional manner. The research will provide insight into decisions regarding identification and placement of students with learning disabilities. The evidence provided by your research addressed standard practices and the need for a critical look at assessment protocols for children with learning disabilities.

Sincerely,

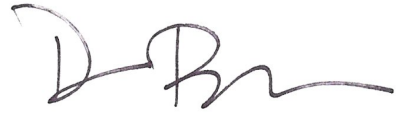

Donna Barrow 